\title{
HYBRID SOCIAL CONDENSER TOWER
}

\author{
by \\ Brad Miles \\ Bachelor of Architectural Science, Ryerson University 2012
}

\author{
A Thesis project presented \\ to Ryerson University \\ in partial fulfillment of requirements \\ for the degree of \\ Master of Architecture \\ Toronto, Ontario, Canada, 2014
}

(C) Brad Miles 2014 
AUTHOR'S DECLARATION FOR ELECTRONIC SUBMISSION OF A THESIS

I hereby declare that I am the sole author of this thesis. This is a true copy of the thesis, including any required final revisions, as accepted by my examiners.

I authorize Ryerson University to lend this thesis to other institutions or individuals for the purpose of scholarly research

I further authorize Ryerson University to reproduce this thesis by photocopying or by other means, in total or in part, at the request of other institutions or individuals for the purpose of scholarly research.

I understand that my thesis may be made electronically available to the public.

Bradley Miles 


\title{
Abstract
}

\author{
Toronto's response to sprawl - and associated \\ transportation issues is to hyper-intensify its core \\ with high-rise condominium development in order \\ to bring people closer to where they work. This \\ intensification has brought new associated problems \\ with the condominium tower which are: its tendency \\ to interact with the city only at grade, creating vertical \\ 'gated communities'; the reliance upon a single unit \\ type, overwhelming at-grade amenities; and the lack \\ of programmatic and economic diversity for reinforcing \\ urbanity. Towers in dense cities such as New York or \\ Hong Kong have embraced pluralism and hybridity to \\ combat segregation. Hybrid Social Condenser Tower is a \\ critique of the condominium tower and a response to the \\ context of urban infill tower development in downtown \\ Toronto. The tower blends ground and roof by having \\ a continuous circulation that moves up the building, \\ connecting and juxtaposing program by interstitial \\ spaces. This tower has been strategically located to \\ provide urban amenities to a context that is lacking \\ them and by doing so it attracts flux of users from both \\ horizontal and vertical directions.
}




\section{Acknowledgments}

I would like to express my gratitude to the following people who have contributed to this thesis project:

I would like to thank my wife and family for all of their help and support through out my education.

My advisor: Cheryl Atkinson, My committee: Taymoore Balbaa and Dr. Ian Macburnie. My friend Dadin Duldul and Margot de Man, Niveen Nabeel, J effrey Ming Jang, David House and Mark Johnson. 


\section{Table Of Contents}

Author's Declaration iii

Abstract v

Acknowledgements vii

Table of Contents viii

List of Figures $x$

List of Appendices $\quad \mathrm{XX}$

Chapter 1: Condominium Explosion 1

1.1 Introduction 2

1.2 Condo market overview 4

1.3 Thesis research intent 6

Chapter 2: Condominium Critique 7

2.1 Condo Typology 8

2.2 Development types and process 10

2.3 Urban Impacts $\quad 15$

2.4 Neighbourhood Unit and Generators of Diversity 18

2.5 Highrise Guidelines 23

2.6 Summary 29

Chapter 3 Hybrid Buildings 31

3.1 What is Hybrid? 32

3.2 What is a Hybrid Building? 33

3.3 History of Hybrid buildings $\quad 34$

3.4 Modern Hybrids $\quad 42$

3.5 World Trade Centre Design Competition 48

3.6 Summary Principles of Hybrid Building 52

Chapter 4 Social Condenser $\quad 54$

4.1 Defining the social condenser 55 
4.2 Architecture examples 59

4.3 Summary of principles for a Social Condenser 65

Chapter 5 Project $\quad 67$

5.1 Project Description 68

5.2 Site analysis $\quad 68$

$\begin{array}{ll}5.3 \text { Zoning } & 71\end{array}$

5.4 Design Process 77

5.5 Design strategies 82

$\begin{array}{ll}\text { Conclusion } & 120\end{array}$

$\begin{array}{ll}\text { Bibliography } & 122\end{array}$

$\begin{array}{ll}\text { Appendix } & 126\end{array}$ 


\section{List of Figures}

Figure 1: Condominiums Toronto Waterfront

Source: Brad Miles

Figure 2: Elementary schools, high school, and libraries in Toronto

Source: City of Toronto, Toronto District School Board, Illustrated by Brad Miles

Figure 3: Recent Condo Developments

Source: Concord City Place: http://urbantoronto.ca/news/2012/01/constructioncontinues-concord-adex-parade-cityplace L Tower http://urbantoronto.ca/ database/projects/l-tower Harbour Plaza Residences http://www. urbantoronto. $\mathrm{ca} /$ database/ projects/sun-life-financial-tower-harbour-plaza-residences 1-7 Yonge Street http://www.urbantoronto.ca/database/projects/1-7-yongetoronto-star-lands Pier 27 http://waterlink.ca/

Figure 4: Typical Condo Plans

Source: http://urbantoronto.ca/news/2014/07/tango2-soon-top-concord-parkplace, http://urbantoronto.ca/database/projects/quartz-concord-cityplace, http: //urbantoronto.ca/news/2014/06/great-toronto-views-top-pinnacleadelaide-condos, http://urbantoronto.ca/news/2014/08/canary-parkcondos-launching-public-saturday, http://urbantoronto.ca/database/ projects/\% C3\%AFce-condominums-york-centre

Figure 5: Suburban Development

Source: (Perry 1929)

Figure 6: Apartment house unit

Source: (Perry 1929)

Figure 7: Neighborhood Unit for an industrial section

Source: (Perry 1929)

Figure 8: Five Block Apartment Development

Source: (Perry 1929)

Figure 9: New Tower Floor Area

Source: City of Toronto 2013

Figure 10: Setback Section

Source: City of Toronto 2013

Figure 11: Setback Plan

Source: City of Toronto 2013

Figure 12: Floor Plate Overlay Source: Google Earth, Brad Miles

Figure 13: Three types of Hybrids 
Source: (Fenton 1985)

Figure 14: Axo Diagram

Source: (Fenton 1985)

Figure 15: Floor Plans

Source: (Fenton 1985)

Figure 16: Exterior Photo

Source: (Fenton 1985)

Figure 17: Section

Source: (Fenton 1985)

Figure 18: Typical Tower Plans

Source: (Fenton 1985)

Figure 19: Exterior Photo

Source: (Fenton 1985)

Figure 20: Axo Diagram

Source: (Fenton 1985)

Figure 21: Section and 9TH Floor Plan

Source: (Fenton 1985)

Figure 22: Axo Diagram

Source: (Fenton 1985)

Figure 23: Exterior Photo

Source: (Fenton 1985)

Figure 24: Circulation and Program Plan

Source: http://www.stevenholl.com/project-detail.

php? type $=$ housing $\&$ id $=58 \&$ page $=0$

Figure 25: Section

Source: http://www.stevenholl.com/project-detail php?type $=$ housing $\&$ id $=58 \&$ page $=0$

Figure 26: Interior Photo

Source: http://www.stevenholl.com/project-detail. php?type $=$ housing $\&$ id $=58 \&$ page $=0$

Figure 27: Exterior Photo

Source: http://www.stevenholl.com/project-detail. php?type $=$ housing $\&$ id $=58 \&$ page $=0$ 
Figure 28: Fire Escape Diagram Source: Riley, Nordenson 2003

Figure 29: Elevator Diagram

Source: Riley, Nordenson 2003

Figure 30: Typical Floor Plan

Source: Riley, Nordenson 2003

Figure 31: Concept Model

Source: Riley, Nordenson 2003

Figure 32: Site Plan

Source: Riley, Nordenson 2003

Figure 33: Typical Office Plans

Source: Riley, Nordenson 2003

Figure 34: Tower Sections

Source: Riley, Nordenson 2003

Figure 35: Circulation Diagram

Source: Riley, Nordenson 2003

Figure 36: Floor Plan Interconnected Lobby

Source: Riley, Nordenson 2003

Figure 37: Narkomfin Communal House

Source: https://www.opendemocracy.net/files/original.jpg

Figure 38: Unite d' Habitation 1947, Marseille, France.

Source: http://classconnection.s3.amazonaws.com/618/flashcards/1220618/

jpg/-0201338796207216.jpg

Figure 39: Boxers Eating Oysters

Source: Koolhaas 1994

Figure 40: Section

Source: Koolhaas 1994

Figure 41: Physical Model

Source: (Eisenman 2008)

Figure 42: Unfolded Section

Source: (Eisenman 2008)

Figure 43: Axo Wireframe Diagram

Source: (Eisenman 2008) 
Figure 44: Floor Plans and Sections

Source: (Eisenman 2008)

Figure 45: Lateral Connection Diagram

Source: (Eisenman 2008)

Figure 46: Context Plan.

Source: Brad Miles

Figure 47: Site Diagrams

Source: Brad Miles

Figure 48: $100 \%$ Site Coverage

Source: Brad Miles

Figure 49: $27 \mathrm{~m} \times 27 \mathrm{~m}$ Floor Plate 123 Floors

Source: Brad Miles

Figure 50: 45 Bay Street Proposal

Source: http://i58.photobucket.com/albums/g240/jwill_01/45b.jpg

Figure 51: Two Point Towers

Source: Brad Miles

Figure 52: 6.4 Million Square Feet

Source: http://www.urbantoronto.ca/sites/default/files/imagecache/display-

slideshow/images/projects/6918/urbantoronto-6918-25861.jpg

Figure 53: Double the Area to 2.4 Million Square Feet

Source: Brad Miles

Figure 54: Current zoning tower diagram, proposed zoning diagram of double the current area for mixed use

Source: Brad Miles

Figure 55: Proposed massing is the product of subdividing one tower into three Source: Brad Miles

Figure 56: Bridge Connections

Source: Brad Miles

Figure 57: Concept Diagrams

Source: Brad Miles

Figure 58: Program and Circulation Diagram

Source: Koolhaas 1994, Brad Miles 
Figure 59: Process Models

Source: Brad Miles

Figure 60: Process Models

Source: Brad Miles

Figure 61: Process Models

Source: Brad Miles

Figure 62: Experiential Section and Plan

Source: Brad Miles

Figure 63: Experiential Section and Plan

Source: Brad Miles

Figure 64: Pedestrian Circulation Diagram

Source: Brad Miles

Figure 65: Vertical Service Cores

Source: Brad Miles

Figure 66: Program Section

Source: Brad Miles

Figure 67: Exterior Rendering

Source: Brad Miles

Figure 68: Final Experiential Section and Plan

Source: Brad Miles

Figure 69: Underground Path and Plaza

Source: Brad Miles

Figure 70: Retail, Lobby, and Loading Diagram

Source: Brad Miles

Figure 71: Plaza Rendering

Source: Brad Miles

Figure 72: Community Centre

Source: Brad Miles

Figure 73: Ground Floor Plan

Source: Brad Miles

Figure 74: Ground Floor Section

Source: Brad Miles

Figure 75: Community Centre Diagram 
Source: Brad Miles

Figure 76: School Diagram

Source: Brad Miles

Figure 77: Community Floor Plan

Source: Brad Miles

Figure 78: Community Centre Section

Source: Brad Miles

Figure 79: School Entrance

Source: Brad Miles

Figure 80: School Atrium

Source: Brad Miles

Figure 81: School Outdoor Space

Source: Brad Miles

Figure 82: School Gym

Source: Brad Miles

Figure 83: School Plans

Source: Brad Miles

Figure 84: Library Plans

Source: Brad Miles

Figure 85: School/Library Section

Source: Brad Miles

Figure 86: Library Reading and Stacks Space

Source: Brad Miles

Figure 87: Library Lounge

Source: Brad Miles

Figure 88: Library Circulation

Source: Brad Miles

Figure 89: Library Stacks

Source: Brad Miles

Figure 90: Library Entrance

Source: Brad Miles

Figure 91: Library Diagram 
Source: Brad Miles

Figure 92: Multi-Faith Diagram

Source: Brad Miles

Figure 93: Multi-Faith Lounge Space

Source: Brad Miles

Figure 94: Church

Source: Brad Miles

Figure 95: Synagogue

Source: Brad Miles

Figure 96: Mosque

Source: Brad Miles

Figure 97: Multi-Faith Event Space

Source: Brad Miles

Figure 98: Multi-Faith Plans

Source: Brad Miles

Figure 99: Multi-Faith Section

Source: Brad Miles

Figure 100: Hotel Lobby Retail

Source: Brad Miles

Figure 101: Circulation Atrium

Source: Brad Miles

Figure 102: Art Gallery, Exhibition Space, Night Club Section

Source: Brad Miles

Figure 103: Conference Centre Diagram

Source: Brad Miles

Figure 104: Night Club, Art Gallery, Exhibition Space

Source: Brad Miles

Figure 105: Art Gallery

Source: Brad Miles

Figure 106: Movie Theatre Diagram

Source: Brad Miles

Figure 107: Event Space, Retail, Amenities, Hotel Lobby 
Source: Brad Miles

Figure 108: Museum Interior Rendering

Source: Brad Miles

Figure 109: Museum Park Roof Rendering

Source: Brad Miles

Figure 110: Museum Diagram

Source: Brad Miles

Figure 111: Event Space, Museum, Park Section

Source: Brad Miles

Figure 112: Exterior and Interior Landscape Diagram

Source: Brad Miles

Figure 113: Commercial Office Space

Source: Brad Miles

Figure 114: Roof Spaces Rendering

Source: Brad Miles

Figure 115: Multi-Faith Roof Rendering

Source: Brad Miles

Figure 116: Housing and Amenities Diagram

Source: Brad Miles

Figure 117: Hotel Lobby Diagram

Source: Brad Miles

Figure 118: Typical Condo and Office Floor Plan

Source: Brad Miles

Figure 119: Typical Condo and Hotel Floor Plan

Source: Brad Miles

Figure 120: Co-Housing Diagram

Source: Brad Miles

Figure 121: Exterior Rendering

Source: Brad Miles

Figure 122: Exterior Rendering

Source: Brad Miles

Figure 123: Exterior Rendering 
Source: Brad Miles

Figure 124: Exterior Rendering City View Source: Brad Miles 


\section{List of Appendices}

A. 1 Final Model

A. 2 Process Design 


\section{Chapter 1 Condominium Explosion}




\subsection{I ntroduction}

Toronto has been in the process of urban transformation ever since extant industrial brownfield sites were being developed in the late 1980's. Much of this condominium growth has been near Toronto's 40 kilometer waterfront (Boudreau 2009). This has transformed Toronto into one of the densest cities in North America. Some of these developments such as the Lower Don Lands and the Portlands have been integrated into secondary plans. Many other high rise tower developments are single one-off developments near the city's waterfront with the exception of Cityplace (fig 1). As of 2010 Toronto has more towers between 12 - 40 stories than any other city in North America (Emporis, Spring 2010). This condominium boom has overwhelmingly preceded the necessary development of amenities and public infrastructure to support the needs of a diverse population. The aggressive condominium development and its propagation in the downtown core have produced a mono culture which responds to individuals that work in the central business district. The economics of rapidly rising construction and land costs had made the provision of significant amounts of family housing in the core untenable, or if available, unaffordable. This 


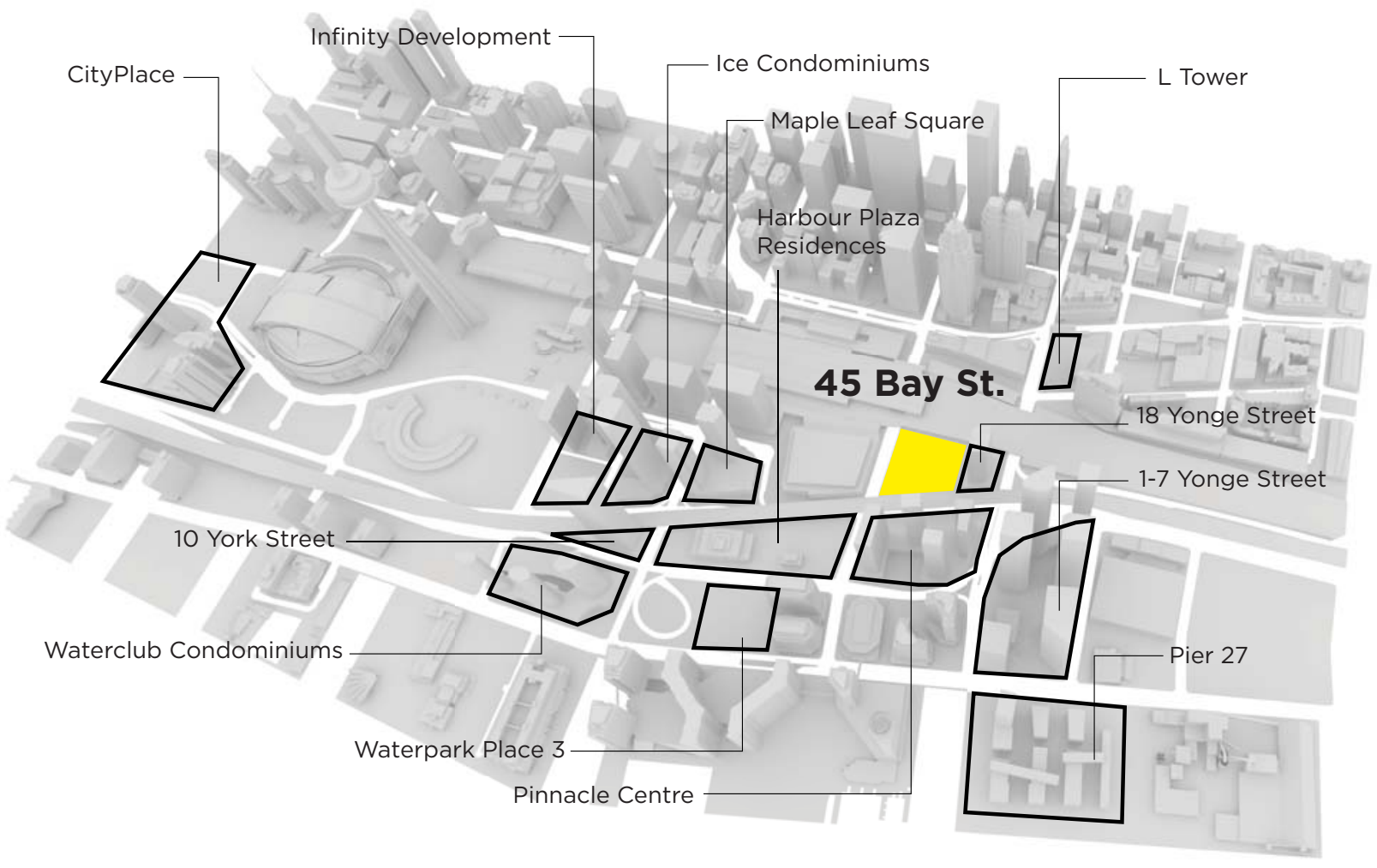

Fig 1: Condominiums

raises concerns on the long term functionality of the condominium typology which are inflexible to change over time as they were designed for a specific user and urban culture. The absence of continuous public realm on grade is the result of internal privatized lobbies which create no essential dialogue with the users by. This thesis aims to investigate the generation of public realm into the monotonous high rise tower typology through vertical integration of ground plane, and fusing of public and private domain. By combining the concept of Hybrid building and Social Condenser, the proposal aims to provide alternative model for vertical living and re defining the banal condominium typology. 


\subsection{Condo market overview}

Toronto's condominium boom has been driven by several factors. Predominantly, the policies of the city curb to sprawl and bring people closer to where they work. Over the past decade, there has been an overwhelming trend to live in the city. Concurrently, cities around the globe are increasingly becoming urbanized. This trend has transformed Toronto into one of the largest cities in North America, with one of the largest areas under development being the Toronto Waterfront (fig 1). The amount of condominium towers between 12 and 40 stories in Toronto is greater than New York and Chicago (Emporis, Spring 2010). Many of these towers do not support public infrastructure and act as single entities in the urban fabric. These city infrastructures are not being built because the cost of land is too expensive and public governess has not been able to keep up the financing or organization of the infrastructure in order to keep up with the rapacity of this development. The new reality for Toronto is that public infrastructure will have to be integrated into private high rise development.

This development in the downtown has encouraged the emergence of a mono-culture that consists of young 


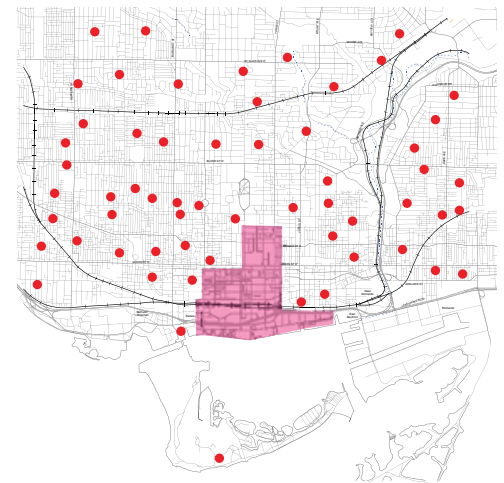

Elementary Schools

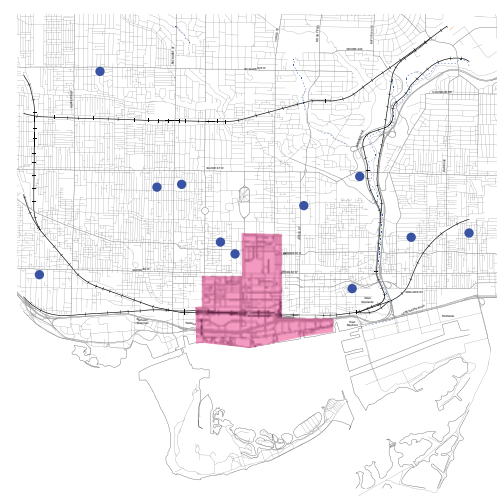

High Schools

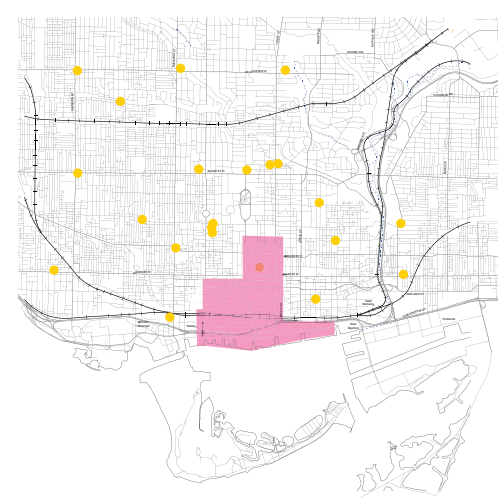

Libraries

Fig 2: Elementary schools, high school, and libraries in Toronto white-collar singles working downtown in the financial district during the day and residing in one of these units at night. As for family housing, the lack of amenities for children raises concern regarding the functionality of these buildings over time due to the fact that the migration of this group will inevitably affect community vibrancy and health.

According to Yelaja, the author of "The 'Manhattanization' of Toronto will change family-housing dreams" (2013), the condominium boom is mainly geared towards young bachelors interested in moving into the city from the suburbs and towards investors purchasing units to rent short-term and later sell for a profit. In the CBC documentary "The Condo Game" (Goddard, Slinger, 2013) it is said that the number of condominium buildings have doubled in Toronto over the last ten years to 1300 . Because speculators are the main buyers, these buildings are built fast with only bachelor and one-bedroom units (Goddard, Slinger, 2013).

\subsection{Thesis research intent}

This research investigates the contemporary tower and condominium typology in the city of Toronto. 
It critiques the homogeneity of single use functionality which does not respond to the notion of hybridity. This thesis will begin with a look into literature that criticizes the existing condominium market, as well as case studies on different types of developments in Toronto and their urban impacts on the city. The focus will then turn to defining the appropriate size of a neighborhood in terms of population and area along with the appropriate amenities necessary in maintaining neighborhood vitality in both the city and suburb. This research supports the hypothesis that these residential buildings do not constitute as neighborhoods and have instead created a mono-culture of young singles. In addition to the critique of the stereotypical tower, the ambition of this thesis project is to create a hybrid and social condenser that can attract the existing population of downtown condominium dwellers by providing institutional, cultural, and social amenities not found in the existing context. The ideal project would connect to existing city infrastructure and reinforce urban connectivity while acting as a destination in and of itself, a city within a city. 


\section{Chapter 2 Condominium Critique}




\subsection{Condo Typology}

By examining the conditions of Toronto's recently built typical point-tower condominiums relative to their circulation, structure, and program, series of issues can be recognized as a result of their connection to the urban context. In most cases the condominium is defined as a tower with a central service core and stacked units organized along internalized horizontal circulation corridors, which connect the occupants to their units (fig 3). The floor plates are repetitive and stacked through the entirety of the building (fig 4).

Structurally, these buildings are constructed with vertically reinforced concrete shear walls and floor slabs

Concord CityPlace
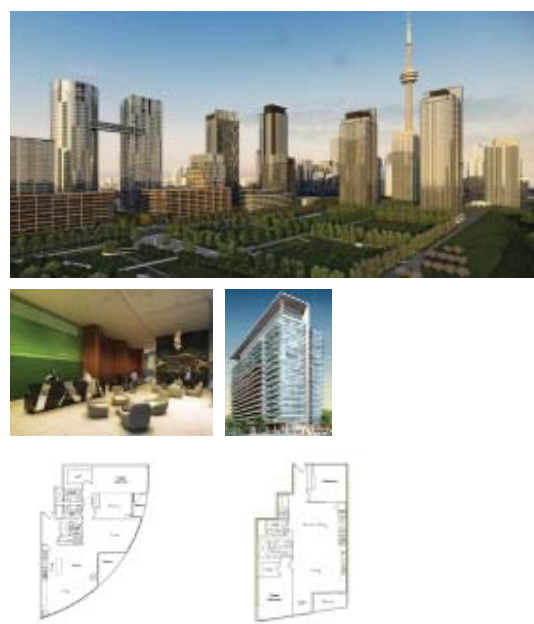

$\mathrm{L}$ Tower
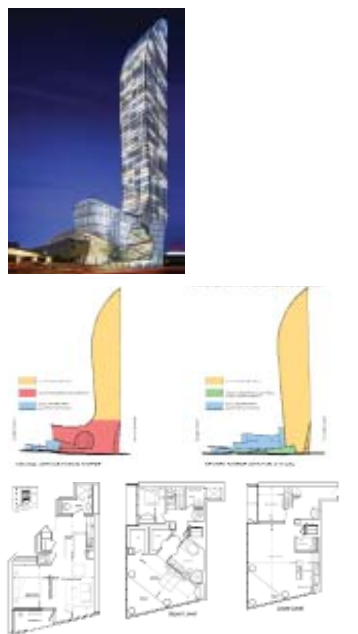

HarbourPlaza Residences
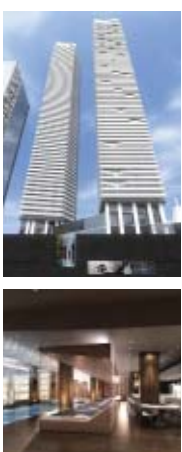

Pier 27

Street
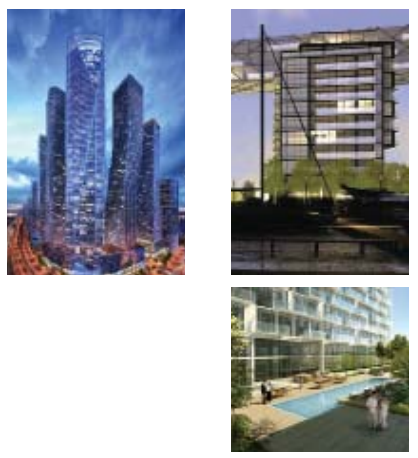

Fig 3: Recent Condo Developments 
which separate adjacent units from the sides, above and below. The bay spacing is often six to nine meters on center for shear walls with floor to floor heights ranging between 2.7 and 3 meters. This type of structural system does not allow for flexibility between units, thus rendering adaptation of the building to other uses such as commercial office and live-work, extremely difficult.

Programmatically, condominiums are singleuse with amenities located at grade or at the top level of the building. If the building faces a major street, it is likely that retail will be located at grade. The units themselves differentiate depending on whether or not they are situated on a corner or by the number of bedrooms it contains. Typological experimentation has still yet to surface in a city that is left with stacked floor plate towers, which contain inflexible units and lack programmatic indeterminacy of city life. The condominium has been successful in attracting people back into the city but has not provoked a response to an experimentation level that considers questions of internalized urbanity in dense environments.

Mixed Use Development is often favored by 


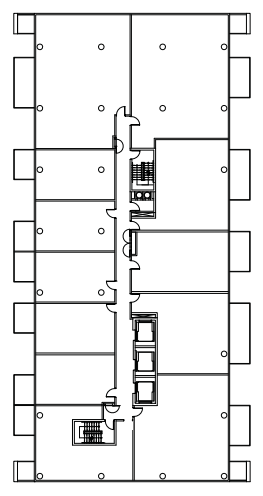

Fig 4: Typical Plan
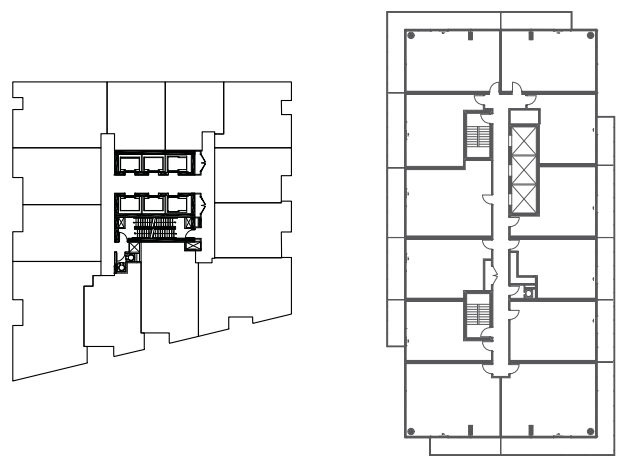

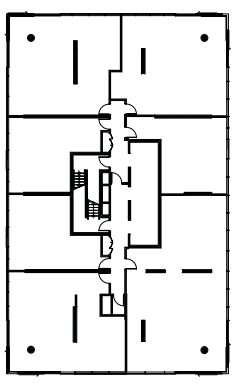

architects and developers. However, this form of

development can be successful to some extent at meeting the market demands while adding to the diversity of the city as a whole. Recent addition of mixed use developments in the city includes the combination of luxury hotels with luxury housing. The Four Seasons, Ritz Carlton, and the Shangri la Hotels are an exemplary precedent regarding this form of development. The main complications that these projects face are the lack of economic diversity in housing units as well as amenities which are catered towards the rich and elite.

\subsection{Development types and process}

As mentioned in the article "The 'Manhattanization' of Toronto will change family-housing dreams," (Yelaja 2013) the condominium boom is mainly focused on units for young bachelors. It has been projected that family housing units will increase in cost between 30 to 50

percent and will inevitably force young families to move 
to the suburbs in search of cheaper real-estate (Yelaja 2013). The Cost to build a condominium in Toronto in 2014 is $\$ 55$ per square foot compared to $\$ 30$ per square foot in Toronto in 2005 (Perkins 2014). If a comparison is made to building a home in Toronto, the cost can start at $\$ 120$ per square foot which is more than double the price (Toronto's Real Estate Team 2014).

In 2014 it is expected that 9,090 condominium units will be completed in the core of the city, where 67 percent are studios, one-bedroom, or one-bedroom plus den units. The average area of a unit in the market is typically only 695 square feet. These measures are appropriated in order for developers to secure construction loans as they need to sell 60 to 80 percent of their units before they construct (Yelaja 2013). In this case, the developer is left with a preferred market catered to young single bachelors which decreases the availability for three bedroom condos downtown. "The developers are catering their product to investors, who are interested in smaller units that are easier to rent or flip, the larger the unit, the longer it takes to rent out or sell" (Yelaja 2013). This is surely apparent when comparing Toronto to other medium or large cities globally. Toronto is one of 
the leading cities for high rise buildings between 12 to 40 stories with 132 high-rise buildings that range between 12 to 40 floors, followed by Mexico City with 88 and New York City with 86 (Emporis, Spring 2010).

More family housing is needed in all parts of Toronto as opposed to just the suburbs, as affirmed by Local Toronto City Councilor, Adam Vaughan who is "worried about what he calls the explosion of single occupancy units in the downtown core" (Yelaja 2013). If the majority single person condominiums are built, sprawl will only be delayed for the next generation. This is due to the fact that those condominium owners might want to start families or settle down, requiring them to own a family house or unit. This has led to the creation of a simplistic monoculture downtown. Vaughan proposes that condominiums should be built with knockout panels, allowing for a unit to expand into adjacent units. More units also need to be designed for disabled residents because of the aging baby boomer population. This can save the consumer money because if you add the average sale price of a condominium in the City of Toronto, $(\$ 384,758)$ (Pigg 2014) vs. the average sale price of a detached house in the City of Toronto, $(\$ 965,670)$ 
the cost is almost triple. If the adjacent unit could be purchased the consumer would save $\$ 196,154$, and this could change the demographics in condominiums. Vaughan concludes the article by stating that diversity keeps the downtown core vibrant. In this case diversity is accommodating different family configurations and different economic price points (Yelaja 2013).

In a CBC documentary called "The Condo Game" that highlights issues concerning the existing Toronto condominium market, future trends for condominiums are not prosperous. Looking into the context of how this developed over time, the number of condominiums doubled to 1300 buildings in the time period from 2003 to 2013 (Goddard, Slinger 2013). This increase came as a result of a greenbelt legislation passed by the Ontario government to curb suburban sprawl. Combining this with two decades of low interest rates, the right economic context with foreign investments was created, allowing the condominium market to prosper.

According to one real-estate expert, the presales pitch is just a pitch not a promise and the supply and demand is because of money not real-estate 
(Goddard, Slinger 2013). The industry is not set up for "Jo average," it is set up for investors who are looking to make quick money through buying then selling after the construction is complete. There are nearly a quarter million condominium units downtown and about half are owned as investments (Goddard, Slinger 2013). Experts are saying that this will bring an affordable housing crisis because currently, condominiums cost 30 percent higher than they are really worth. Bachelor and one-bedroom units are faster to build because they are standardized units with one main bathroom and they usually require less services and minimal parking. These units are easier to sell to investors because the flexibility of one bedroom units will always be attractive to renters and have a low to medium purchase cost compared to larger penthouse units or larger detached properties. Three bedroom condominium units tend to be found in luxury condominium buildings. Previously, there had not been much demand for a three bedroom condo unit, but rather smaller single and young couple units (Yelaja 2013). Currently, there is a higher demand for three bedroom condominiums in proximity to the downtown core. They are selling faster, which indicates a growing trend for much needed larger unit sizes that will accommodate 
families who desire to live closer to where they work. (Dautovich 2014). A recent concern has been that the cost of a three bedroom condo unit in the downtown core can exceed the price of a house while possibly lacking in outdoor spaces, community amenities and support infrastructures. The average selling price for a three bedroom condominium unit in the downtown core of Toronto is $\$ 800,000$. This is double the price of the same unit in the Mississauga and North York city centers with averages at $\$ 400,000$ and $\$ 450,000$ respectfully (Toronto Real Estate Board, 2013).

\subsection{Urban I mpacts}

City Place is the largest residential development in Canadian history, built by the developer Concord. It covers 18 hectares of former rail yards with 25 towers and 18,000 people (Goddard, Slinger 2013). The "Condo Game" reveals that there are 11 lawsuits currently initiated by city place condominium boards. To give some context, the leaky condominium crisis in British Columbia in the early 1990's, cost the province over $\$ 3$ billion dollars (Goddard, Slinger 2013). It is estimated that within the current condominium stock from the past 5 years, between $60-80$ percent are going to be rented out. The lack of direct ownership and increase in 
foreign investors has led to a diminished community. At city place, 14,000 people reside but only 375 of those are children (Goddard, Slinger 2013). The condominium typology could exhibit social problems in the future due to such isolation. This could threaten the city infrastructure because it will be overloaded with the increased density. Services such as schools and other amenities might become overloaded and the residents will have to travel to other parts of the city.

Even though the construction of a large number of high rise residential towers has been identified as a potential problem in this thesis, it is still in our best interest to have compact cities. How can we make more sustainable and functional compact cities? Jenks and Dempsey (2005) suggest that compact cities have more positive environmental, economic, and social impacts. Denser living makes for better public transit and more pedestrian activity because buildings are closer together with shared services. More people can be serviced from less infrastructure, and a greater concentration of people equals to social, health, recreational and other services. Hence, compact dense cities can be more efficient in the long term. 
Shelton, Karakiewicz, and Kvan (2011) state that like in many other cities, Hong Kong has a changing demographic which has transformed lifestyles regarding personal and work relationships, blurring the line between home and office. This has raised the demand for more convenience and proximity to essential and leisure services, private and public.

Lau, S. Wang, J. Giridharan, R. and Ganesan, S. (2005) discuss the way that multiple use of spaces - both inside and outside in Hong Kong is based on market forces rather than from a formal planning mechanism. The urban concentration has forced amenities and other city programs to be stacked on each other, creating vertical stratification. The UN (2000) claims that the vertical urban planning approach of Hong Kong (stacking uses on top of another) has created one of the most energy efficient urban built forms in the world. Lau, S. Wang, J. Giridharan, and R. Ganesan, S. (2005) identify Hong Kong as a "Sky City" due to the abundance of raised foot bridges, escalators and pathways, both interior and exterior. This multi-layering is a by-product of an excess of people traveling on the sidewalks. Even 
with this infrastructure, the street remains the most vibrantly active and the vertically connective, which fuels pedestrian circulation on the ground plane.

However extensive the list of differences between Hong Kong and Toronto, there are similarities in Toronto's ambition to become a compact vertical city. For this to transpire, developers, architects, and politicians will need to consider Toronto on a basis not solely at grade but in the vertical direction. New ways of defining neighborhood scale and community are needed in order to create a more sustainable city.

\subsection{Neighborhood unit Clarence Perry}

The concept of creating a scheme for an arrangement of family-life community was derived from the conclusion of a study completed on Clarence Perry's “The Neighborhood Unit" (Perry 1929). Perry states that four community programs are essential for the existence of a strong neighborhood; the elementary school, small parks and playgrounds, local shops, and residential environment. Perry developed neighborhood unit principles that consist of the size of the population, boundaries of the neighborhood, open space, institutional 
sites, local shops, and the internal street system. He hypothesized that the size must be based off of the population of an elementary school. However, this would depend on the population density. The units should be edged on all sides by arterial streets which are sufficiently wide enough to facilitate the by-passing of all traffic. A system of small parks and recreation spaces, planned to meet the needs of the particular neighborhood should be incorporated. Sites for the school and other institutions having service spheres coinciding with the limits of the unit should be suitably grouped about a central common area. One or more shopping districts of adequate size for the population to be served should be laid out in the circumference of the unit, preferably at traffic junctions and adjacent to similar districts of adjoining neighborhoods. The unit should be provided with a special street system, each highway being proportional to its probable traffic load, and the street net as a whole being designed to facilitate circulation within the unit and to discourage use by through traffic. He conceived that the total number of families would need to be 1,241 with 4.93 persons per family. This would result in a population of 6,125 people with a density of 7.75 families per gross acre. (Perry 1929) 


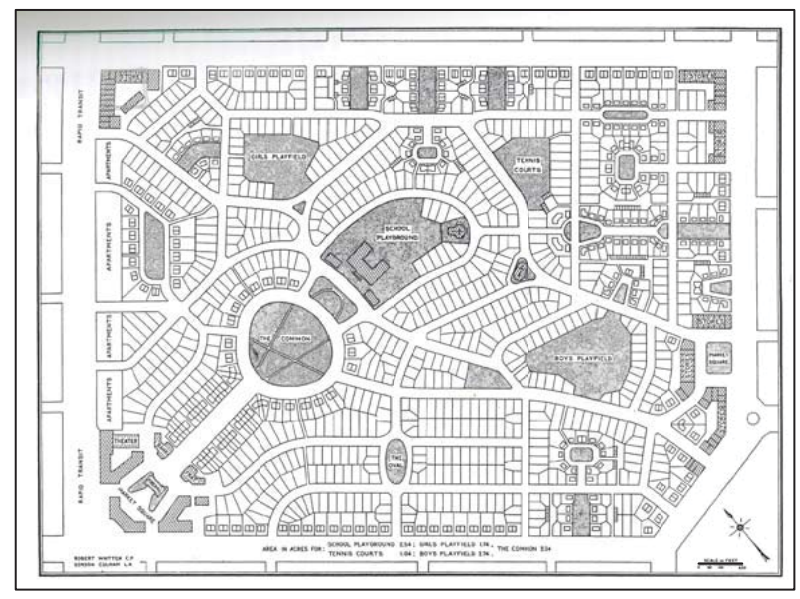

Fig 5: Suburban Development

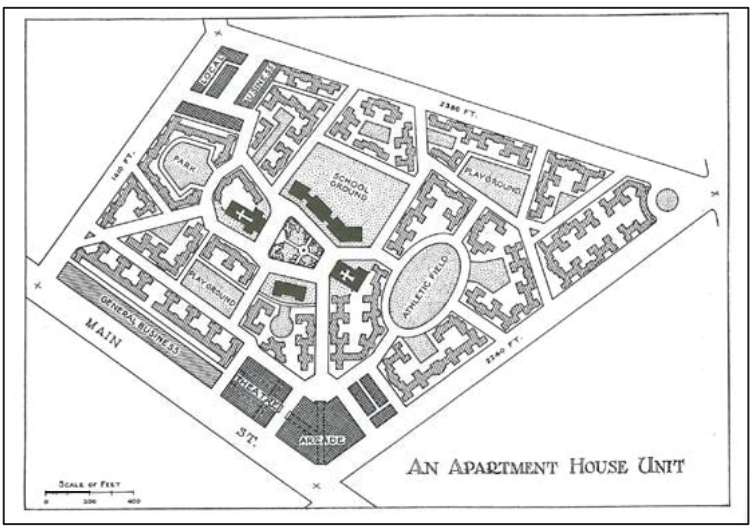

Fig 6: Apartment House Unit

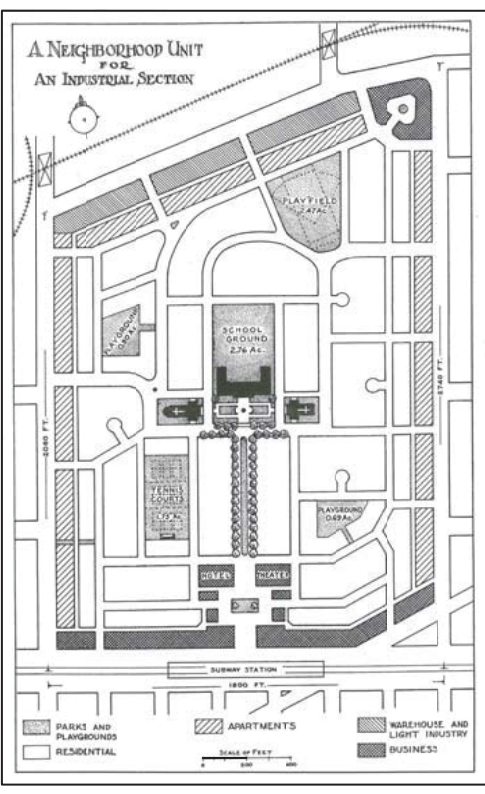

Fig 7: Neighborhood Unit for an industrial section

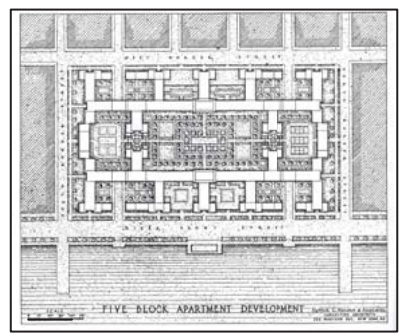

Fig 8: Five Block Apartment Development

Perry composed three diagrammatic schemes of what the ideal neighborhood would be in the context of low-cost suburban development, which includes: industrial section, the five block apartment house unit, and the five block apartment development fig. 5,6,7 and 8 (Perry 1929). Of these three indicated, the apartment development is the most applicable to this thesis due to its direct relationship to density. Conceptually, they 
share the centralized location in relation to the city.

Referring to figure 8 , the blocks chosen for the apartment development are 200 feet wide and 670 feet long which are found in several sections of Manhattan. The overall dimensions of the plot are 650 feet by 1,200 feet and a total area of 16 acres. The central courtyards are placed in a way to organize the various residential zones that take up 53 percent of the area. The central space is divided into three segments with two smaller courtyards. The smaller courtyards contain three tennis courts at one end, and a children's playground at the other (Perry 1929). As for the central segment, it correlates to Gramercy Park in Manhattan relative to proportion where the park is centralized and connected to the entire site. The cross sectional width of the building structure is $\mathbf{5 0}$ feet to ensure quality daylight in the apartment's interior. The capacity of the buildings is 1000 families with suites ranging from three to fourteen rooms in size. In addition there would be room for a hotel, an elementary school, a swimming pool, handball courts, locker rooms and other athletic facilities (Brody 2013). The first floor on one or more of these buildings is devoted to shops. There is an auditorium for movies, lectures, live theatre, and public meetings. There is a gymnasium and squash court in the 
basement. The buildings have a height range between 2 to 3 stories along the edges of the streets, 10 stories in the mid-section, 15 stories in the main central zone, and 33 stories in the two towers (Perry 1929).

In "The Death and Life of Great American Cities," Jacobs states that neighborhoods need to supply some means for civilized self-government from the residents that live within. There are three types of neighborhoods which are useful:

1. The city as a whole

2. Street neighborhoods

3. Districts of large sub-city size composed of 100,000 people or more in the case of the largest cities.

Successful street neighborhoods are not discrete units, but rather physical, social, and economic continuities; interweaving neighborhoods where upon turning a corner, you enter a new neighborhood ( acobs 2011).

In respect to mixing of uses: if it is complex to sustain city safety, public contact and cross-use, needs an enormous diversity of ingredients. Jacobs outlines four 
conditions that would generate diversity in a city's streets and districts:

1. The district, and indeed as many of its internal parts as possible, must serve more than one or two primary functions where there is the presence of people going outside at different times of the day and using different facilities within the area.

2. Urban blocks must be short to allow for pedestrians to easily turn corners.

3. The district must have a diversity of buildings by age and type with the mingling fairly close-grained.

4. There must be a dense concentration of people who live, work or play there.

Jacobs suggests that the combination of these 'Generators of diversity' creates effective economic pools of use (Jacobs 2011).

\subsection{Highrise Guidelines}

The Tall Buildings Guidelines were created to assist the implementation of the official plan and it identifies where tall buildings are to be concentrated by outlining specific locations in Toronto. These design criteria cover tall buildings in the areas of urban design, building 
design, environment, etc. (City of Toronto 2013). The

guidelines will allow city council to gain more power and influence on the Ontario Municipal Board (OMB) which has approved many inappropriate condominiums in the

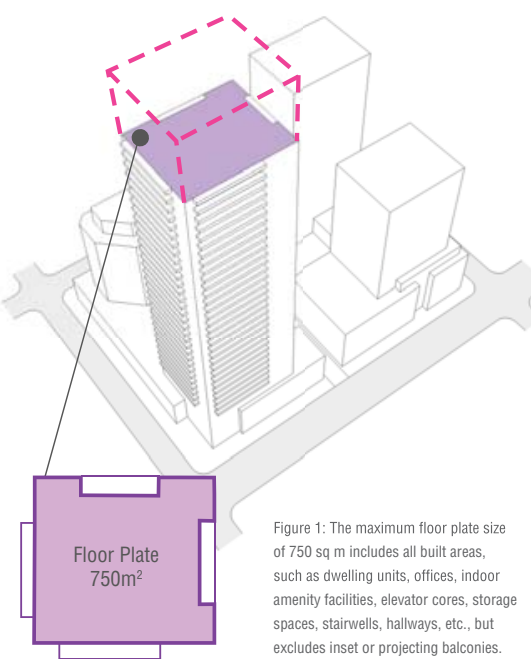

Fig 9: New Tower Floor Area

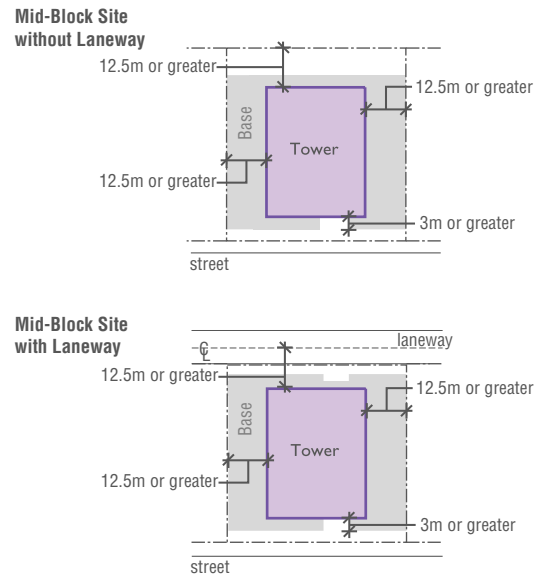

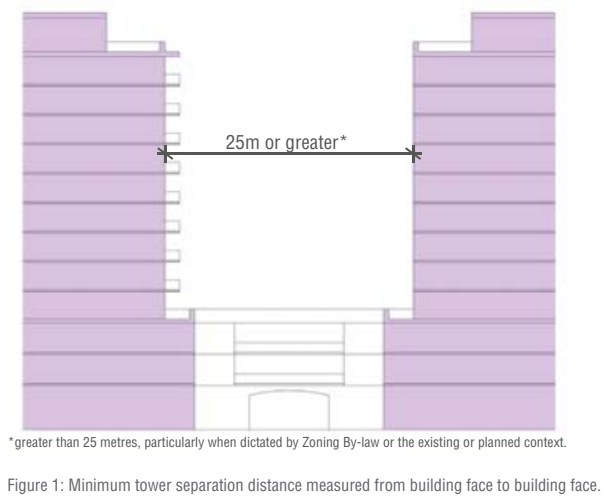

Fig 10: Setback Section

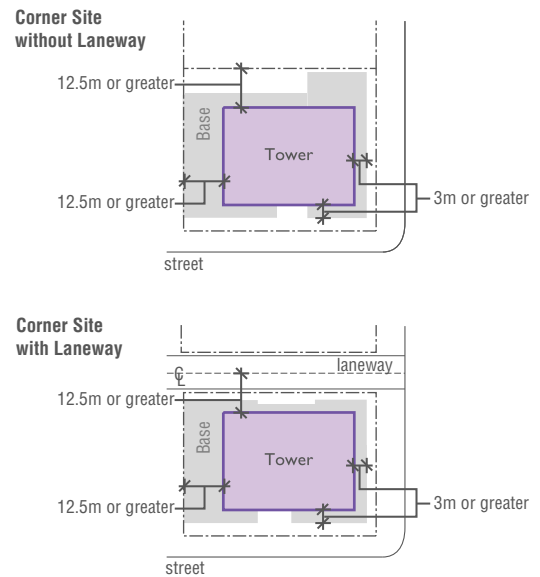

Figure 6: Conceptual "small sites" showing recommended minimum tower stepbacks from the base building and setbacks from side and rear property lines or centre line of an abutting lane.

Fig 11: Setback Plan 
past 10 years. These guidelines give more control to city planners in making the right choices for the city as a whole.

As defined by the city of Toronto tall building guidelines, a tall building is one that has a height greater than the width of the adjacent street right-of-way or the wider of the two streets if it is located at an intersection (City of Toronto 2013). Street widths in Toronto typically range between 20 and 36 meters, therefore the definition changes depending on the context.

In the guidelines, the tall building is broken down into three parts: the top, middle, and base (City of Toronto 2013). The tops of tall buildings, including upper floors and roof-top mechanical or telecommunications equipment, signage, and amenity space should be designed primarily through tower massing and articulation, and secondarily through materials to create an integrated and appropriate conclusion to the form. The middle portion of the tower should be designed with location, scale, floor plate size, orientation, and separation distances in mind as they have an effect on sky views, privacy, wind, and neighborhood properties as 
well as the amount of sunlight and shadows reaching the public realm. The base of the building refers to the lower storeys which have the role of articulating entrances and framing the public realm while also assisting in the creation of an attractive and animated public realm which provides a safe, interesting, and comfortable pedestrian experience. The base building should define and support adjacent streets, parks, and open spaces at an appropriate scale while integrating with adjacent street wall buildings, and minimizing the impact of parking and servicing on the public realm. (City of Toronto 2013)

Further approaches to designing tall buildings are articulated in order to: create slender point towers, rising above well-proportioned and articulated base buildings with a strong relationship to the existing context and adjacent public realm; avoid towers without a podium or relationship to the street; avoid big, boxy, dominant massing, and large elongated floor plates to minimize shadows on the adjacent properties; and embrace design creativity and variation in built form and architectural expression, including variation in tower shape, orientation, and the design of each facade for the purpose of visual interest and sustainability (City of Toronto 
2013).

The strategies outlined in the guidelines concerning sustainable design are to: offer a range of ownership types and unit-size choices in residential mixed-use buildings, including the provision of larger units suitable for families with children; design and construct tall buildings for flexibility of use and potential for future change, including versatility in interior design, layout, and construction practices to encourage building longevity and adaptability to potential shifts in demand over time; provide flexible interior spaces to accommodate changing uses in the base buildings, including the transition from residential to commercial uses; provide conditions in the tower portion to allow residential units to be converted or combined in order to adjust to changing occupancy requirements; incorporate renewable energy systems or district energy where feasible; and include energy efficiency measures and evaluate energy performance through changes in glazing ratios, building placement, massing, orientation and articulation, balcony design, materials and construction methods (City of Toronto 2013). 
According to the guideline's section 3.2.1 on floor plate size and shape: the floor plate size should be limited to 750 square meters or less per floor, including all built areas within the building, excluding balconies; the tower floor plate should be organized and articulated to minimize shadow impacts and negative wind conditions on surround streets, parks, open spaces, and properties; the loss of sky view from the public realm to adjacent streets should be minimized; and passage of natural light should be allowed into interior spaces through shallow rather than deep floor plans (City of Toronto 2013). Tower placement from section 3.2.2 suggests placing towers away from streets, parks, open spaces, and neighboring properties to reduce the visual and physical impacts of the tower and to allow the base building to be the primary defining element for the site itself and the adjacent public realm (City of Toronto 2013).

To understand the implications of this new floor plate proposed in the City of Toronto Tall Buildings Guidelines, it was overlaid onto a variety of tall buildings. Figure 6 shows the TD Centre, CIBC Tower, the Spire Condominium, and Maple Leaf Square. The first three examples are commercial office towers developed 
between the nineteen-sixties and seventies. For the most part the red box overlay of seven hundred and fifty square meters is roughly between a third and a half of the total floor plate size of these three towers. How was this decision made regarding the floor plate size in reference to the commercial office space market demand? If offices are typically over double the floor plate size, then how would you integrate commercial offices into the new Tall Buildings Guidelines? How would this affect elevator access to upper floors and the overall structural design of the tower, given that a taller building would require a larger floor plate? If we look at this overlay on the Spire and Maple Leaf Square towers, it fits the existing floor plate size. These two towers are residential occupancy and do not require the same vertical infrastructure as an office tower. The 750 square meter floor plate was also compared with five towers outside of Canada. The Downtown Athletic Club approximately fits the floor plate. This could potentially relate to the Rem Koolhaas's "building as a social condenser", (Koolhaas 1994). This will be further elaborated on in the chapter on social condensers.

\subsection{Summary}

Given the state of the current condominium 


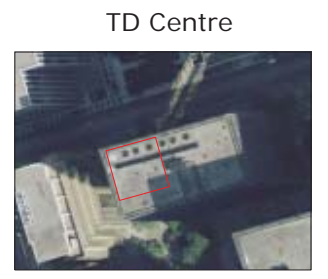

Downtown Athletic Club

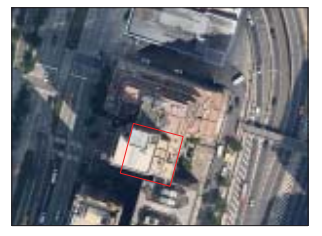

Fig 12: Floor Plate Overlay
CIBC Tower

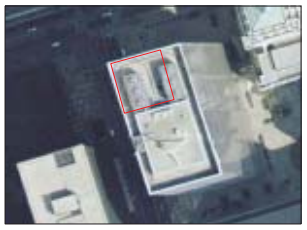

Seagram Building

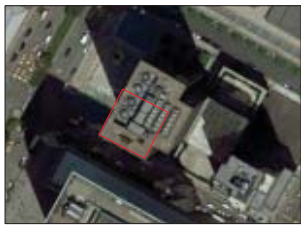

BMO Tower

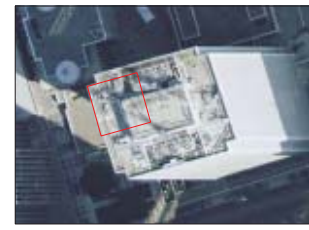

SearsTower

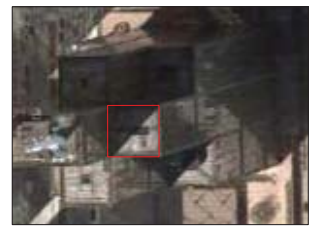

Spire

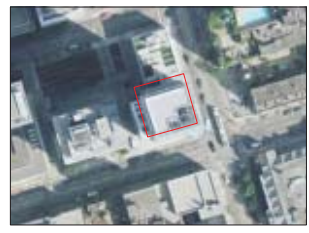

John Hancock Tower

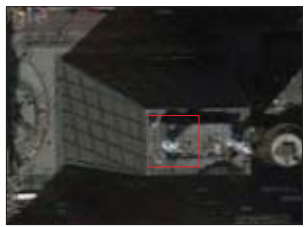

Maple Leaf Square

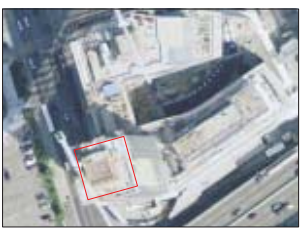

Burj Khalifa

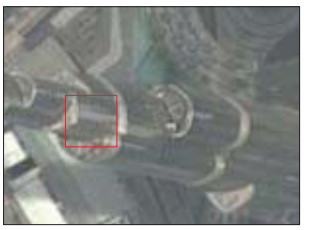

market, there is an evident need of a new process for property development and architecture that would respond to the monoculture which persists today. Land prices along with a short-sighted development model has detoured developers from integrating diverse and institutional programs into their projects. The interests of the developers lie in making the most profit for the least amount of effort. Architects and developers have not investigated how to properly integrate these occupancies into dense urban environments. It is fair to say that the new Toronto Tall Buildings Guidelines only deal with the regulating of microclimate conditions that are created by clusters of tall buildings. How would the proposed 750 square meter floor plate work with the type of commercial office towers (in figure 6) when there is a clear difference between the two? Will this force more fluid vertical circulation systems to have tenants occupying multiple floors? Or will it mean that sites are developed with multiple towers to respond to the market demands while respecting the Tall Building Guidelines? 


\section{Chapter 3 \\ Hybrid Buildings}




\subsection{What is Hybrid?}

Oxford Dictionary: Biology the offspring of two plants or animals of different species or varieties, such as a mule: the bird was a hybrid of a goose and a swan

Hybridity is a genetic concept dating back to the time of Aristotle and his experimentation with the crossbreeding of animal species (Fenton 1985). In the 18th and 19th centuries Kolreuter and Mendel pioneered geneticists by underlying hybridization of life forms which lead to the biological and mathematical foundation of this process (mendelian ratios) (Fenton 1985). Hybrid is also a term that can relate to the concept of heterogeneity because it is used to describe relationships of complexity and differences. 


\subsection{What is a Hybrid Building?}

In Steven Holl's "This is Hybrid," he states that the emergence of Hybrid Buildings in the twentieth century was a result of urbanization and the concentration of social activities within an architectural form (Fernández 2011). Diverse associations have been combined together, sharing physical adjacencies and thus leading to the observation of the anti-typology. Holl claims that 'Hybrid Buildings' are those with functions mixed, disparate uses combined and structures collected. Urban densities and evolving building techniques have affected the mixing of functions where the transformation of architecture has gone from the homogeneous to the heterogeneous in regard to use. In the industrial revolution, urban centres grew outwards, swallowing small towns and upwards in the form of towers. In this period, people were driven to live in denser environments, closer to work. This resulted in architects having to reinvent the building by creating hybrids; combinations of different program and building types to create "Hybrid" towers that were the result of the contextual complexities. The term hybrid is referring to the evolution through combinations of different typologies and programs. Early examples of this can be found by looking at the Downtown Athletic club in New York City 
which contained a community centre, residences, and shops. (Kaplan 1985)

\subsection{History of Hybrid buildings}

The history and the literature on Hybrid buildings is documented in a 1985 publication known as Pamphlet Architecture by Joseph Fenton, as a response to "offer a model for revitalization of American cities" (Kaplan 1985). According to J oseph Fenton, the Hybrid Building Typology emerged as "a response to the metropolitan pressures of escalating land values and the constraint of the urban grid. With horizontal movement restricted, the city fabric moved skyward. Unable to occupy these vast new volumes with an individual use, functions were combined" (Pamphlet Architecture, 1985).

Although Hybrid buildings are programmatically multifunctional, they differ from conventional forms of mixed use buildings by scale and form, where the scale is being influenced by the size of a city block. Hybrid buildings focus more on the creation of individual form which supports the underlying pattern of the city grid. Programmatic relationships are determined by and support a particular context or community, which can 
be related back to a larger neighborhood or district of the city. Hybrid buildings comprise various typologies, anything from dwellings to courthouses, bridges and jails. The restriction of the city fabric growing horizontally caused it to move vertically, resulting in taller forms and various functions combined, allowing the Hybrid typology to emerge out of necessity. Such is the case with Manhattan. (Kaplan 1985)

In the United States, Fenton indicates that Hybrid buildings were largely constructed from the late 19th century until the Great Depression of 1929, which terminated many construction plans. After the Great Depression, Post WWII America experienced the influence of Modernist theories in planning and developing urban city centers (Kaplan 1985). Much of the reconstruction was shaped through the modernist principles of the Charter of Athens by CIAM IV, which advocated for separating functions, and the "systematic segregation of dwelling, work and recreation" (Kaplan 1985). This caused the decline of Hybrid buildings, until the midtwentieth century where a renewed interest in revisiting segregationist urban planning policies were re-evaluated. 
Fabric
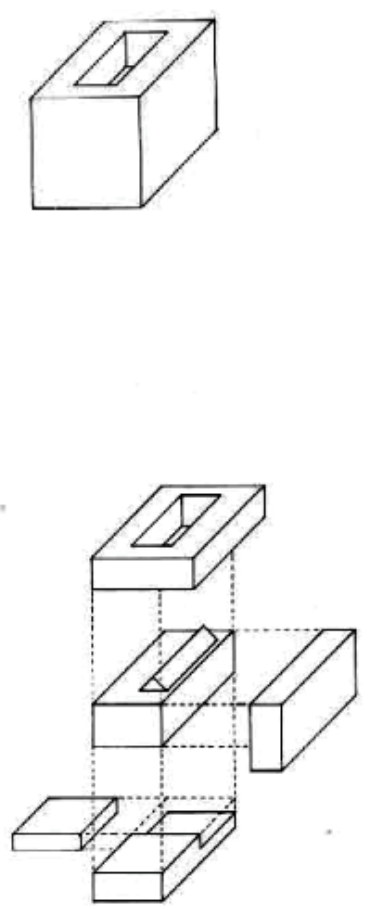

Graft
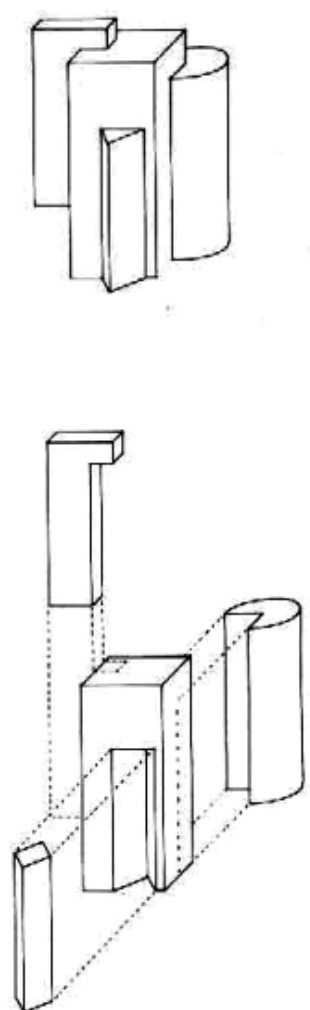

Monolith
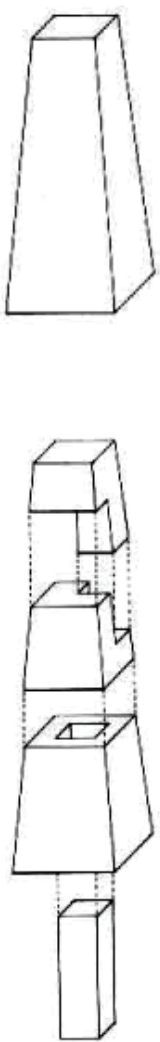

Fig 13: Three types of Hybrids, (Fenton 1985)

Fenton elaborates programmatically on the Hybrid building typology that generates two specific categories of program: Thematic and Disparate . Thematic programmatic combinations increase the dependency between programmatic parts, therefore increasing interaction between them. Disparate program combinations allow fragmented parts to exist in mutual alliance without conflicting with each other. Since Hybrid buildings are a by-product of vertical urban growth, stacking of programmatic functions was a common solution to hybrid combinations. As a result, these combinations often brought interesting formal changes 
in plan and section that could express function through massing and elevation treatment. (Fenton 1985)

In regards to Formal composition, Hybrid buildings are classified into three categories: Fabric Hybrids, Graft Hybrids and Monolith Hybrids (fig 13). The formal composition of the Graft Hybrid expresses its programmatic functions, volumetrically or through elevation. Fabric and Monolith hybrid types, both embody the expression of programmatic components within a continuous building envelope. (Fenton, 1985). Each classified Hybrid form is a result of a composition that either expresses the functions of the program or represses it. The expression or repression of programmatic elements depends on the relationship of the building to its immediate environment.

Fabric Hybrid:

Adhering to site conditions, Fabric Hybrid buildings appear to have an inconspicuous formal character in their total appearance as a result of the repressing of the programmatic elements within a singular building envelope. Fenton suggests that though fabric hybrids appear unpretentious externally, they can be innovative 
through the use of internal programmatic arrangements.

He uses the example of the Schiller Building in Chicago

where the elements of the program are stacked vertically

as a result of site limitations and context. As a hybrid

building, it combines the functions of a theatre with

offices and a private club. The theatre's auditorium and

Fig. 14-17 Example of Fabric Hybrid building. The Schiller Building in Chicago, Illinois. Built in 1892 by architects Adler and Sullivan.

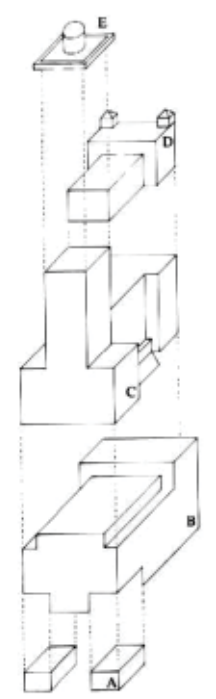

A. Stores

B. Auditorium

C. Offices

E. Belvedere

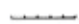

Fig 14: Axo Diagram

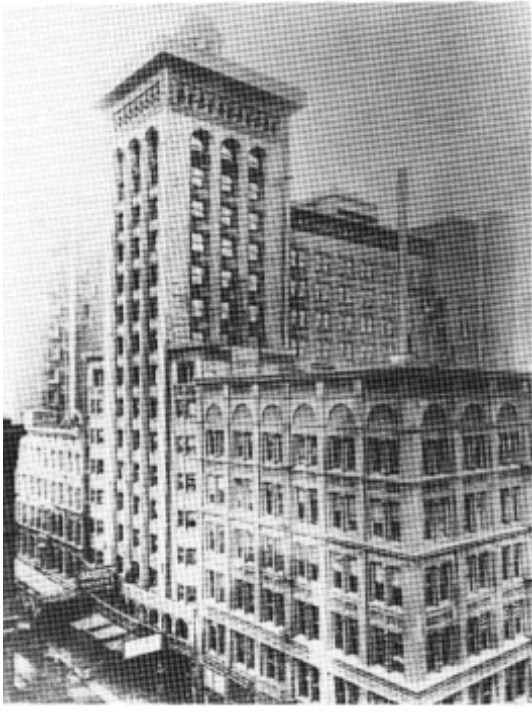

Fig 16: Exterior Photo

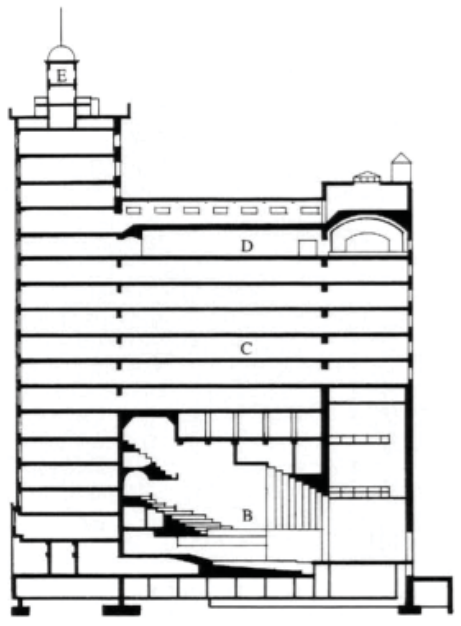

Fig 17: Building Section

Fig 15: Floor Plans
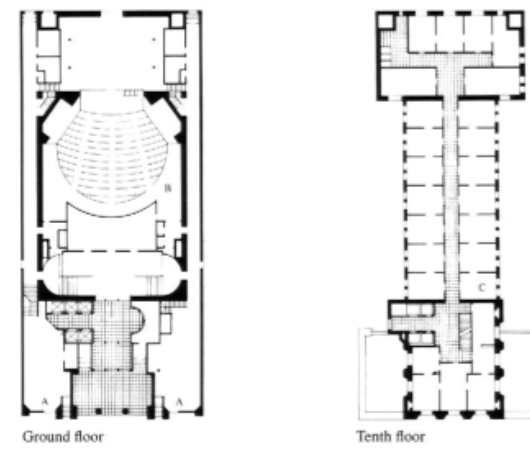
auxiliary spaces span between the ground level to the sixth floor, placing the auditorium in the centre of the building which is supported with long span steel trusses. The long span steel trusses that are two stories tall also support six floors of commercial retail space. The innovative relationship of plan and section to the function of the program is partially due to the structural system that supports a diversity of occupancies, otherwise hidden by the exterior facade. (Fenton, 1985)

Graft Hybrid:

Graft hybrid forms are distinguished by clearly expressing the integration of internal programmatic functions between building types, and the projection of them on to the exterior. This form of hybrid emerged in the early twentieth century during the expansion of American urban centers when the need to limit street grids and an increase in vertical density, caused architects to stack and integrate traditional building types. As a result, new hybrid types such as Bridge houses emerged. The Aquarium Restaurant and the Commercial Church were examples which also emerged during this period (Fenton, 1985). Distinct functions in these buildings are legible but are integrated with other functions in 
Figure 18-21: Example of Graft Hybrid building. Downtown Athletic Club, New York. Built in 1931 by Starrett \& Van Vleck, Duncan Hunter architects.

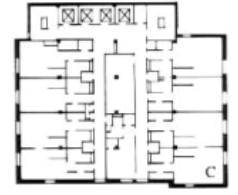

Twenty-sixth floor

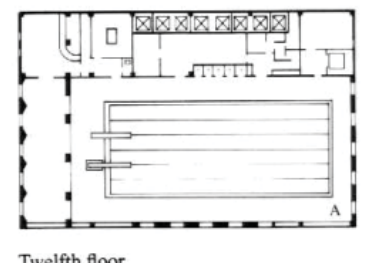

Twelfth floor

Fig 18: Typical Tower Plans

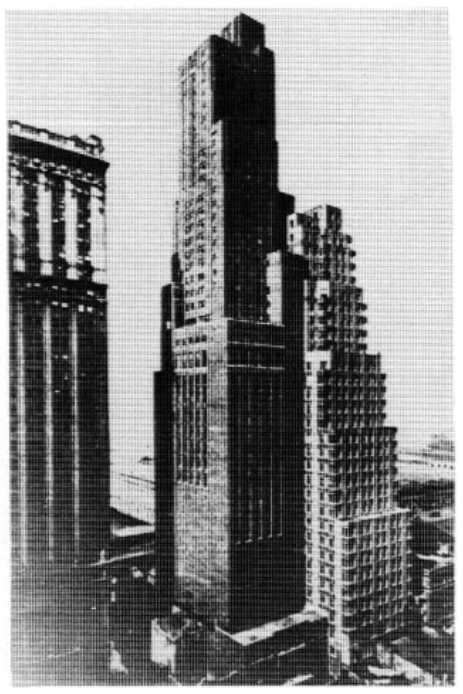

Fig 19: Exterior Photo an apparent union. A prominent example which is both identified by Fenton in Pamphlet Architecture and Rem Koolhaas in Delirious New York is the Athletic Club (Koolhaas 1994). Situated in lower Manhattan on a midblock site, the tower contains an athletic club, restaurant, and a hotel. With the hotel being situated at the top, the Athletic club occupies the majority of the building. The restaurant which is shared between the two programs is located at the intersection of the two major functions.

The form of the building relates to the internal programmatic divisions of the major programs. The

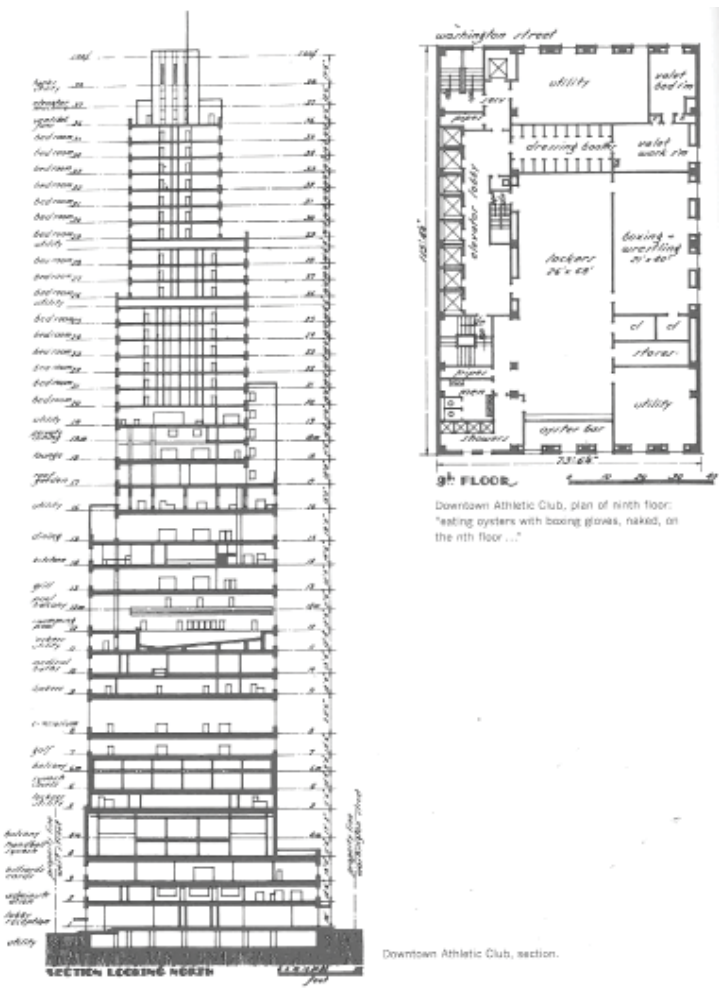

Fig 21: Section and 9th Floor Plan 
Figurel 22-23: Example of Monolith Hybrid building. Daily News building, Chicago. Illinois. Built in 1928 by Holabird and Root architects.

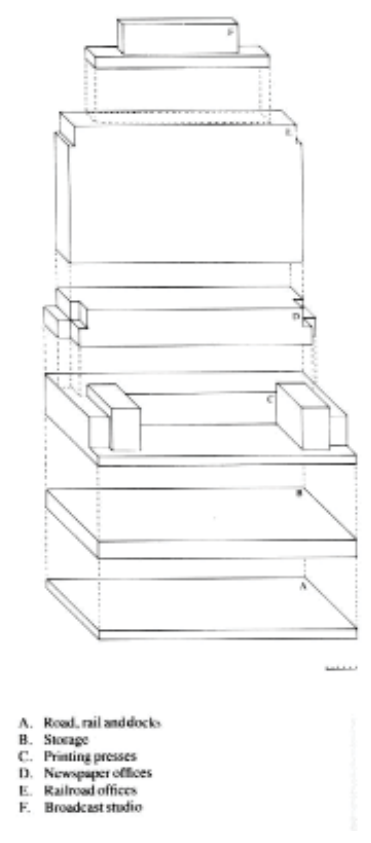

Fig 22: Axo Diagram

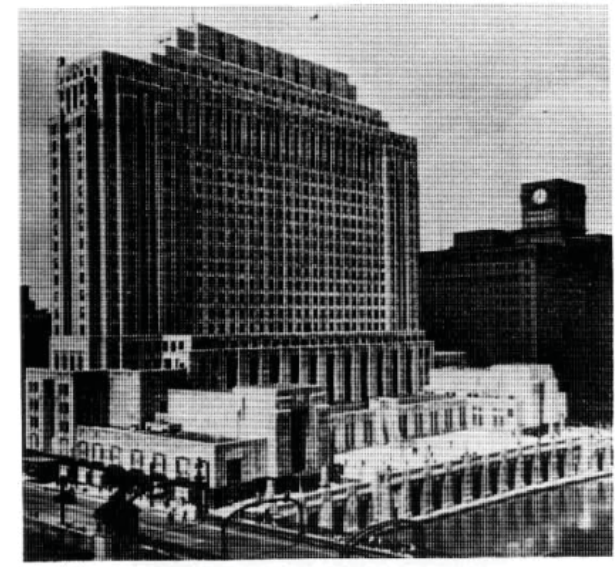

Fig 23: Exterior Photo

single and double height rooms inhabit a larger floor plate on the lower level to accommodate the diverse functions of the Athletic club. The setbacks on the top floor allow for light and air to reach the hotel rooms. (Fenton, 1985)

Monolith Hybrid:

Monolith Hybrid buildings are identified through their monumental scale. There scale represents a substantial concentration of metropolitan functions within a single structure on a single building block. This allows for greatest diversity in accommodating functions, compared to the previous hybrid types. In highly populated cities, this hybrid building can contribute to a better city life by promoting efficiency through reducing urban congestion, and by offering versatile uses under 
one roof. For this reason, the Monolith hybrid building can be perceived as a city within the city. (Fenton, 1985)

One example of this hybrid is the Daily News Building, which was the first building to be constructed in air rights over active railroad tracks in Chicago. Monolithic in form and scale, it features facilities for publishing and printing on lower floors and for radio broadcasting facilities at the top. Internal programmatic variations are coherently legible within the singular exterior facade, which represses any formal expression of internal programmatic arrangements. The building is efficient because it achieved its purpose of rapidly disseminating news by optimizing the potential of the site. Situated above the active railroad tracks, and adjacent to the river, information was received at the top floor of the building. It would then be processed by journalists and editors on the lower levels, then printed at the bottom floors and distributed from the basement by truck, rail and water. (Fenton, 1985)

\subsection{Modern Hybrids}

The subject of hybrid buildings in architecture has become increasingly relevant as the global trend of rapid 
urbanization of city centers in the 21st century becomes evident. A greater challenge is not only accommodating six hundred million people in the process of migrating from rural to urban centers, but to create better quality of life within the limited resources of a city. Rapid urbanization often results in banal architecture, without architectural quality to urban space. The role of Hybrid buildings has become increasingly questionable as architects are faced with complex issues surrounding the increasingly dense metropolis of the contemporary city (Holl 2011).

Rethinking urbanity has become fundamental in a city of high rise living where spatial scarcity in urban city centers and a multitude of programs accommodating singular use has become inefficient. Consequently, the lack of public realm, and programmaticindeterminacy are issues that continue to govern the urban city today. The public realm is one of the issues that has dominated architectural and urban planning discourse throughout history, but is more imperative to urban living today than ever before. Therefore, a built environment which shares programmatic use and generates public realm is not only efficient but has become almost necessary for the future 
of city and urban culture. What is the role of Hybrid buildings in shaping the 21st century contemporary urban space? The proposition of Hybridized buildings is to generate an architectural environment which creates an impact on an urban scale rather than being a single typology or prototype. (Holl 2011)

In This is Hybrid, Steven Holl suggests the potential role of hybrid buildings in the theoretical framework which can offer "pedestrian oriented urban spaces that contain living, working, recreation and cultural facilities...they can become localized social condensers for new communities" (Fernandez, 2011). Freedom of invention and newer architectural concepts that correspond to metropolitan challenges in innovative ways are a particular potential of hybrid buildings. Holl elaborates on the modern hybrid scheme through several points:

Typology: Hybrid buildings are anti-type as by principle their purpose is to integrate multiple typologies and a set of functions fused together. Hybrid buildings emerge as a response to continued persistence of the modern ideology that advocated for segregated uses. Hybrid buildings are yet to reach the pinnacle of 
successfully integrating functions and typologies.

Processes: The concept of Hybrid reaches beyond the point where mixing of uses is not limited to the program of a building. Hybridization allows for the integrating of general processes such as combining property and land development through public and private partnership. For a dense city such as Toronto, public private partnership gives alternatives to the city for reaching demands, such as building new infrastructure which is much needed. Construction, Structure and Management of these projects can be hybrid by allowing for integration on different levels.

Programmes: Since hybridization distinguishes itself from mixed use, programmatic functions in a Hybrid building are interconnected symbiotically to offer diversity in uses for planned and spontaneous activities. Central to hybridization is the notion of sectional juxtaposition of program as opposed to the stacking of program on different levels in vertical buildings. Holl biologically compares the relationship of hybrid uses to a "system of connected vessels" which benefits all users. 


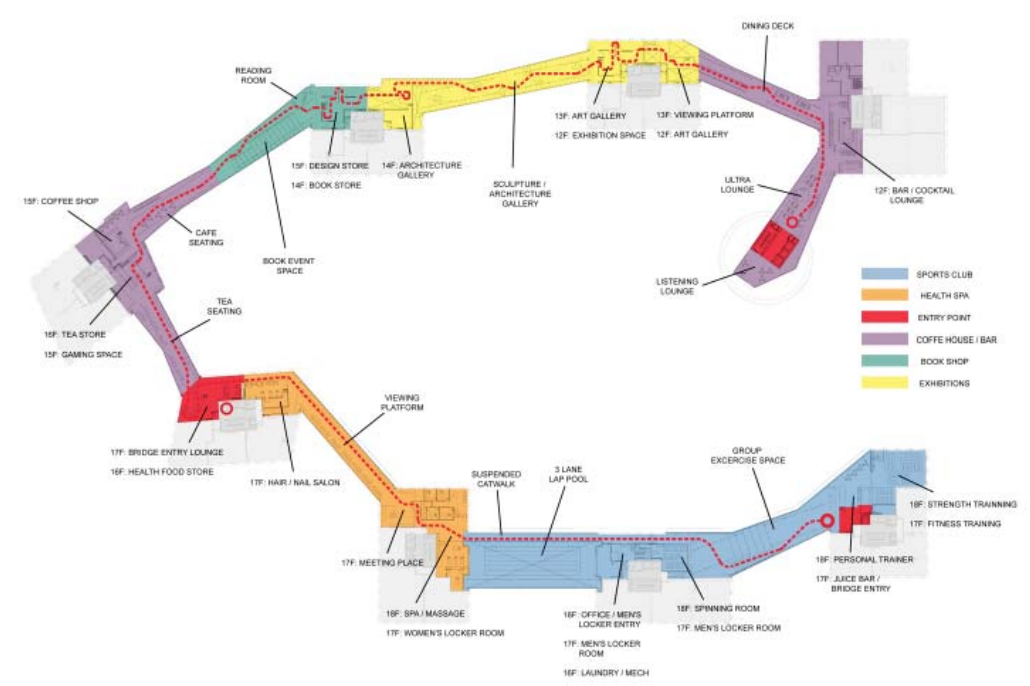

Fig 24: Circulation and Program Plan
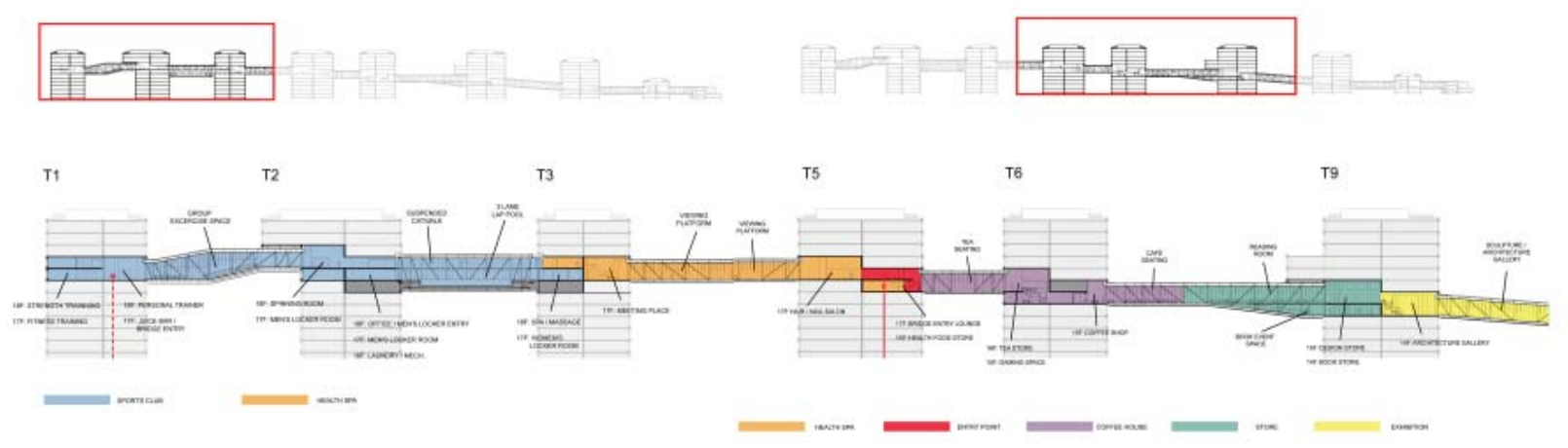

Fig 25: Section

Density: Hybrid situations are best created in dense environments which allows for "cross fertilisation", an analogy which describes the interchange between differences (such as culturally or socially) to generate mutual interaction. This would benefit and improve living conditions for everyone.

Scale: Since Hybrid is not a type but rather a combination of types, Hybrid buildings often take on the character of mega structures which can be perceived as 
a "city within a city." Programmatic functions in a vertical hybrid are combined through superimposition, where as in a horizontal hybrid it is through floor additions.

City: Hybrid buildings create a dialogue with the city through compositional strategies which relate to the grid, perspective, urban landmarks and relationships surrounding the public realm. Due to its mega scale, the hybrid building can be considered as an urban plan which consists of mono functional buildings situated around a common ground which reflects a cross section of the city.

\section{Linked Hybrid:}

Linked Hybrid was designed by Steven Holl Architects and built in Beijing China. The project was conceived as eight mid-rise towers, linked together by horizontal bridging. This bridging is used as public space,

connecting all eight towers together at the top. The initial uses were intended to generate random juxtapositions that would adapt over time, elevating the palimpsestlike effect that historic cities have at ground level (Petit 2013). The design responds in many ways to Chinese urbanism. The following traditional Feng-Shui principles of using the new phenomenon of vertical living, giving 


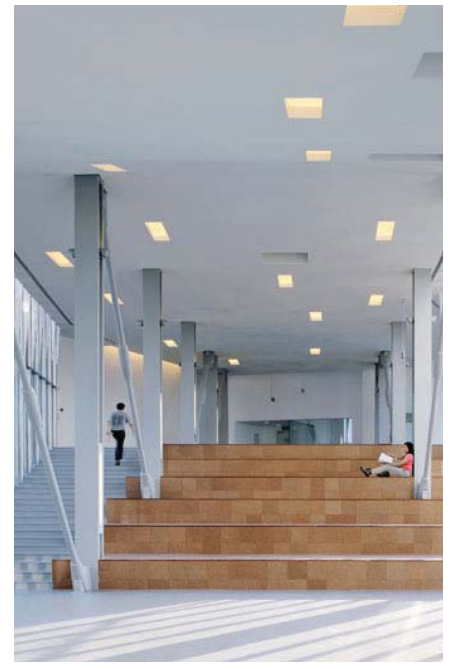

Fig 26: Interior Photo

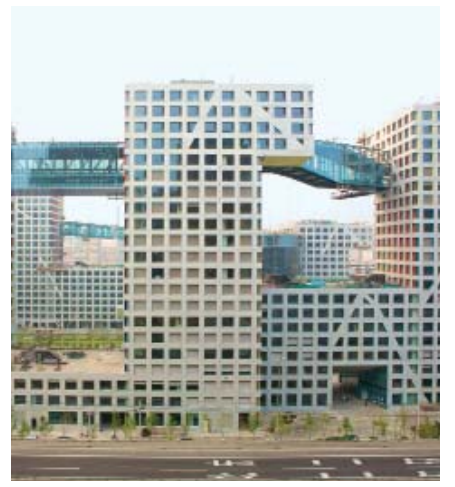

Fig 27: Exterior Photo opportunities for individual expression that Chinese mass housing typically lacks. The overall complex houses 2500 residents of 620 apartments. Recreation and shopping are in the sky as well as on the ground (Fig 24) (Fernández 2011).

Linked Hybrid does succeed, to some degree at creating the vertical street, however the main issues found with this project are that it's located in a more suburban area so it might be harder to encourage foot traffic to enter the lifted street. Although one of the main design focuses was to create collective services for both visitors and people who reside in these buildings, this might become problematic because none of the program is state owned and it might transform into a big gated community.

\subsection{World Trade Centre Design Competition}

After the horrific attacks of September 11, 2001 there was a competition held for a new World Trade Centre which brought some of the best international architects to New York City to participate. Leading up to this competition there was debate regarding the safety and accessibility of the towers including appropriate height and placement of fire stairs. Many design proposals 
sought to redefine the skyscraper typology. One of the main concepts explored was the decentralization of fire stairs and elevators. This was done by breaking the traditional one tower model with a central core and exterior tube and creating instead a series of smaller towers of equal height with horizontal bridging acting as sky lobbies. The sky lobbies were interstitial spaces, trans-programmed to accommodate different occupants and almost creating a vertical street or internal circulation network, moving in all axes. (Riley, Nordenson 2003)

\section{Steven Holl Architects, Richard Meier \& Partners Architects; Eisenman Architects, Gwathmey Siegal \& Associates:}

This proposal, for the WTC comprises of two slender towers running east-west along Vesey Street and north-south along Church Street. These towers are theorized as a "matrix of voids and solids" reaching 1,111 feet tall with a total area of 8.5 million square feet (Riley, Nordenson 2003). The towers feature orthogonally intersecting elements extending vertically and cantilevering from the points of intersection. Steel bridges link the vertical cores creating "super floors" of approximately 80,000 square feet in the Vesey Street 
tower and 110,000 square feet in the Church street tower (Riley, Nordenson 2003). The office towers have three elevator zones, equipped with double-decker express elevator ferries to the sky lobbies from which local elevator services connect to the floors. The top of the tower has public spaces in the form of an observation deck, conference centres, restaurants, a hotel, and a memorial chapel.

\section{United Architects, Un Studio, Kevin Kennon Architects, Greg Lynn Form, Foreign Office Architects, Reiser + Umemto}

The project concept was to have five linked and canted towers with over 10 million square feet of space. The structural concept for the towers was developed

Fig 28: Fire Escape Diagram
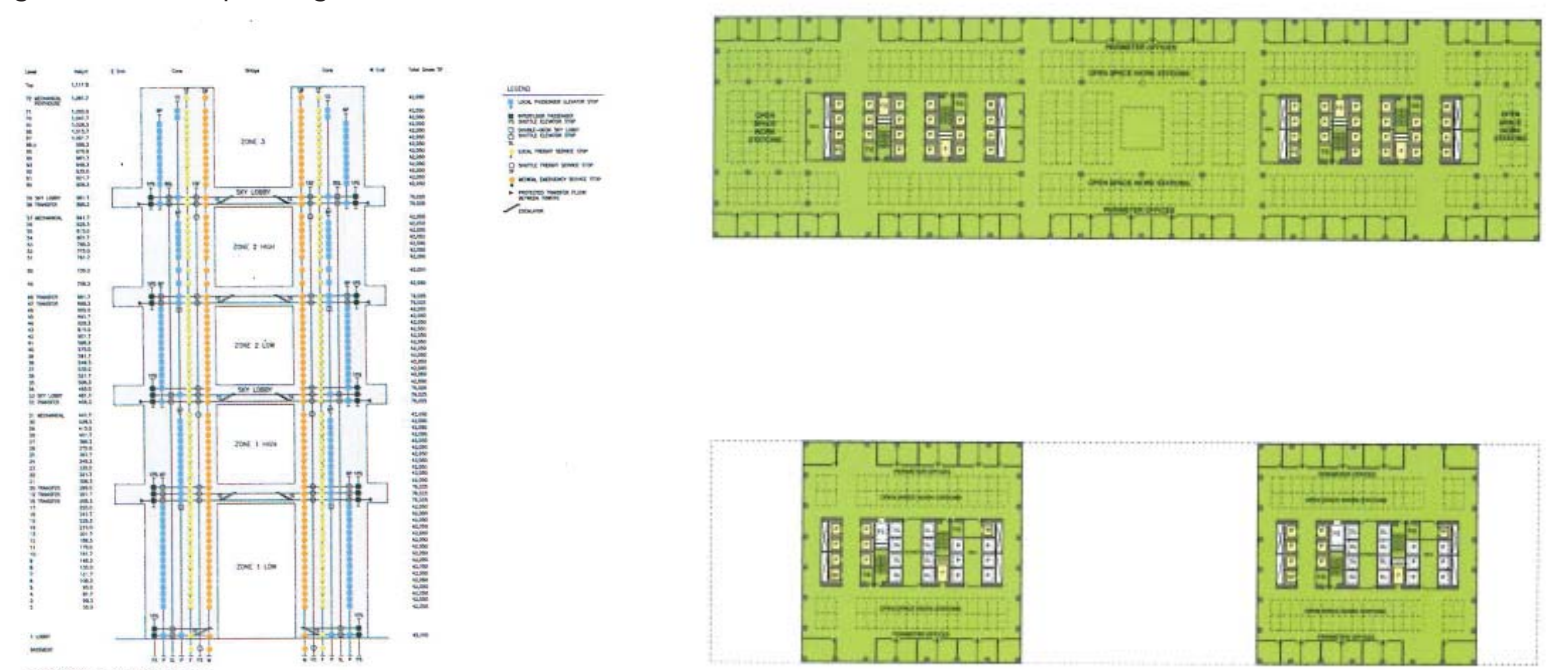

Fig 29: Elevator Diagram

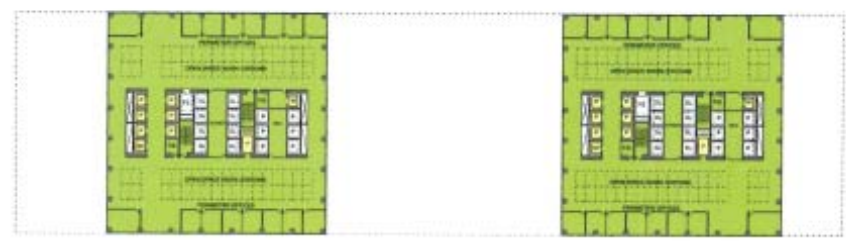

Fig 30: Typical Plan 


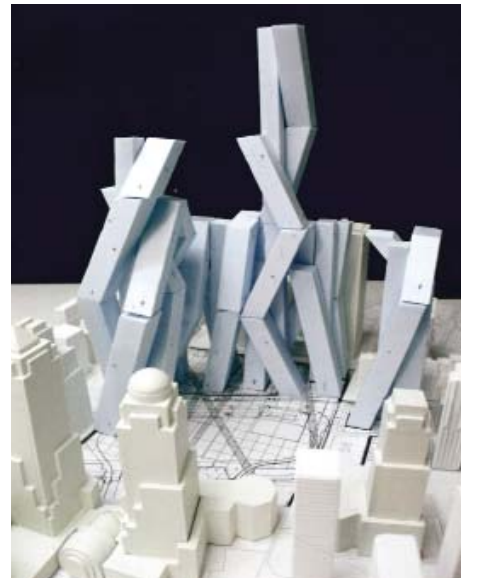

Fig 31: Concept Model

with the intention of establishing a new tower typology based on the logic of the envelope acting as structure and angling the towers to join and detach at strategic points. Each tower was to have a 20 square metre concrete core wrapped with interior space. The spaces are braced with the exterior skin, a "tube within a tube," absent of interior support structure besides the cores (Riley, Nordenson 2003). The externalization of structure as skin affords the ability for the floor plates to weave back and forth, oscillating between an aggregation of individual floor plates to detached and autonomous floor plates. The assemblage of towers with connecting vertical and diagonal shafts allows for multiple ways of connecting and escaping in the case of an emergency. The sky park connects all the towers together on the fifty fourth floor providing an uncontested and enthralling view to the skyline. Each of the linked points contain prominent

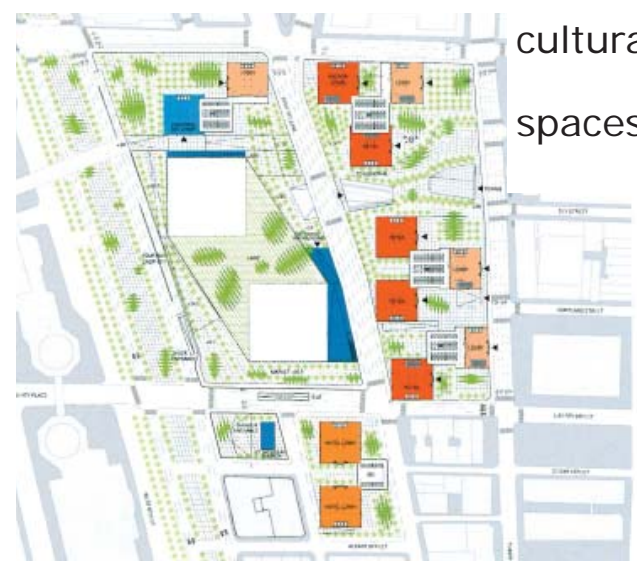

LEVEL GRADE

Fig 32: Site Plan 

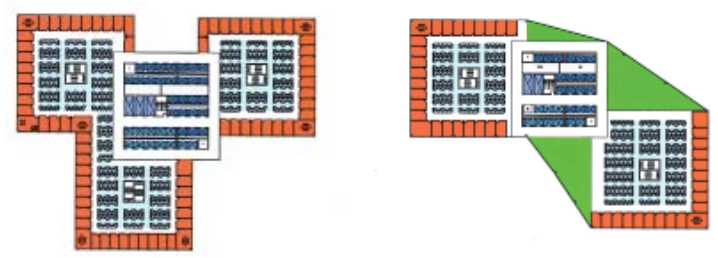

Fig 33: Typical Office Plans

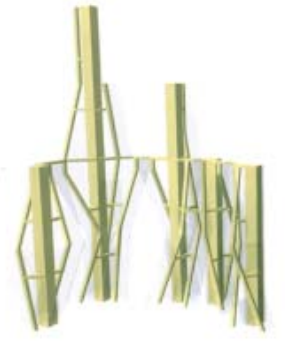

Fig 35: Circulation Diagram

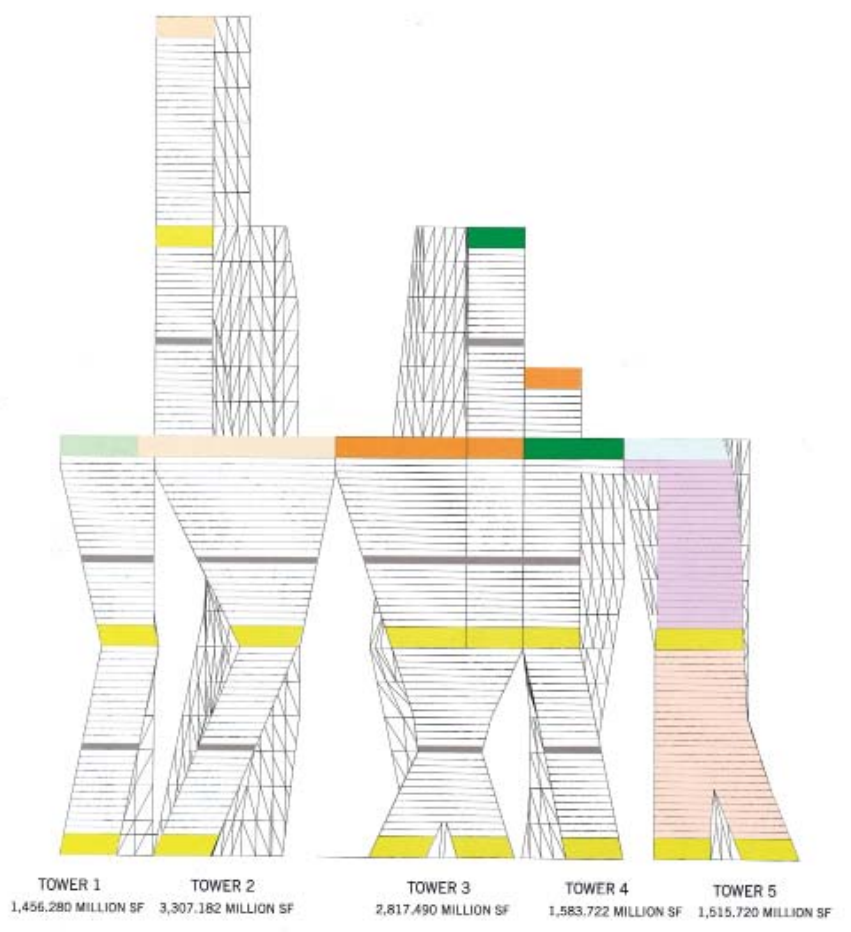

Fig 34: Tower Section

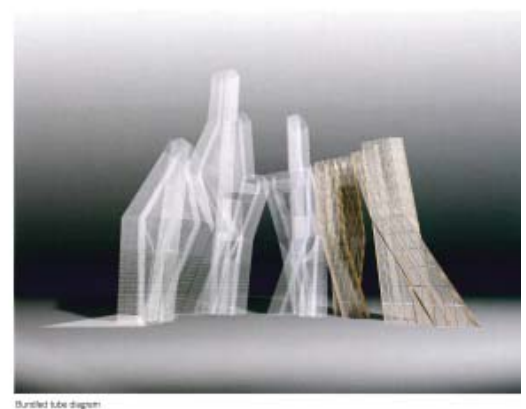

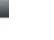


where a set of functions are fused together. Hybrid buildings are best cultivated in dense environments which can allow for diverse environments to occur. Creating dialogue with site, infrastructure and the surrounding environment makes hybrid buildings open up to the city, encouraging contact with external users. Programmatic functions are combined through superimpositions. Due to their mega scale, Hybrid buildings are able to facilitate planned and unplanned activities and can be conceived as a urban plan. 


\section{Chapter 4 Social Condenser}




\subsection{Defining the social condenser}

Historically, the concept of Social Condenser first emerged in the 1920's from Soviet Constructivist theory which was based on the notion that architecture can influence social behavior, and break down social hierarchies. This principle was first demonstrated in Narkomfin Communal House, a collective housing project which contained private living units and excluding essential amenities. It was intended that the fully glazed collective facilities which housed communal kitchens, laundry, gymnasium, swimming pools, and library, would encourage a socialist way of life. Smaller scale living units barely offered freedom for other uses, except the only function they were designed for (Koolhaas 2004).

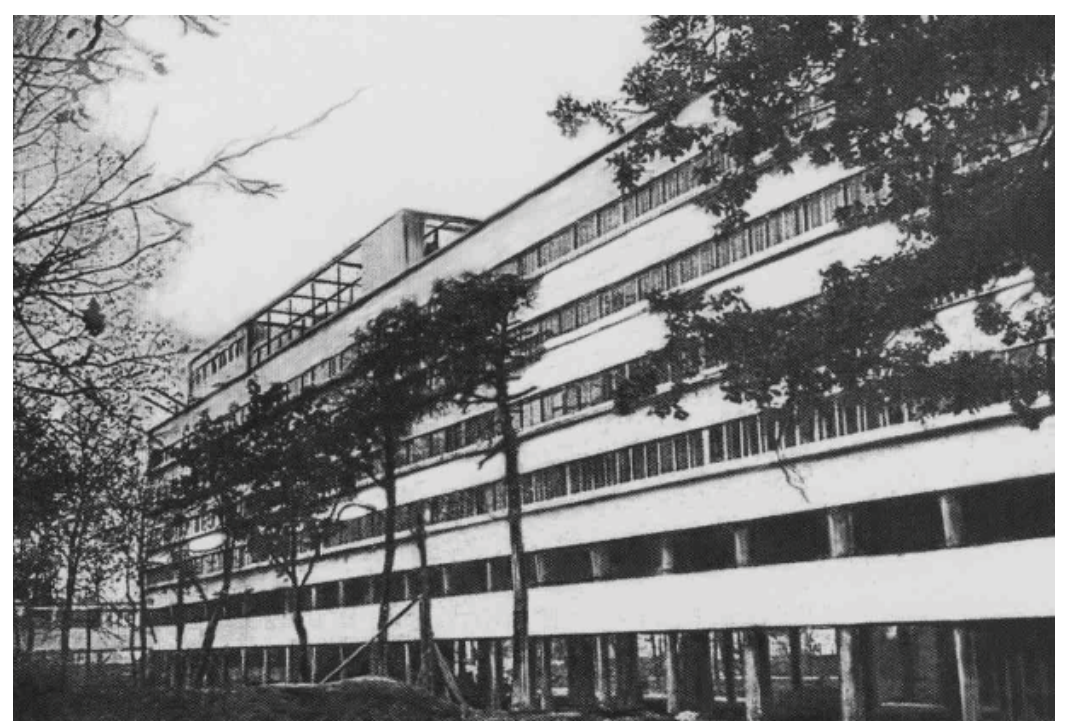

Fig 37: Narkomfin Communal House, Built in 1932. Moscow, Russia. Architects Moisei Ginzburg, Ignaty Milinis. 
Traditional private realm was discouraged in socialist ideology, where it was converted to semi public shared living and communal spaces. Through the means of condensing collective areas, architecture was able to control the social behavior and create equitable social spaces. The Narkomfin Communal House became influential on later projects, such as the post WWII housing project, Unité d'Habitation by Le Corbusier. As a mixed use high rise residential project, its innovation was based on integrating collective functions of a city in a single building. Comparatively to a neighborhood, Unité offered a mix of institutional, retail, leisure and commercial programs along communal corridors, which functioned as internalized streets. Other communal spaces such as a gym, running track, swimming pool and garden terrace take place on the roof, allowing the residents to engage with the suburban landscape in which the building is situated in. Unité became a self-sufficient building for its inhabitants, a machine for living.

The concept of the Social Condenser reappears in Delirious New york and later throughout the works of Rem Koolhaas. Koolhaas is famously noted to document the Athletic Club as a building which exemplifies social 


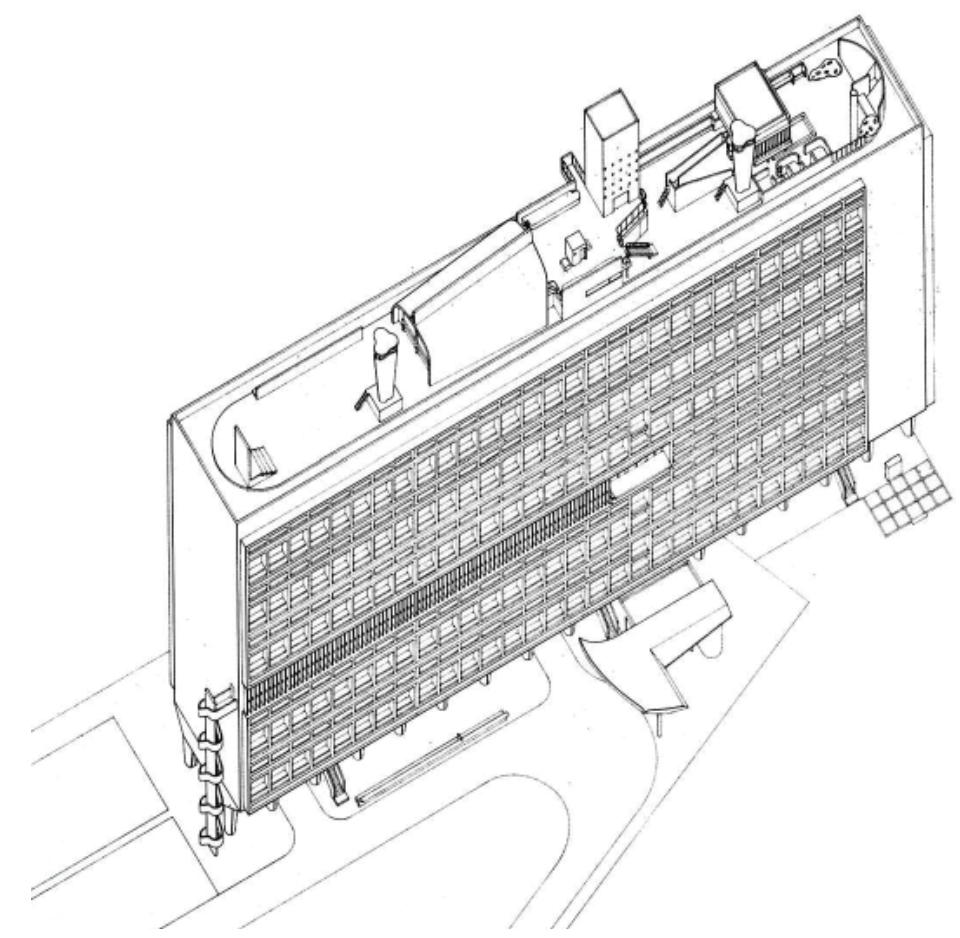

Fig 38: . Unite d' Habitation 1947, Marseille, France.

condenser through the superimposition of programmatic floors which contain diverse functions. An elevator shaft which intersects at different floors, allows users to spontaneously experience the program. Are the effects of Social Condenser solely produced by contiguously stacking diverse programs inside a building?.

Koolhaas indicates that the "culture of congestion" generated by the complexity of dense urban environments creates the environment for social condensers.

(Koolhaas, 1994). A recurring conceptual reference to social condenser and its integration with architecture and urbanism can be traced through the works of OMA. Projects such as the Tres Grande Bibliotheque 
competition and the Jussieu library explore questions surrounding circulation, its reference to the continuation of ground plane and diverse uses. In the Seattle Library, conventional functions of the library is transformed to function as a giant social condenser. Partially because the culture surrounding information technology has shifted from being exclusively dedicated to books, to different forms of media (archdaily 2009). This allows for flexibility in accessing information anywhere in the library. The spatial arrangement of floating volumes with intersecting planes provides an interface to transform social interactions between users occupying space. (Koolhaas, 1994)

Koolhaas suggests that in order to maintain high usage of libraries, cities should reinvent the conventional typology to mitigate financial constraints caused by operations and provide better public and collective spaces. Comparatively, The Social Condenser and the Hybrid differentiate in terms of their emphasis on public space. While the hybrid urban space is established on the premise of encouraging a mix of external different users and diversity of land uses. Social condenser's prioritize internal public domain and rely on programming. Hybrids 
depend on connectivity with its immediate surroundings, Social Condenser's predominantly depend on their collective communal spaces to encourage active use. However, both Social Condenser's and Hybrid buildings aspire to be self-sufficient and provide efficiency in their urban context. As documented through previous research in this thesis, and unpredictable events leading to the World Trade Centre competition, the need to rethink the tower typology in terms of form, function and circulation has become fundamental for urbanized cities

\subsection{Architecture Examples}

Delirious New York:

In Delirious New York, Rem describes the culture of congestion and proposes the conquest of each block by a single structure where each building will become a house. Each house will represent a different lifestyle and ideology which further supports the notion that diversity in downtown cities is needed in regards to typology, program, and scale. Koolhaas states that on each floor, the culture of congestion will arrange new and exhilarating human activities in unprecedented combinations that would break down social hierarchies. “Each city within a city will be unique enough will 


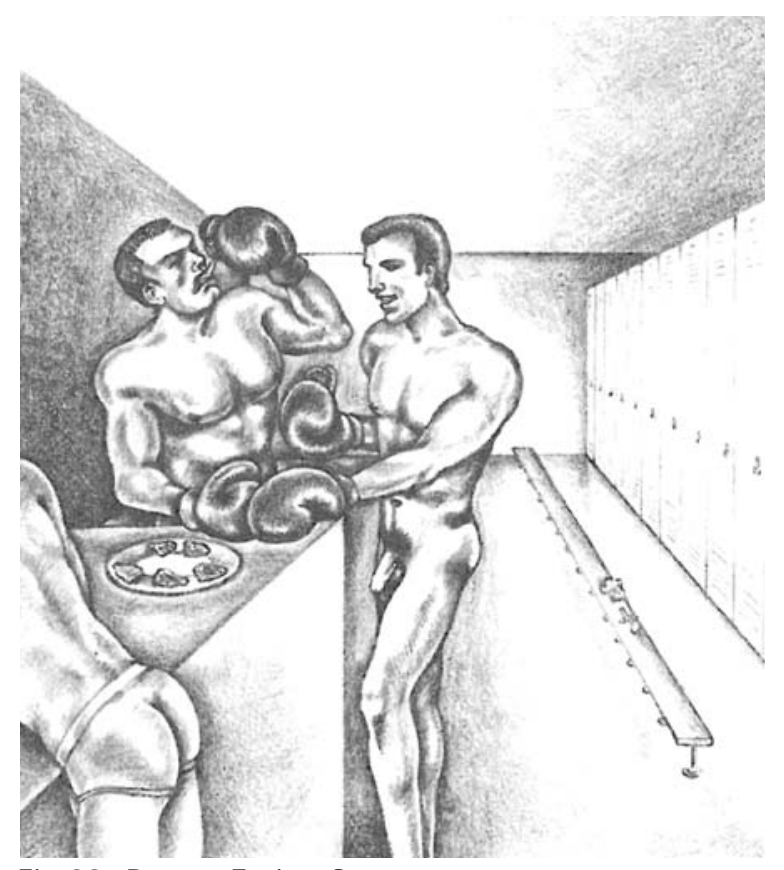

Fig 39: Boxers Eating Oysters

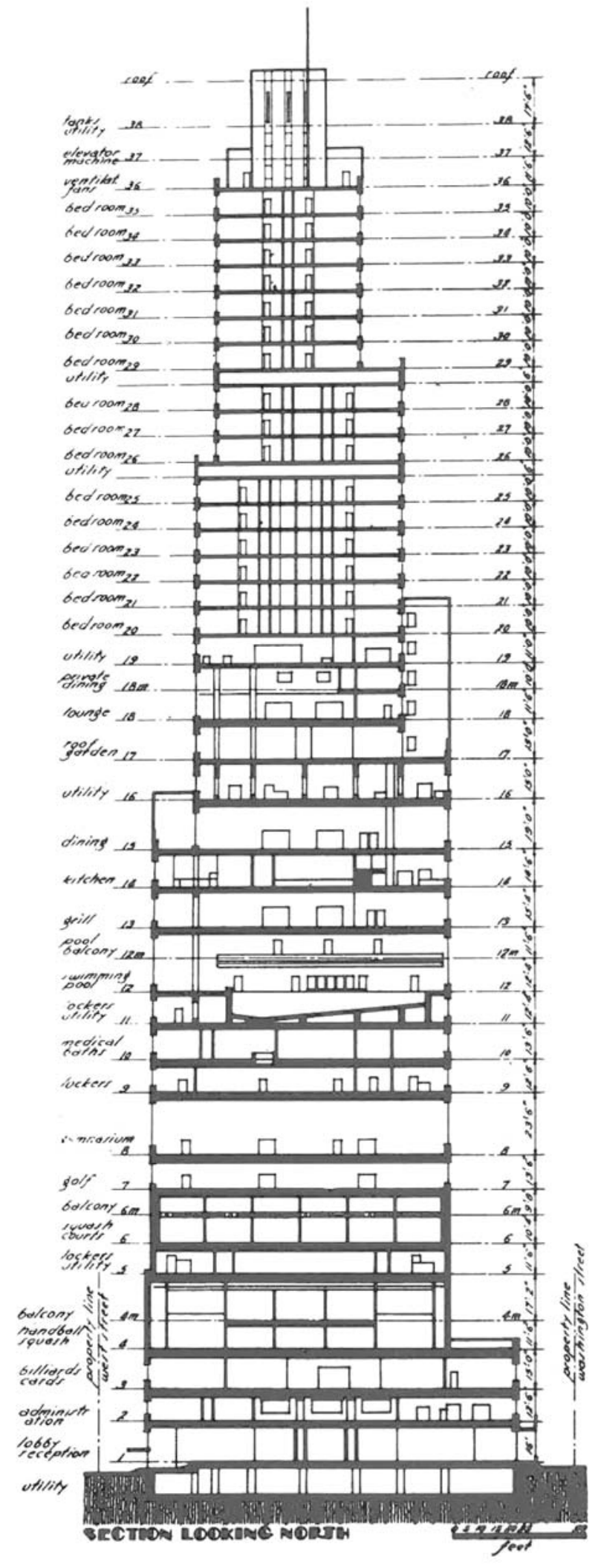

Fig 40: Section 
naturally attract its own inhabitants" (Koolhaas 1994). Rem describes this to be a series of thirty eight superimposed platforms, which repeat themselves more or less within the original area of the site. In the Downtown Athletic Club " the skyscraper is used as a constructivist social condenser: a machine to generate and intensify desirable forms of human intercourse", (Koolhaas, 1994). The diversity in the program and interplay of spaces in relationship to the whole, allows for the breaking down of social hierarchies.

In Delirious New York, Koolhaas presents the building section of New York Athletic Club as a functional diagram which allows one to rethink the relationships of part-to-whole in a traditional tower. The tower typology consists the traditional stacking of floors which is perceived to be isolated, providing no interaction. Koolhaas reveals the dynamic relationships of program by showing a building section of the New York Athletic Club. This section is unlike other tower sections because of the interesting programmatic contrasting elements that exist and the fluidity that occurs between different moments of the Athletic Club, hotel and restaurant. This project was most influential in Rem's studies moving forward to 

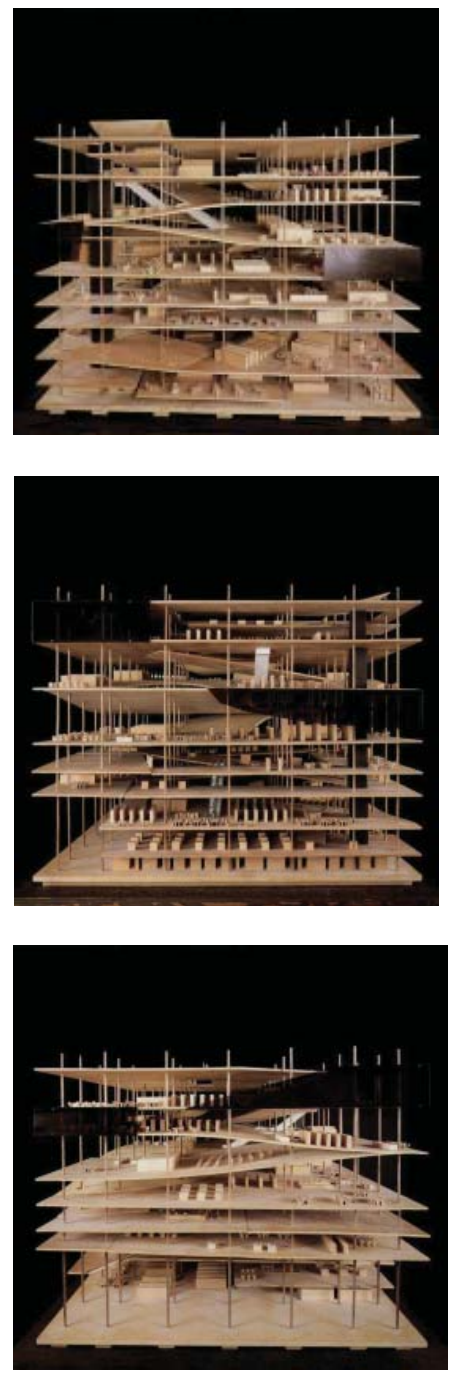

Fig 41: Physical Model the Jessieu Library - This gave him ideas for integrating lateral circulation through the building. (Eisenman 2008)

J ussieu Library:

"Denying the ground plane as a datum, the wrapping interior boulevard conceptualizes the void as a latent force contained between layers of solid floors" (Eisenman 2008) In the Jessieu Library competition, Koolhaas explores the dialectic relationship between static elements of solid floors and dynamic movement of circulation flows. Continuity between the ground and the entire building is created through means of ramping, which is conceived as an interior boulevard. The vertical landscape is superimposed by program which choreographs the street with uses such as parks, plaza's, shops and cafe's. This creates a network of continuous circulation and social presence throughout the building.
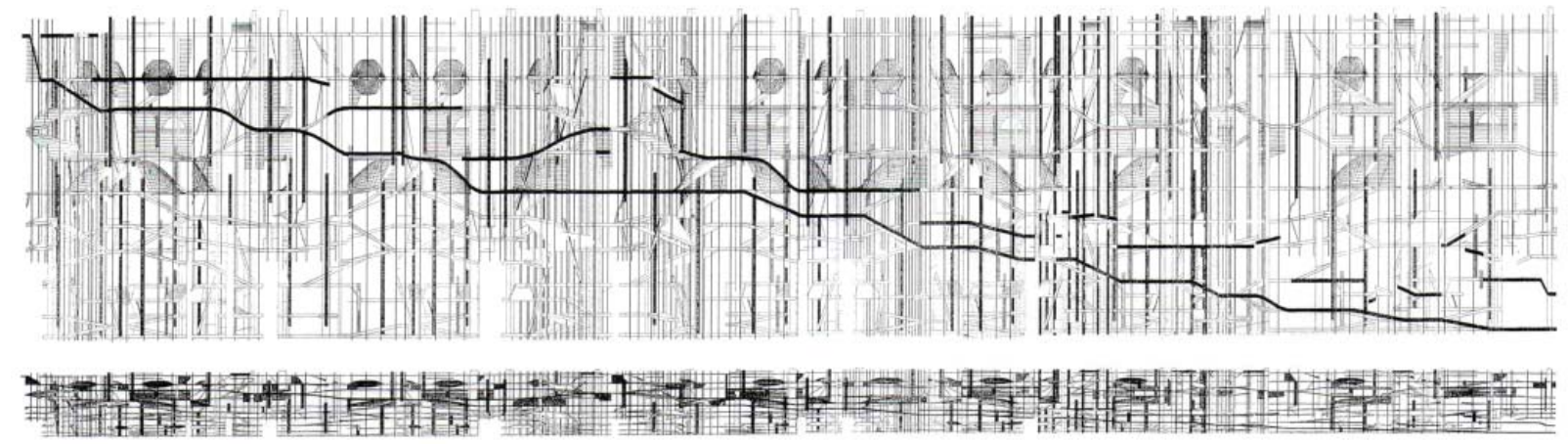

Fig 42: Unfolded Section 


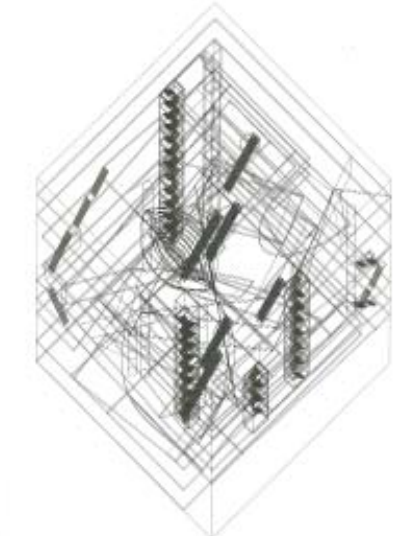

Fig 43: Axo Wireframe Diagram
The unfolded section of Jussieu Library captures the internal continuity of the surrounding surfaces. The only true volumetric spaces in the building are the interstitial spaces between floors, the voids. The sectional drawing illustrates circulation to be the dominant form as it links between different floors, while conveying the relationship to the buildings exterior elevations using classical architectural notation. The cross section reveals the ramped floors and its relationship to program as continuous surface, rather than stacked layers. (Koolhaas, Mau 1998)

In the Tres Grande Bibliotheque competition, Koolhaas uses the strategy of the void where the library is conceived as a solid volume in which volumes that represent public spaces are carved out. They are defined as "absences of building.. where voids are cut out of the information solid" (p. 202, Jussieu libraries) The strategy of the void provides an alternative way to rethink the relationship of figure to ground, and part to whole relationship. In the library, circulation and its associated elements are considered to be the object where it is given form. 


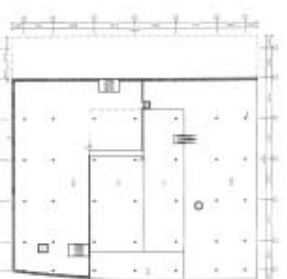

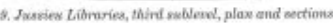

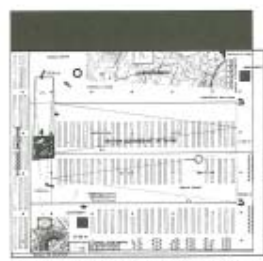

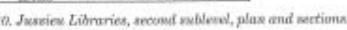

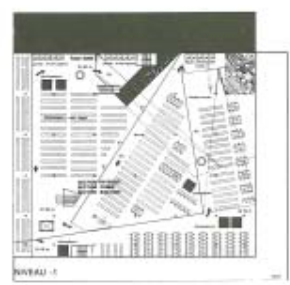

-6-C

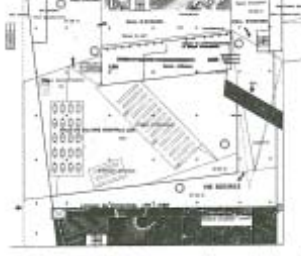

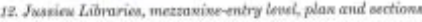
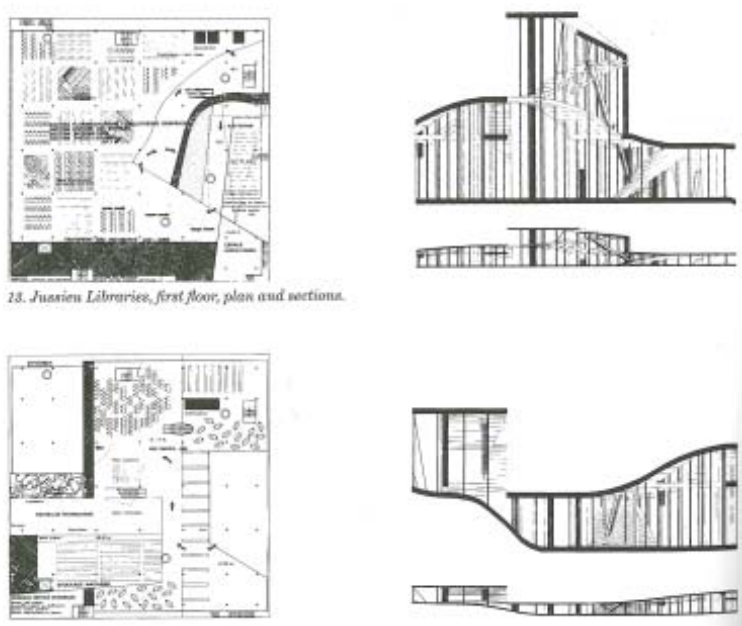
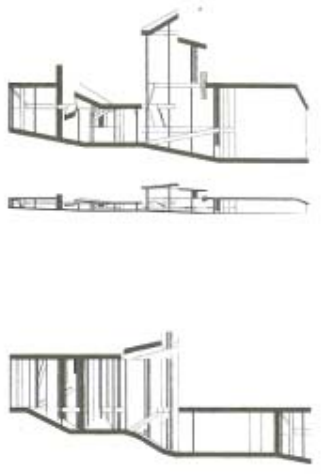

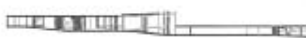
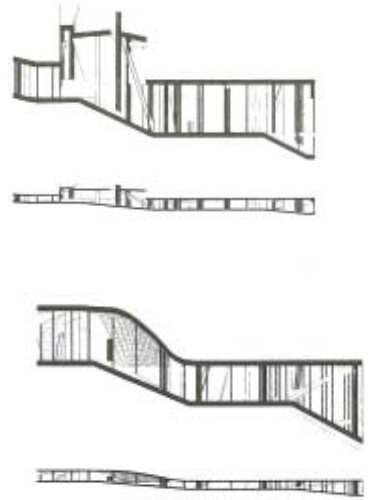

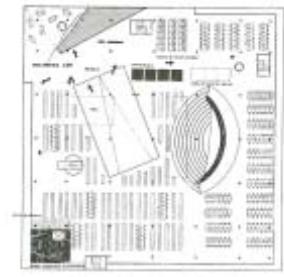

15. Juseies Lioneries, fuirth floor, plan and sections

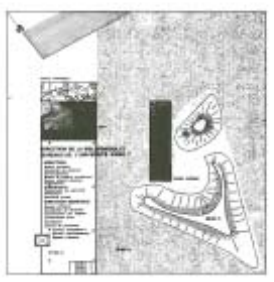

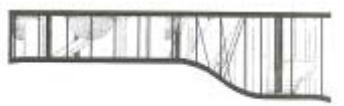

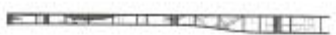

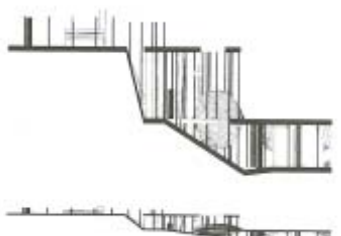

Fig 44: Floor Plans and Sections 


\subsection{Summary of principles for a Social Condenser:}

As a model, Social Condenser concentrates social activities and its transformation capability to a relative closed community. Internalized communal spaces rely on diverse programming to encourage flows. It aims to create situations for indeterminate and unprecedented events by strategies corresponding to layering, superimposing and juxtaposing diverse uses, which is interfaced by circulation routes. Since Social condenser aims to be self-sufficient for the internal users, these buildings can isolate itself from its context. 


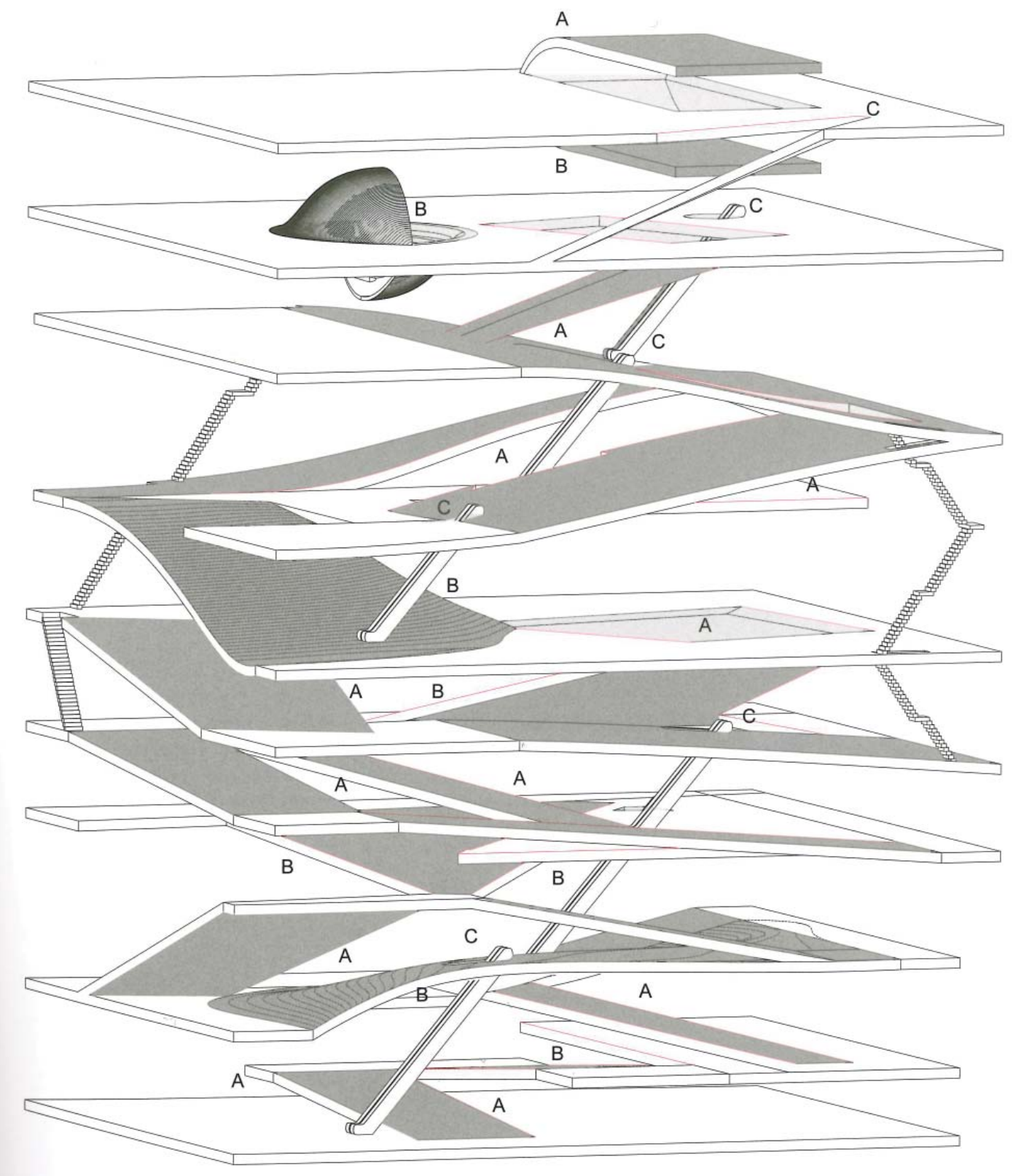

Fig 45: Lateral Connection Diagram 


\section{Chapter 5 Project}




\subsection{Project Description}

The thesis project is a critique of the existing stereotypical tower with the ambition of becoming both - a hybrid and social condenser, and that can attract the existing population of downtown condominium dwellers by providing institutional, cultural, and social amenities, that are not currently found in the existing context. The ideal project would connect to existing city infrastructure and reinforce urban connectivity while also acting as a destination in and of itself - a city within a city.

\subsection{Site Analysis}

The proposed site for this thesis is at 45 bay street, located on the north-east corner of Bay Street and Lake Shore Blvd. This site is important because of its close proximity to City Place, and other large condominium developments in the area. The $\mathrm{GO}$ and $\mathrm{CN}$ rail lines which run east-west on the north end of the site are elevated 8 meters above grade. A bus station is also located on the north end which is linked into Union Station. Union Station is located at the north-west end and is connected to the Yonge-University subway line. The Air Canada Centre is on the north-west corner of Bay St. and Lake Shore Blvd. The goal for this thesis is to link into the 
surrounding city infrastructure by connecting to the underground path system that located on the north end of the site. This would connect the building to Union Station, Go Transit, and subway. The other opportunity would be to continue this underground path system to future developments south of the site, towards the waterfront.

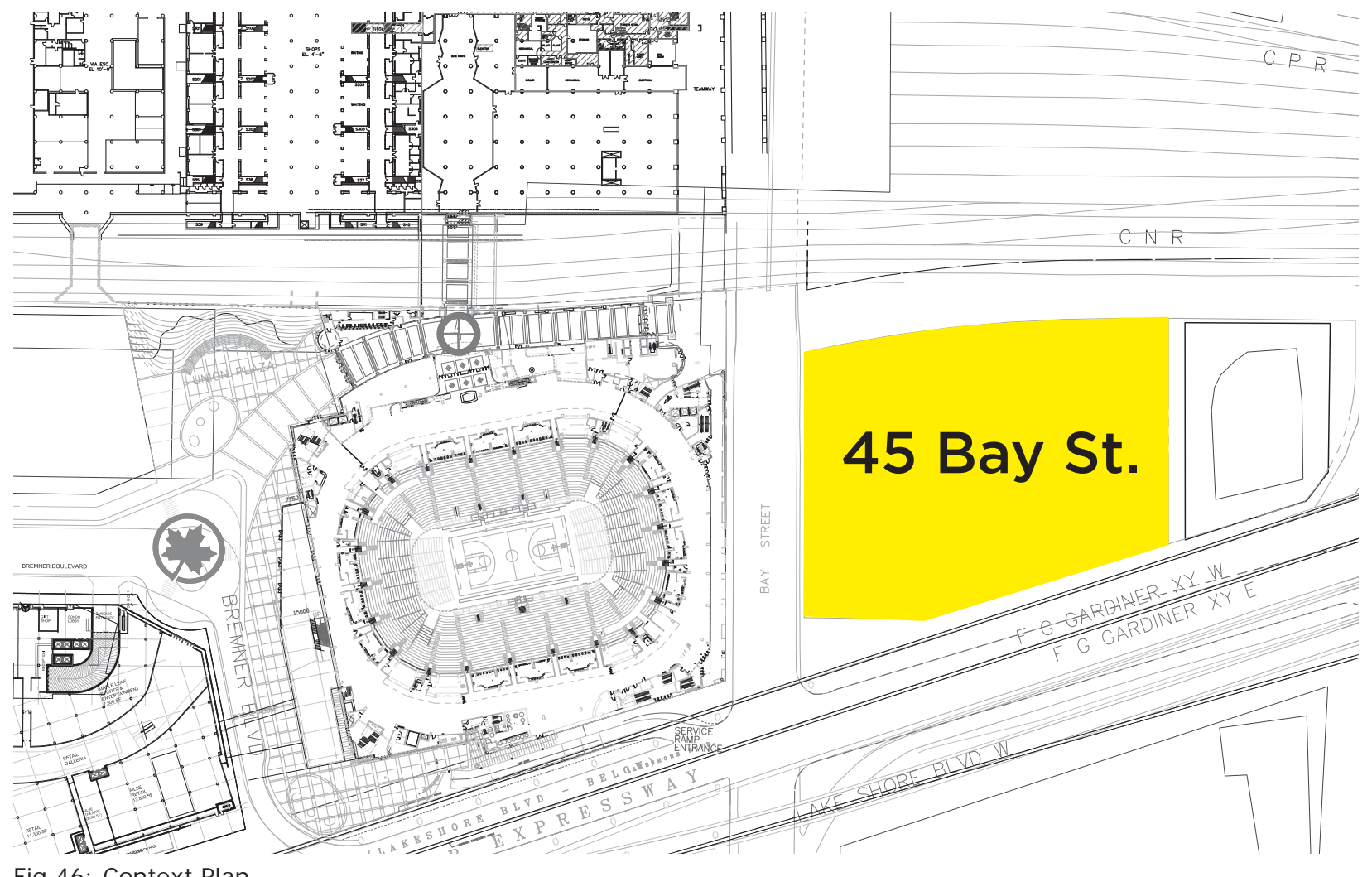

Fig 46: Context Plan 


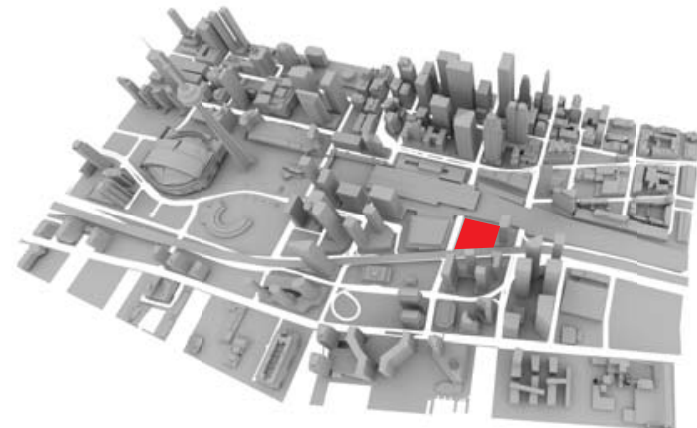

Site Location

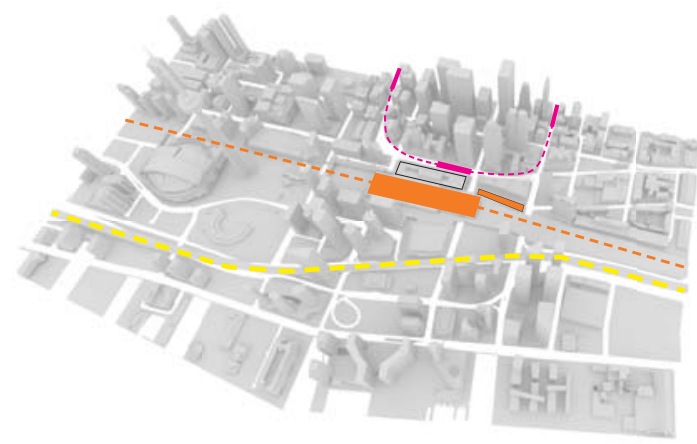

Subway Line

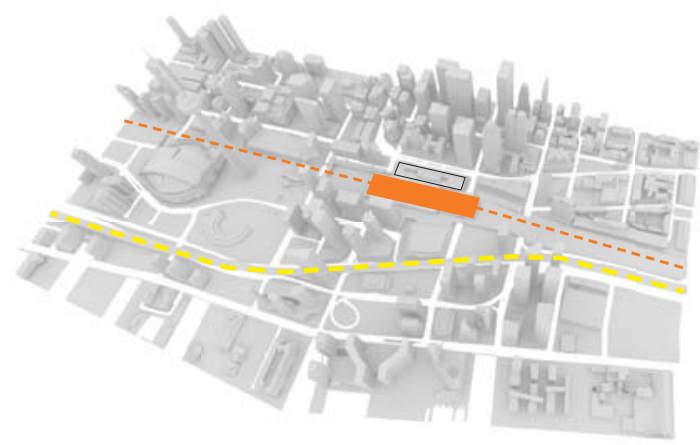

Highway Infrastructure

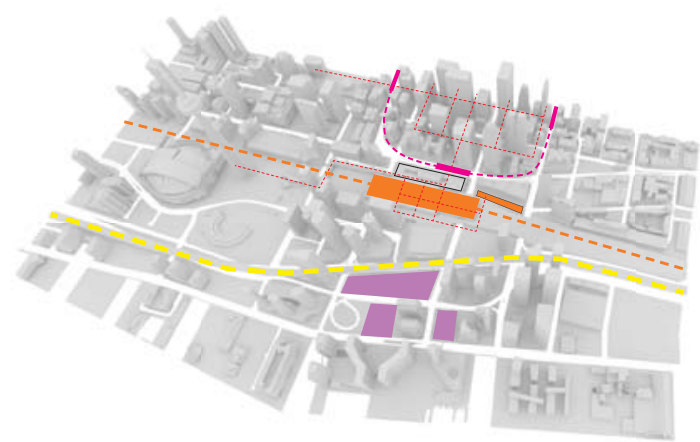

Future Development Sites

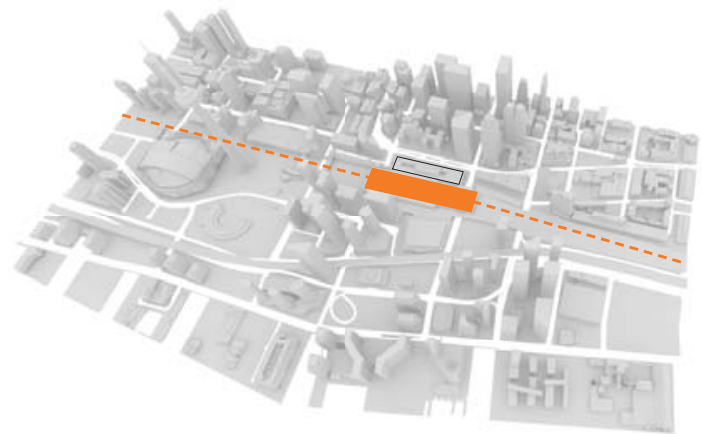

Train Station

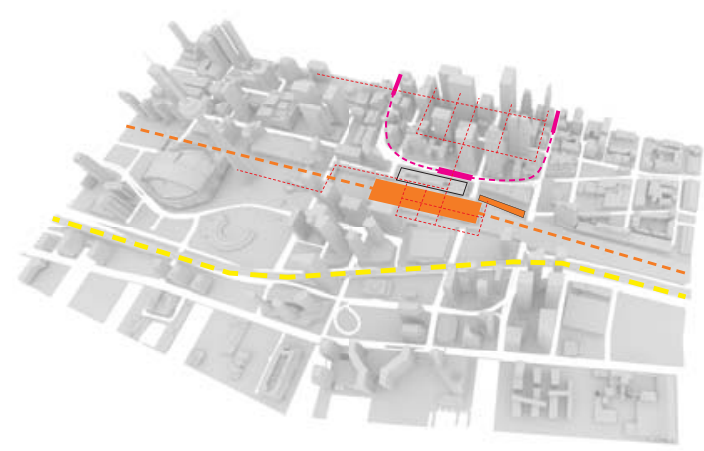

Underground Path System

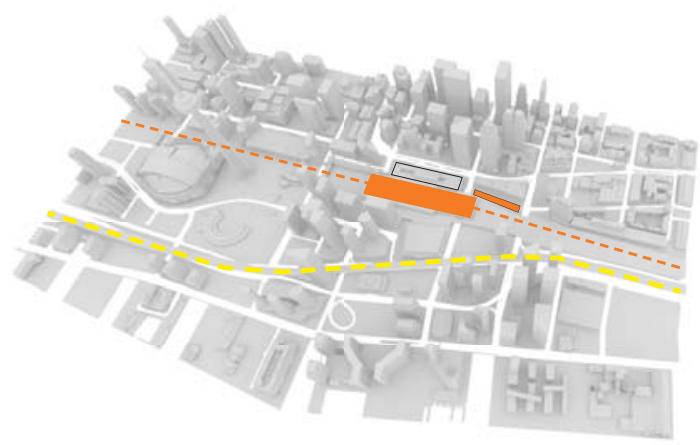

Bus Station

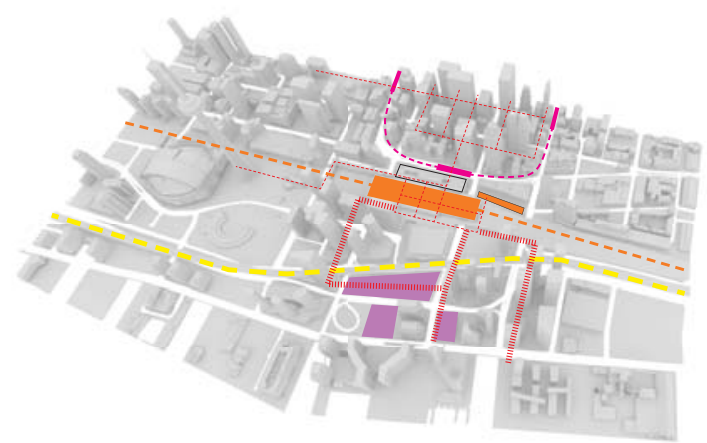

Future Underground Path Connections

Fig 47: Site Diagrams 


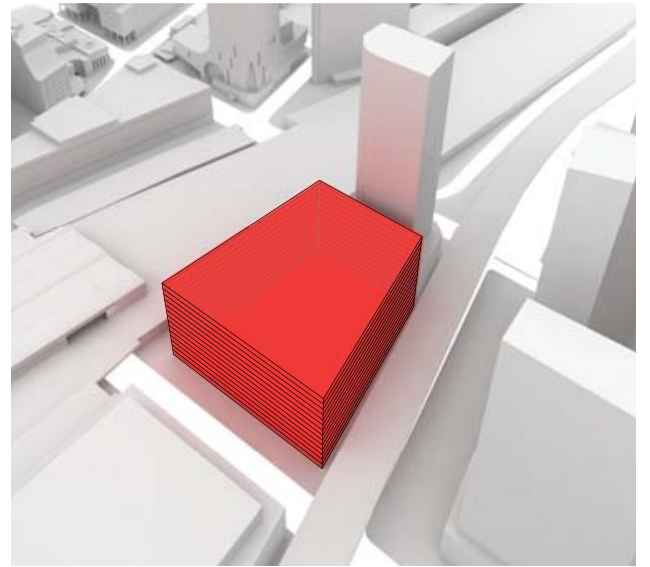

Fig 48: 100\% Site Coverage

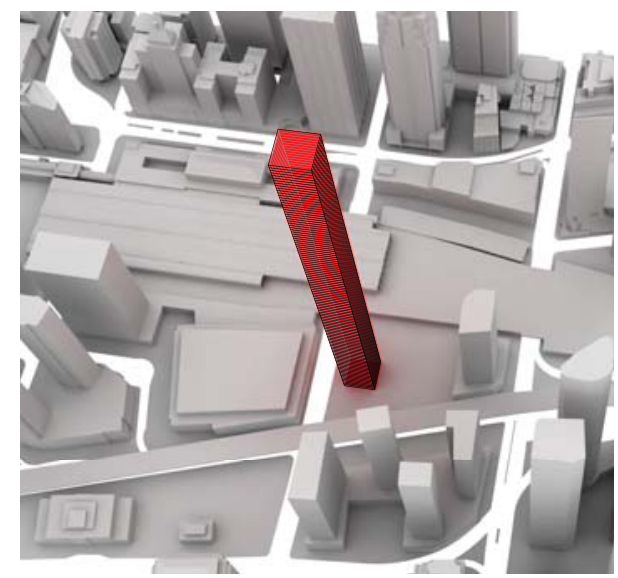

Fig 49: $27 \mathrm{~m}$ x 27m Floor Plate 123 Floors

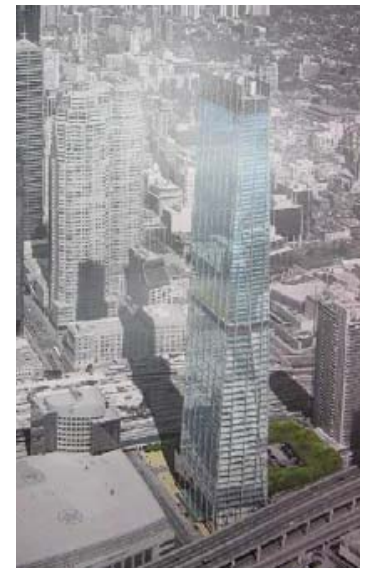

Fig 50: 45 Bay Street Proposal

\subsection{Zoning}

Zoning for the site:

The site is zoned for 1.2 million square feet of office space (111483.7 square meters). 


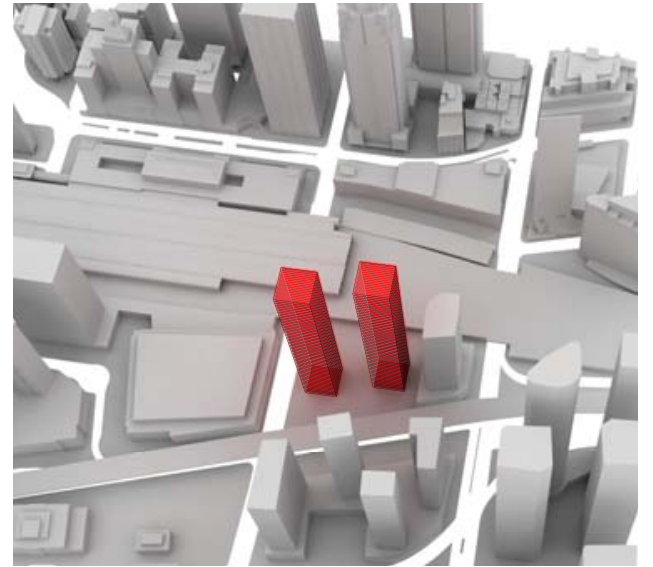

Fig 51: Two Point Towers

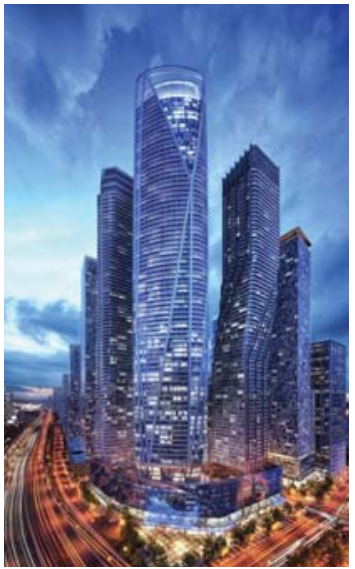

Fig 52: 6.4 Million Square Feet

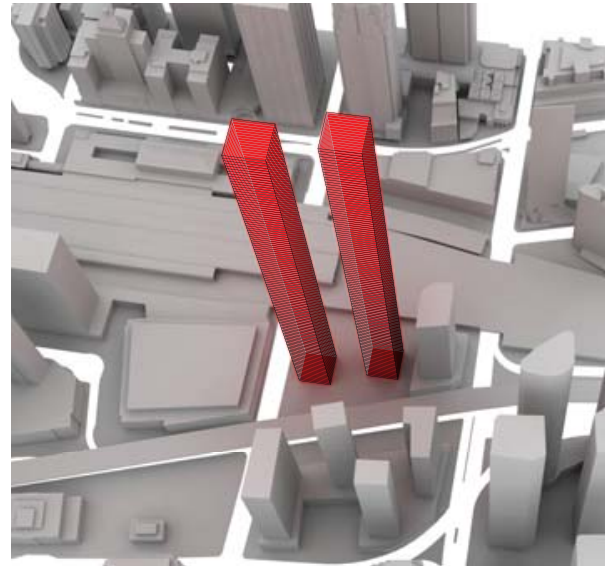

Fig 53: Double The Area to 2.4 Million Square Feet

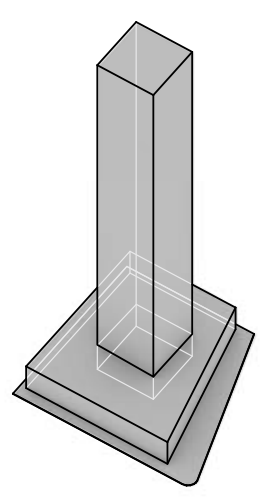

Fig 54: Current zoning tower diagram, proposed zoning diagram of double the current area for mixed use

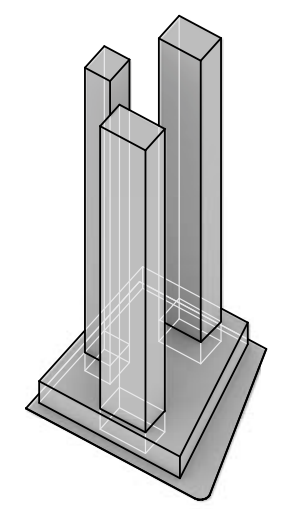

Fig 55: Proposed massing is the product of subdividing one tower into three 
If two, three or more towers will become the new norm for downtown redevelopment, can we use this condition to generate horizontal vertical and lateral connections that could act as social condensers?

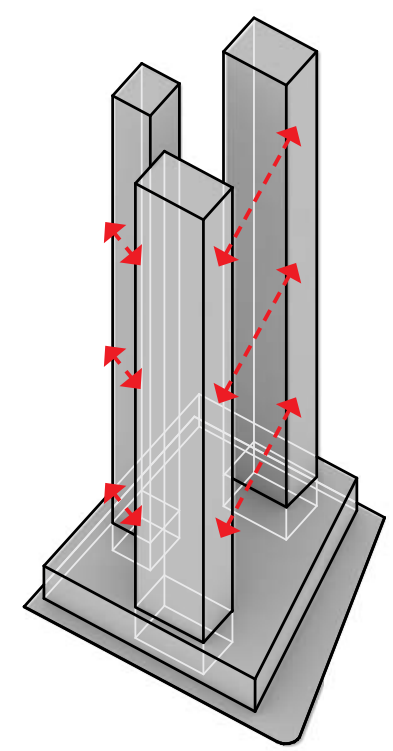

Fig 56: Bridge Connections

The form of the tower was derived by considering the zoned area of the site and positioning it with the same approach used to design towers before the implementation of the Tower Guidelines. There would be a podium occupying 100 percent of the site and rising 20 meters. The tower would be set back from the property line by approximately 10 meters. The proposed massing evolved from the City of Toronto highrise guidelines which dictated the maximum floor plate and setbacks for the towers. The resultant of this outcome is that their would 
be three towers occupying on one site as opposed to the conventional single tower with a deep floor plate (fig $54,55)$. The proposed towers share a carved out central plaza on the ground plane.

The first tower is located at the north end of the site and is focused on circulation. This saves important real estate space in the other two towers by combining the placement of elevator shafts inside the one tower and with the accommodation of scissor stairs for fire egress. Above the conference center component, the tower is occupied by residential condominium units. At this point, the elevator shaft is reduced by 5 cars leaving 3 for the units and two for the museum and park at the top. The remaining two towers, fully occupied at 750 meters square are positioned on the south-east and south-west corners to minimize shadows. This three tower framework becomes the opportunity for creating horizontal, vertical, and diagonal bridging which will provide structural rigidity and will open opportunities for the creation of a variety of interstitial spaces within the building.

The tower form was derived from the City of Toronto's new tower guidelines where a floor plate cannot 
be greater than 750 square meters. If this footprint is overlaid on existing tower examples in Toronto, along with other global examples, it does not equate to the standard floor plate for commercial offices. It is inefficient for very tall buildings because tall buildings need to have a wider floor plate to withstand structural loads. Slenderness in towers does not solve the monochromatic culture of development that is encountered in Toronto today, it just insures that there will be better environmental conditions around clusters of new condo towers.

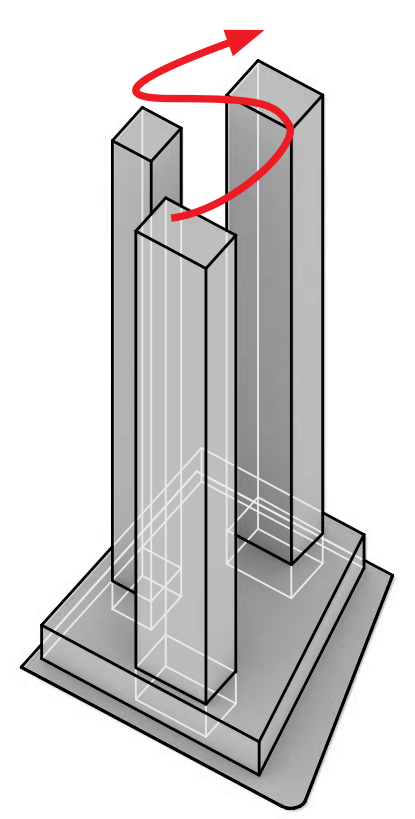

Spiral

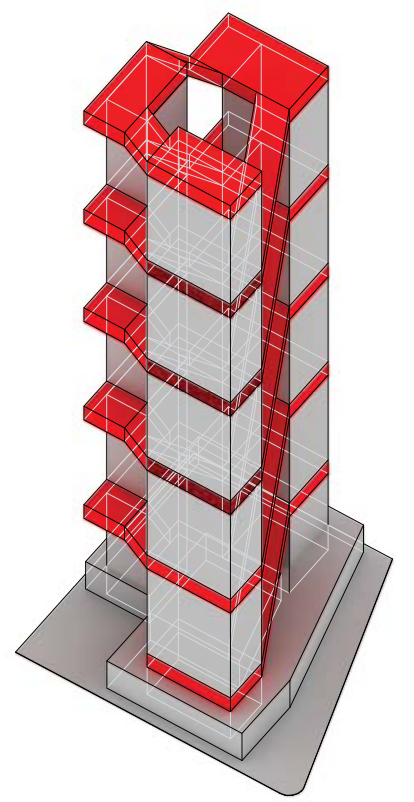

Lateral Connections

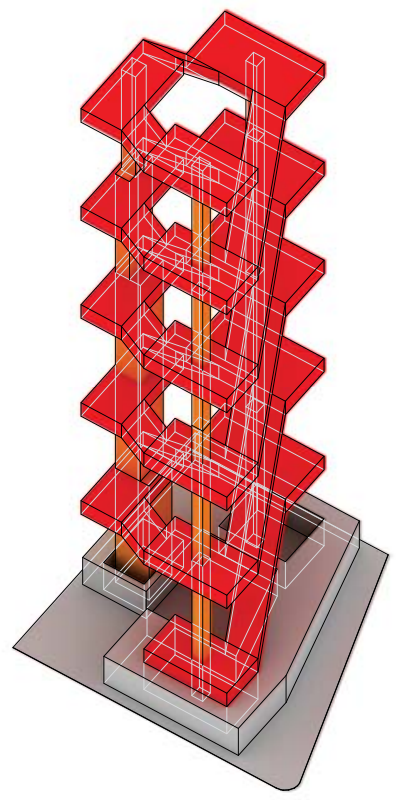

Vertical Elevator Conections

Fig 57: Concept Diagrams 
Juxtaposed Program
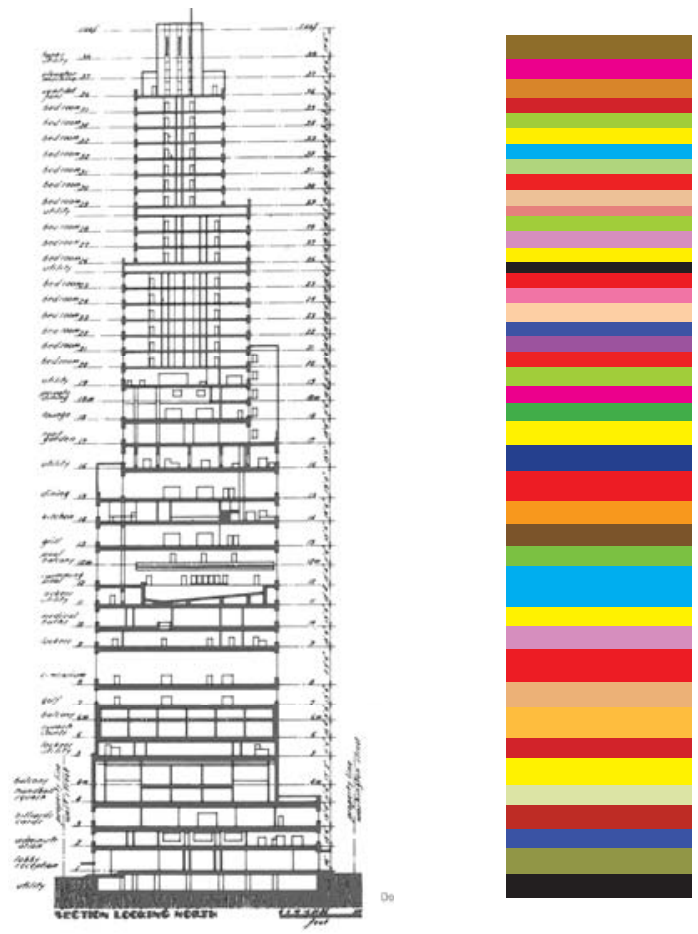

\section{Interweaving Lateral Circulation}

Forms Social Condenser

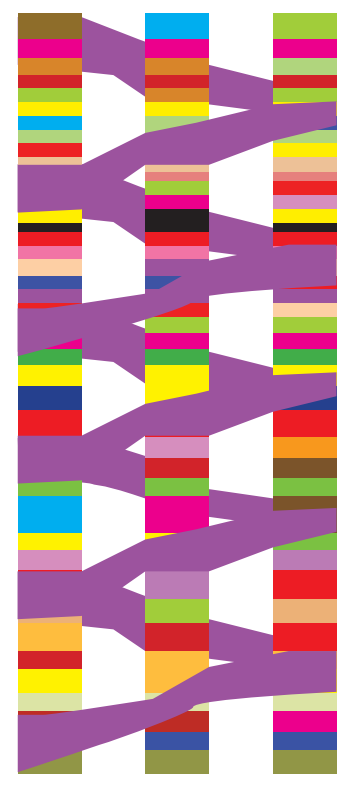

Fig 58: Program and Circulation Diagram 


\subsection{Design Process:}

The design process began with the investigation of program uses that were significant in forming and servicing whole communities. The program uses were then organized along the circulation route which gradually progresses vertically on the interior of the building. (fig 58)

The distribution and location of the program corresponds to contextual relationships. Larger occupancy programs such as the library, community center, school and multi faith center are located closer to grade for logistical reasons such as servicing. The exceptions to this were the art gallery, night club, and museum, where the formation of meaningful perspective views held design precedence. The event space and conference center are used as buffer zones in the upper portion of the building. In the main portions, the tower was broken down into three different types; private residential, public commercial office, and zones that would 'blur' the boundaries of the first two types. The private residential zones retrieve access only by the localized elevator shafts which connect to the major horizontal interstitial spaces. These programs are a mix of family housing units, single 
bachelor units, and retirement housing. The commercial office zones are a mix of differing layouts, with links to the vertical atriums of the tower. The 'blur' zone consists of Co-Housing and a Hotel where the public spaces become visually linked to the atriums. The section and plan were studied as a holistic experience, considering the relationship of the ground in the horizontal, vertical, and diagonal directions. Physical models were constructed parallel with the section and plan drawings. The physical model was crucial in testing the various potential connection points between the three different towers.
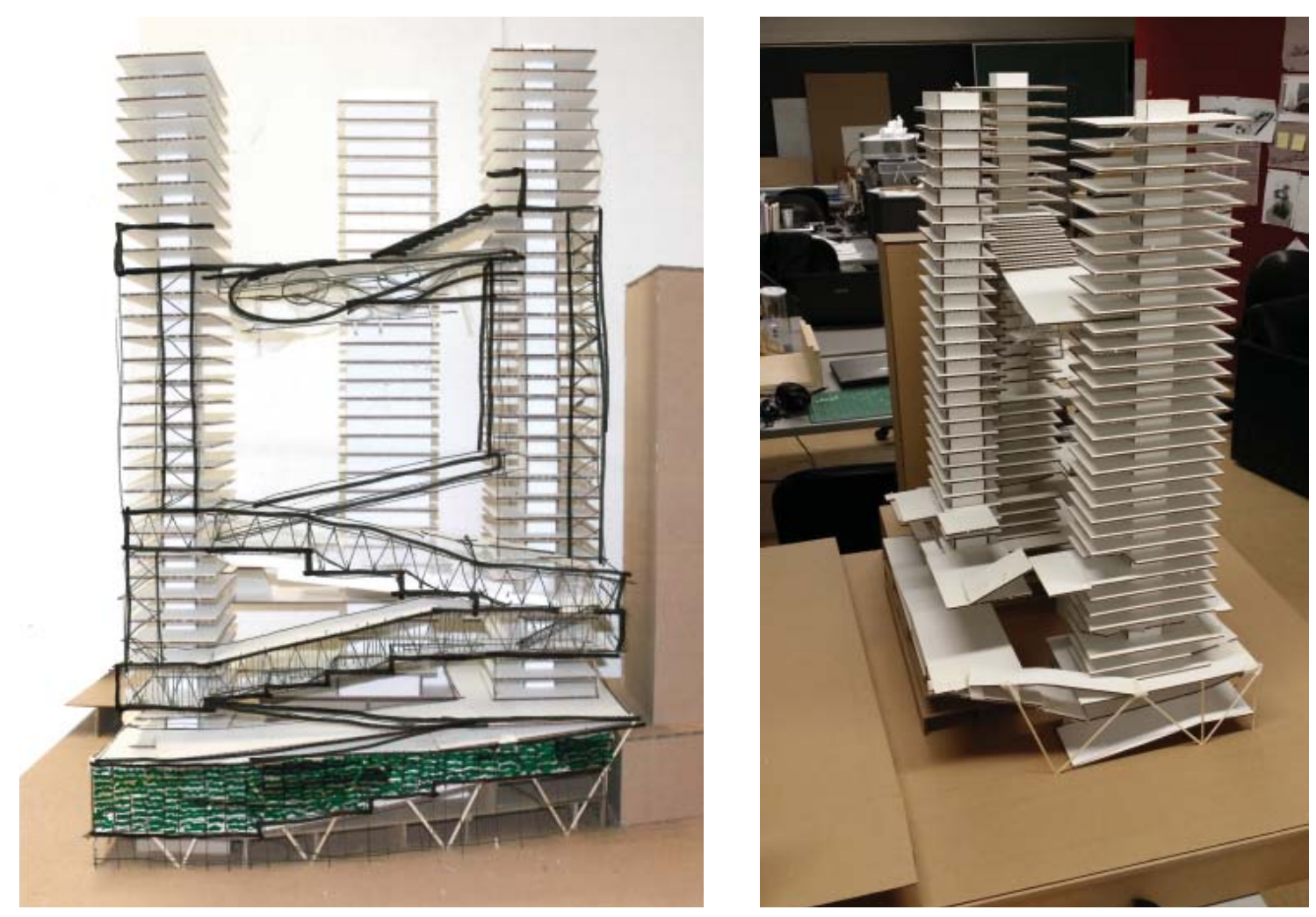

Fig 59: Process Models 

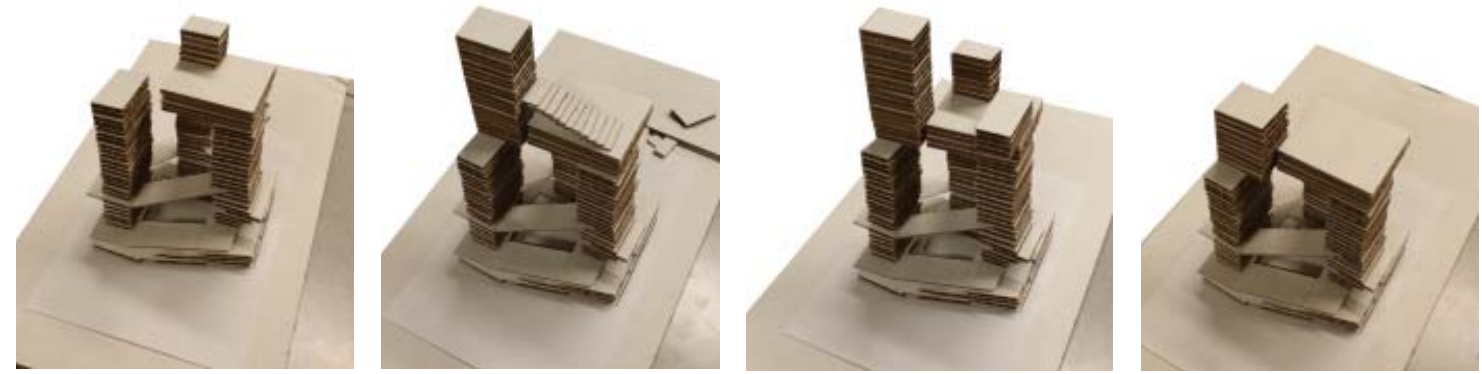

Fig 60: Process Models
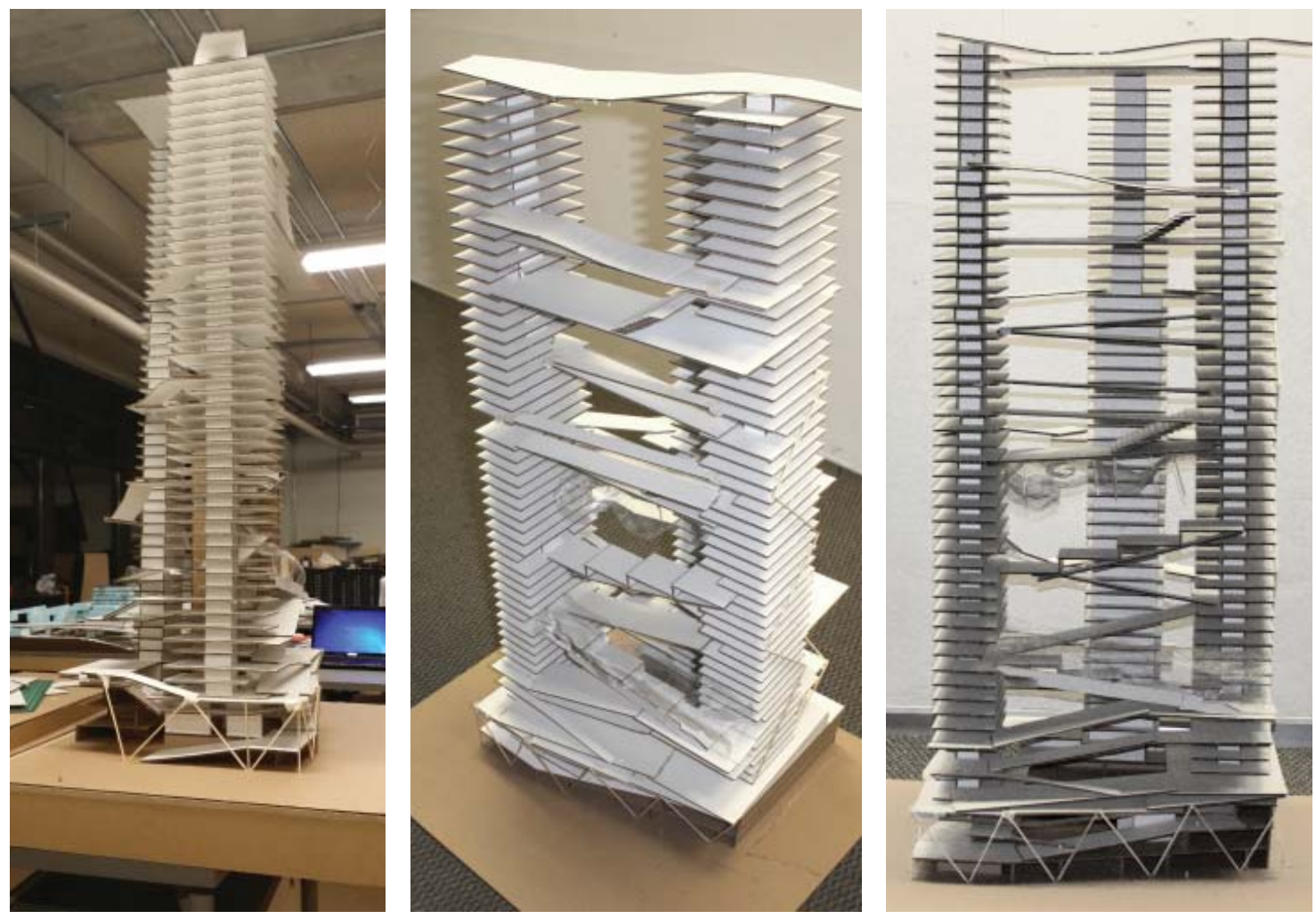

Fig 61: Process Models 

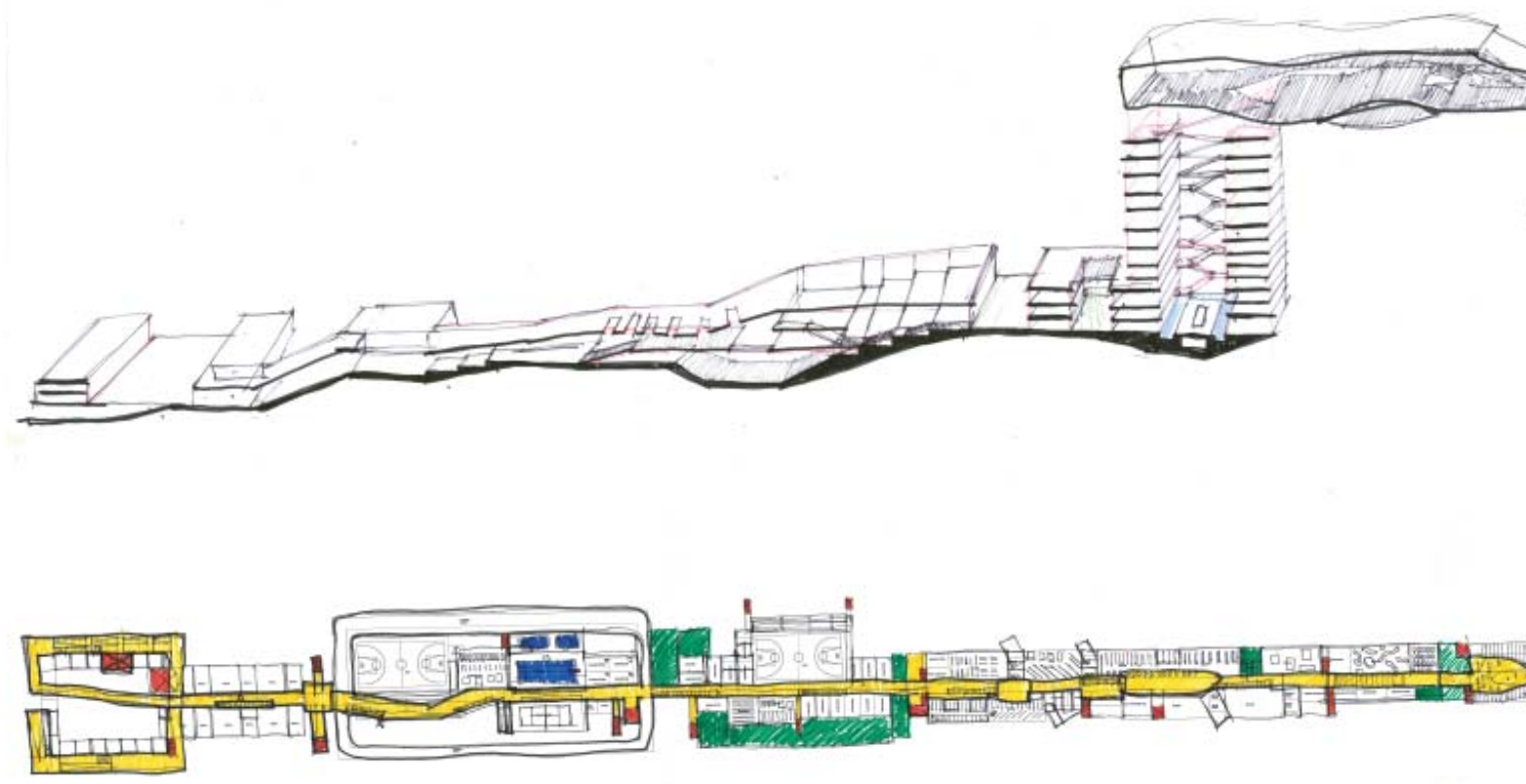

Fig 62: Experiential Section and Plan

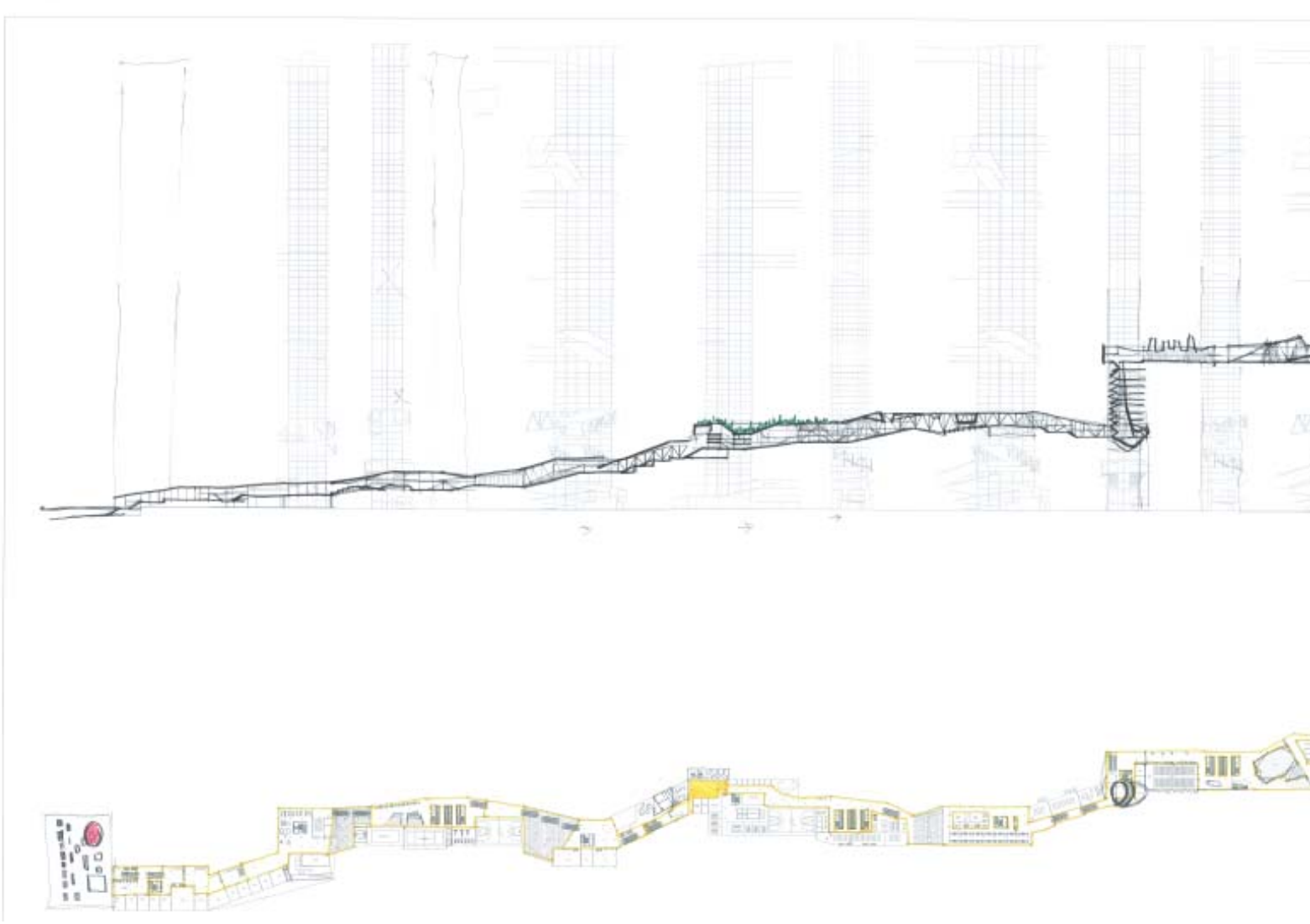

Fig 63: Experiential Section and Plan 


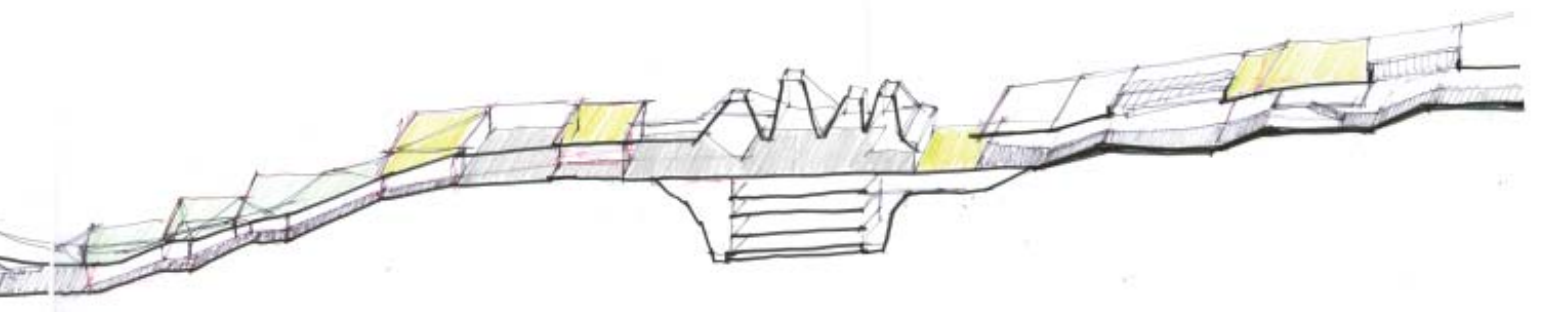

सी

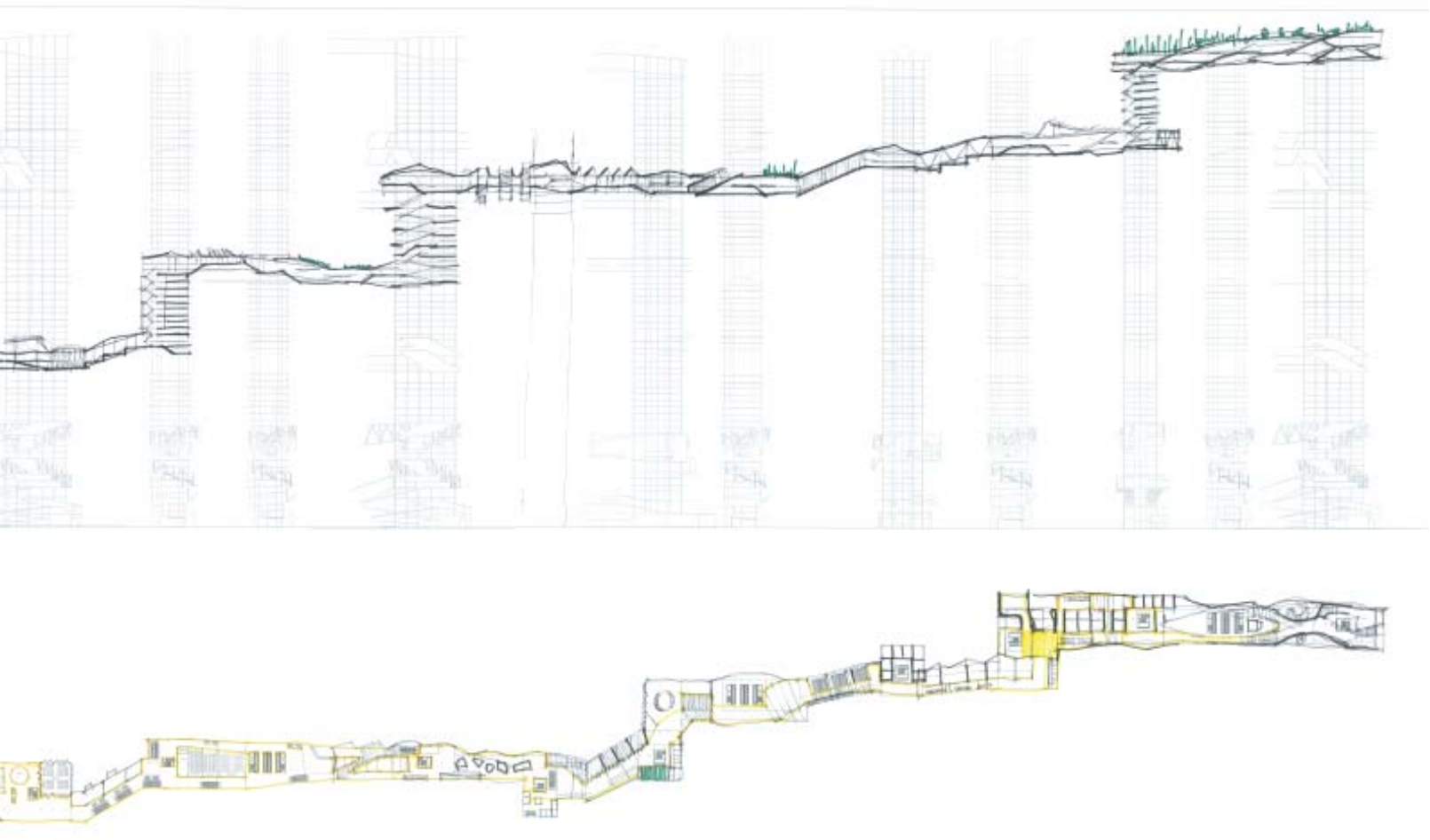




\subsection{Design strategies}

Creating a continuous urban ground plane that can be characterized as a social condenser, connecting through the building. The ground plane takes form as interstitial spaces which become interwoven with the spatial experience of the tower.

Create a building of mixed use and income that uses diversity in every way to articulate the spatial experience.

The problem with current high-rise living in Toronto is that it is homogenous in nature. This issue is amplified in downtown Toronto, resulting in the absence of crucial program for cities to function. Additional programs that were added to the design were done so to challenge the norm of what we typically see in a tower. The tension of these contrasting programs becomes the experiential aspect of the circulation. 


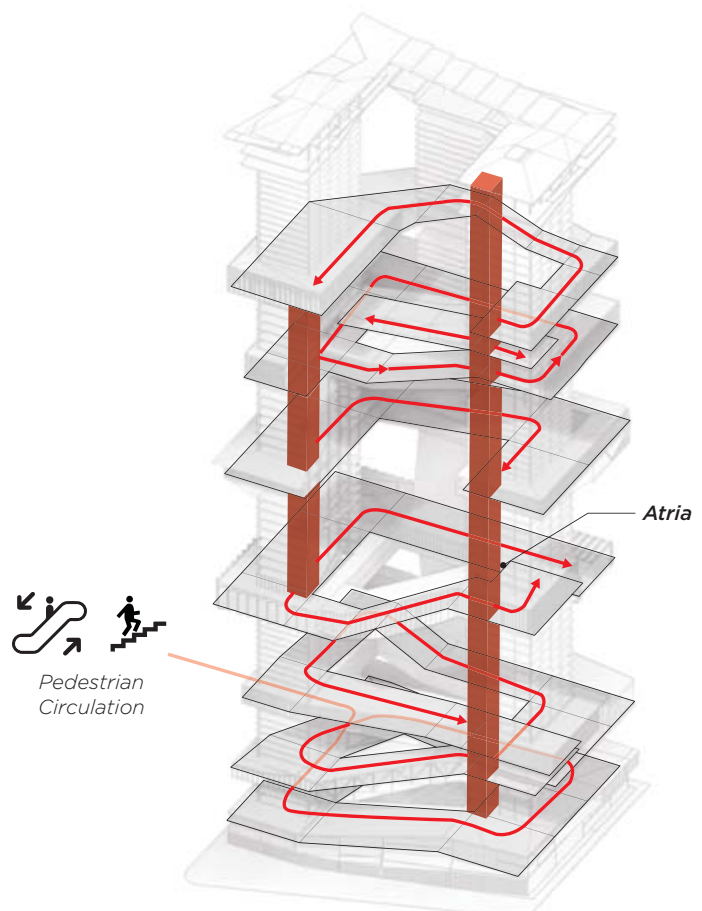

Fig 64: Pedestrian Circulation Diagram

Fig 65: Vertical Service Cores

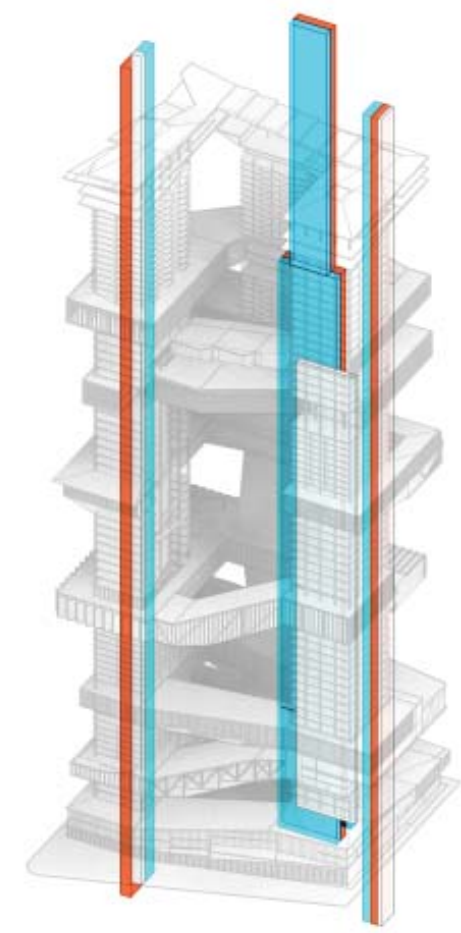




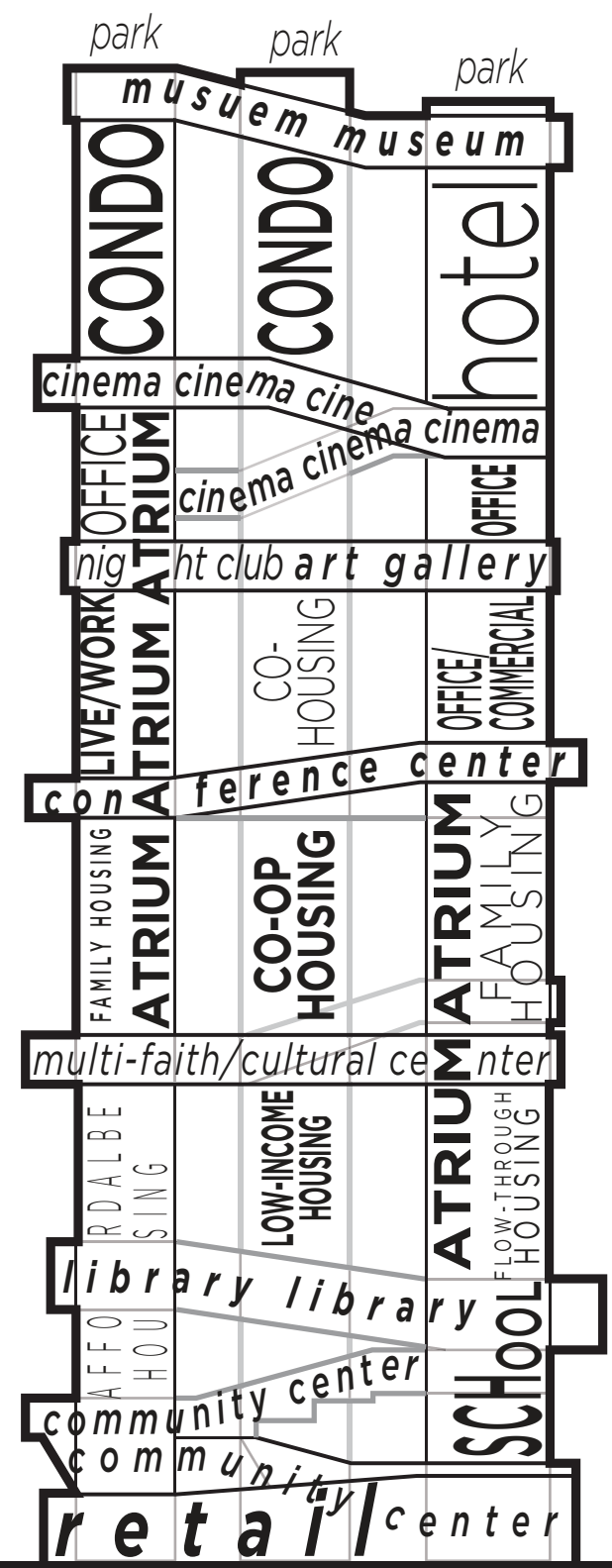

Fig 66: Program Section

Fig 67: Exterior Rendering 


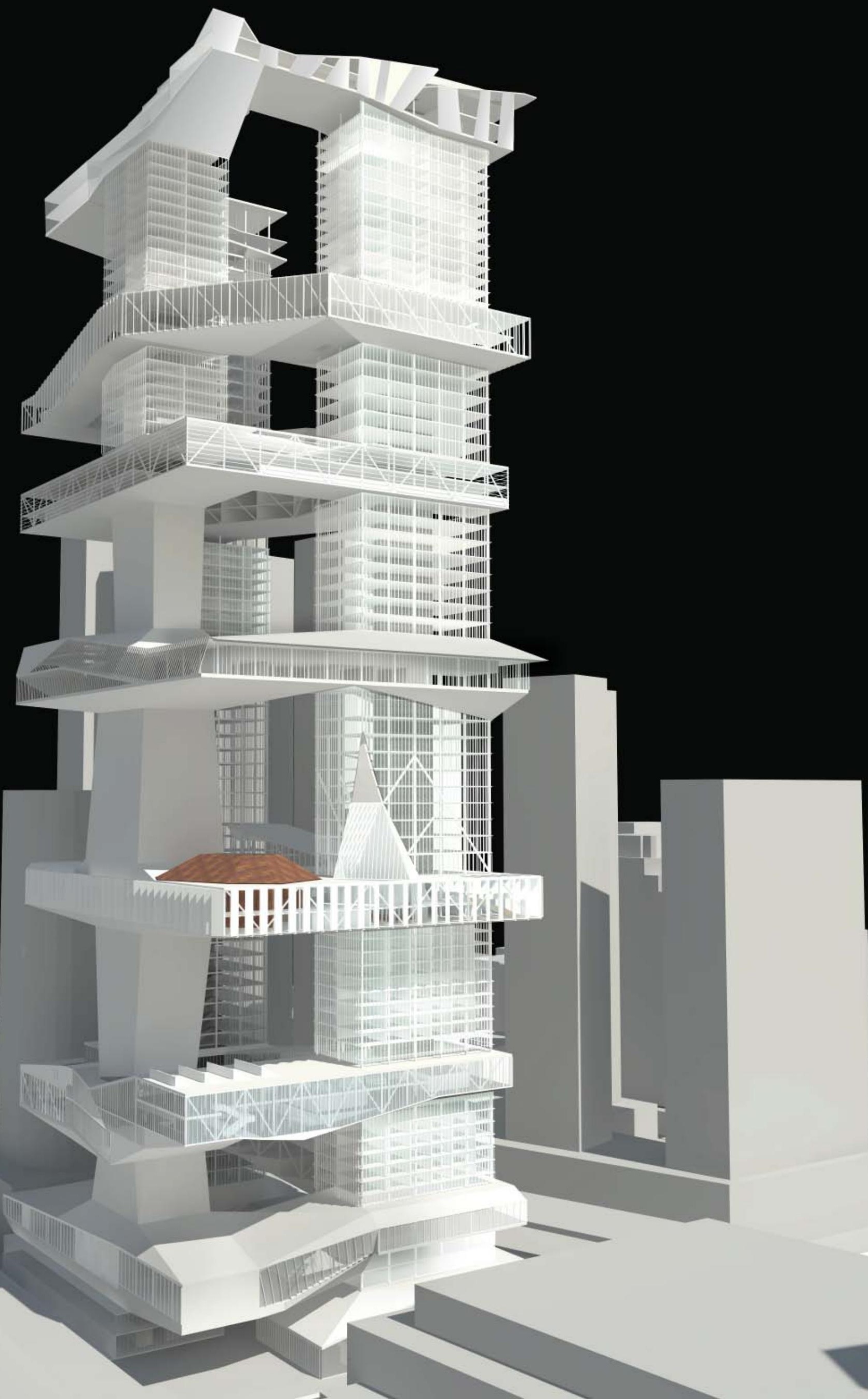



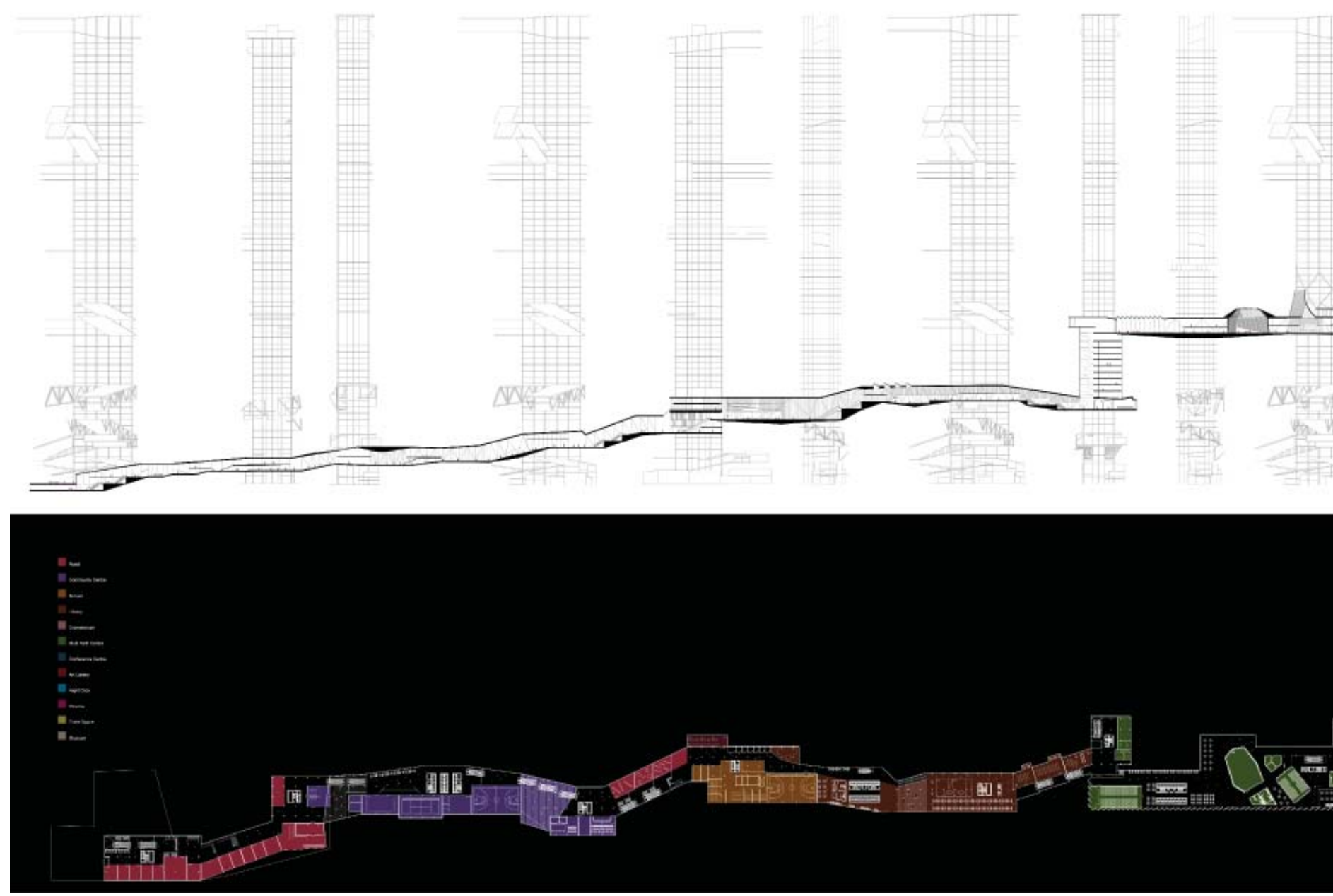

Fig 68: Final Experiential Section and Plan 


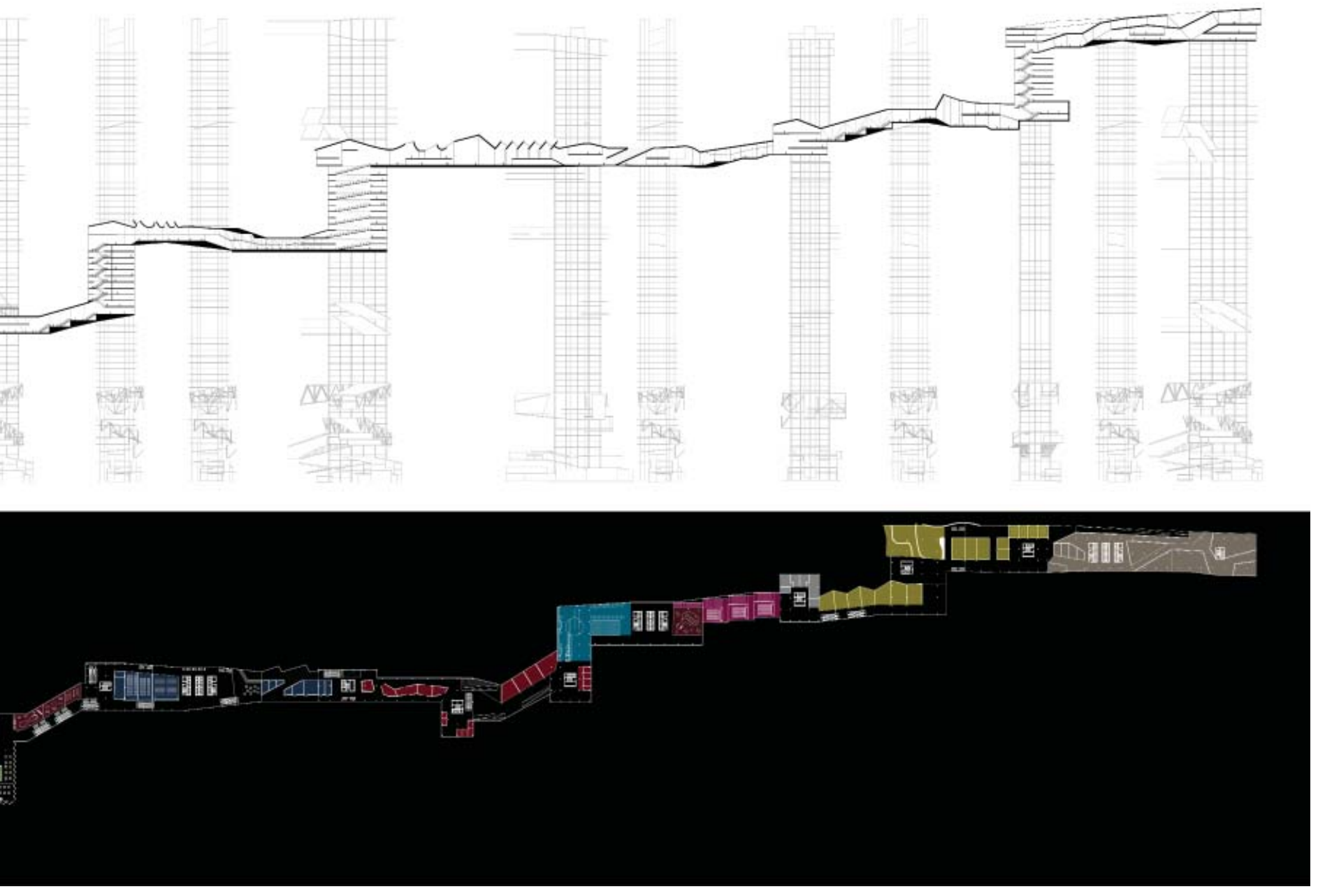




\subsection{Design Strategies:}

The vertical, horizontal and diagonal circulation is a part of a larger network which becomes expressed in the tower.

The north tower elevator shaft is expressed as a monolithic form that wraps vertically and extends outward towards the various horizontal components. Once the shaft has reached a particular point for servicing the occupants, it becomes enclosed by residential units which continues to the top of the tower. (fig 65,67 )

Culture of congestion: programmatic juxtapositions within various segments of the tower create areas of interference, forcing people to engage.

The initial parti diagram (fig 58) illustrates the vision for mixing uses, through the representation of vertical colour barcode diagram that indicates the contiguous relationships of the program. In order to break away from traditional condo types, more detailed residential and office types were explored. Residential program was divided into Co-Housing, Large family condo units, small lower-income units, townhouses, lofts, and live-work units.

Ground Floor Plaza: 
Fig 69: Underground Path and Plaza

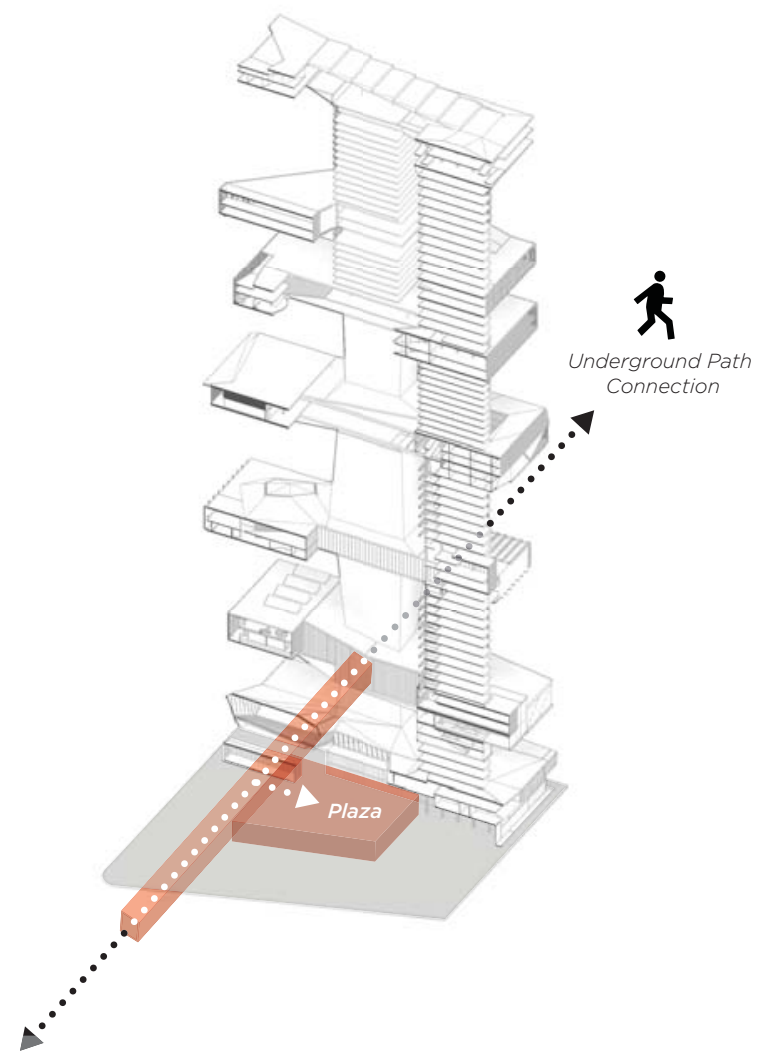

Fig 70: Retail, Lobby, and Loading Diagram

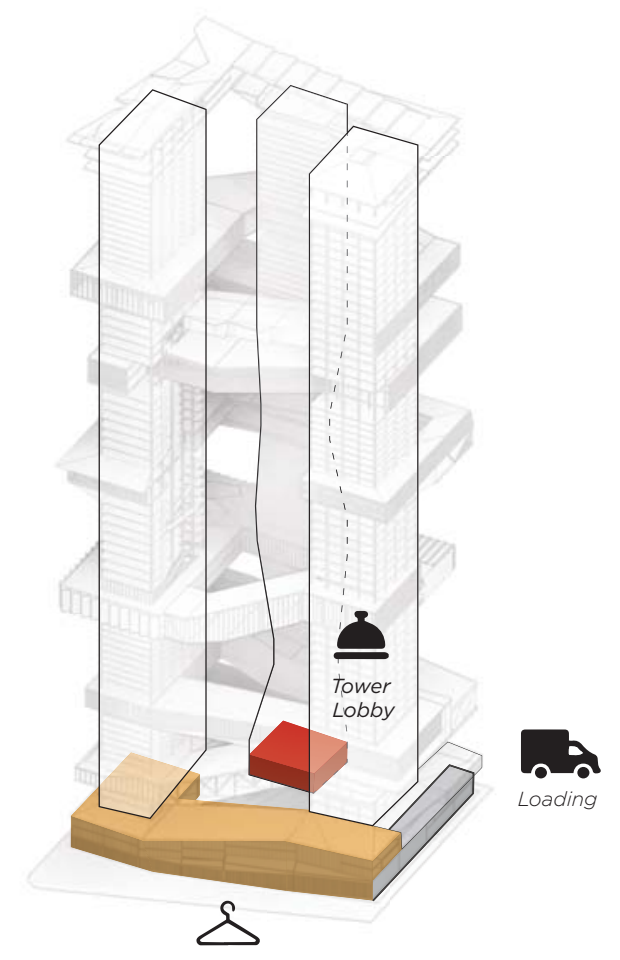


The proposed Hybrid tower strengthens its urban connectivity through the Ground Floor which has been designed to plug into the existing urban infrastructure, with a courtyard plaza linked by the underground path system (fig 74). The plaza consists a variety of retail types that surrounds it, and provides the opportunity

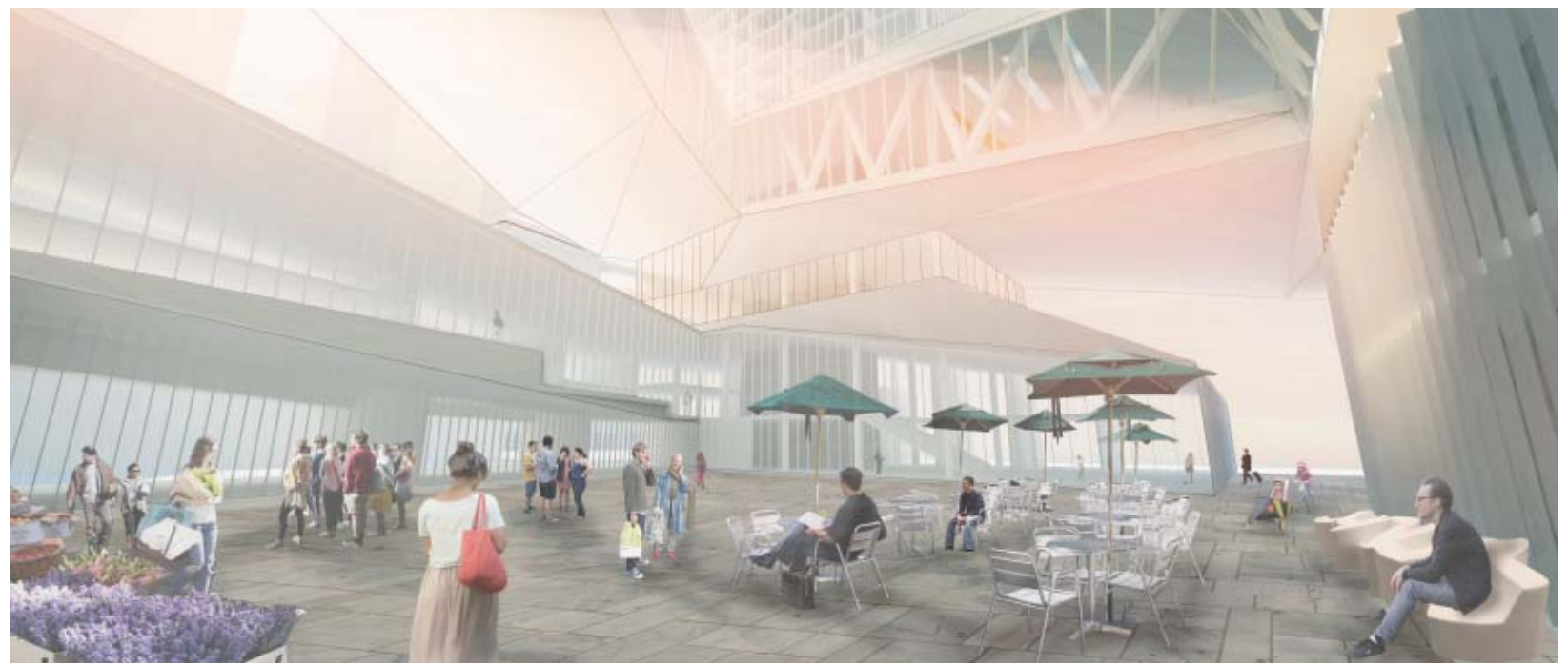

Fig 71: Plaza Rendering

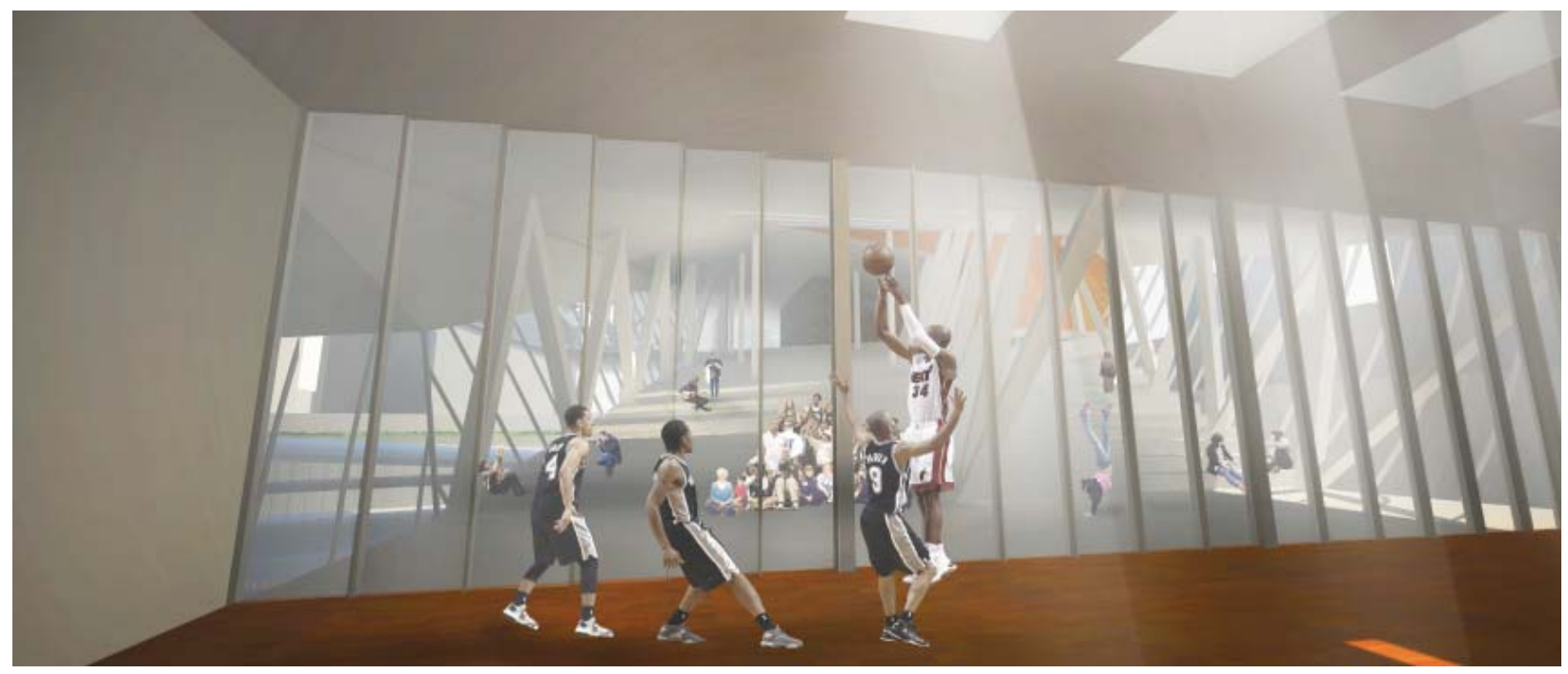

Fig 72: Community Centre 


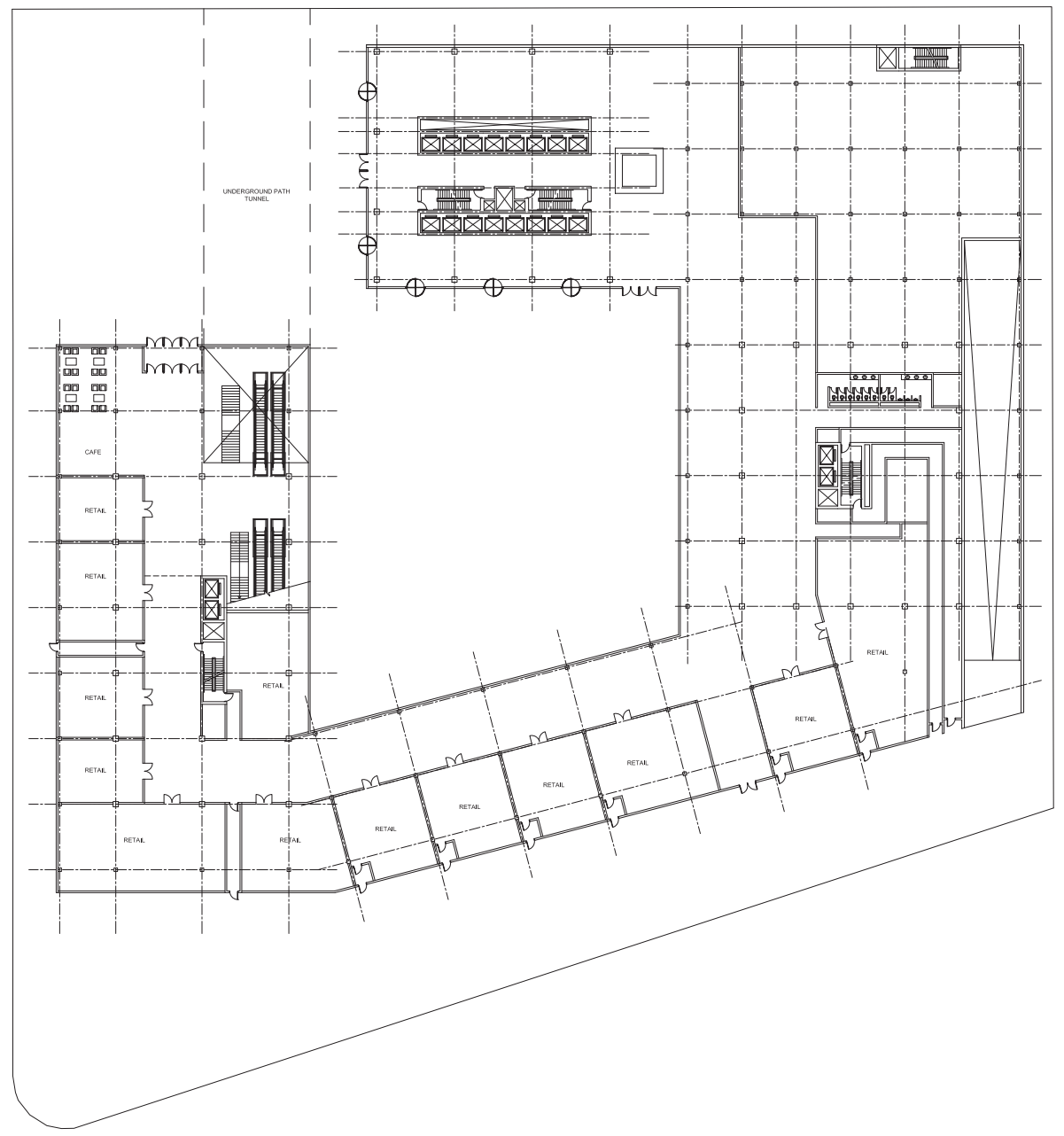

Fig 73: Ground Floor Plan

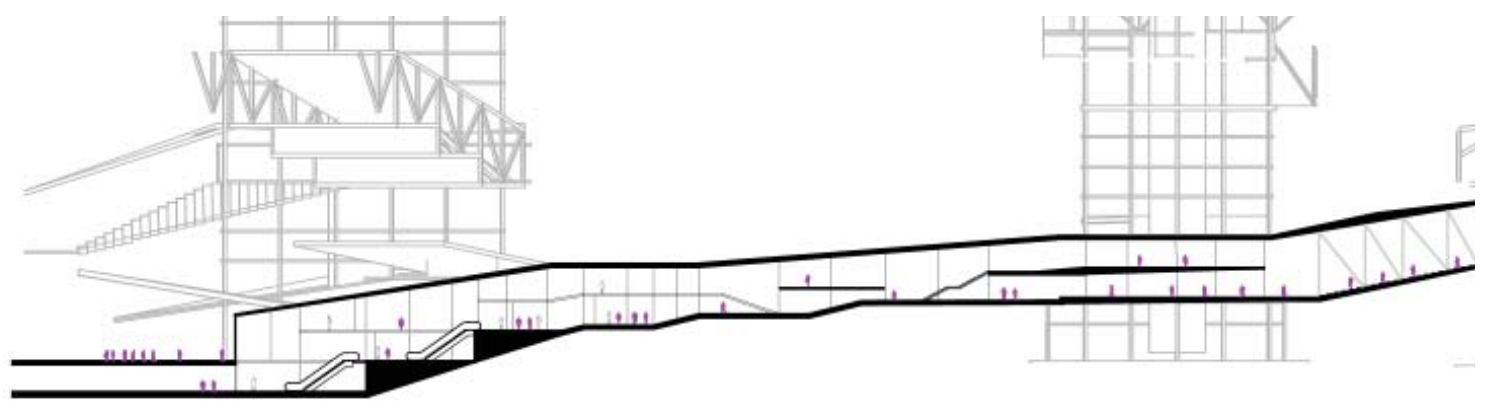

Fig 74: Ground Floor Section 
Fig 75: Community Centre Diagram

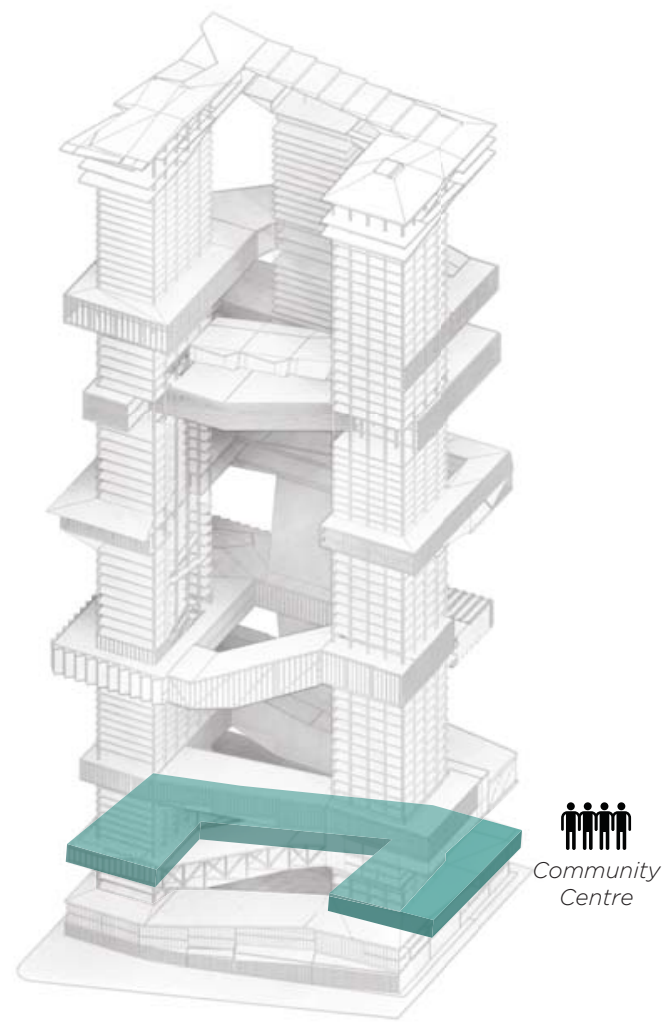

Fig 76: School Diagram

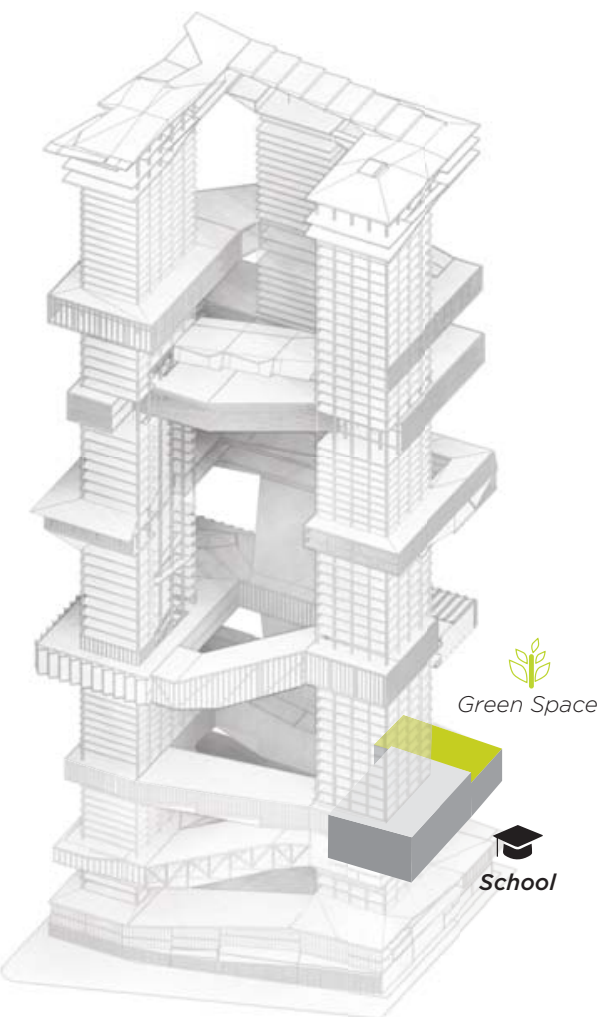




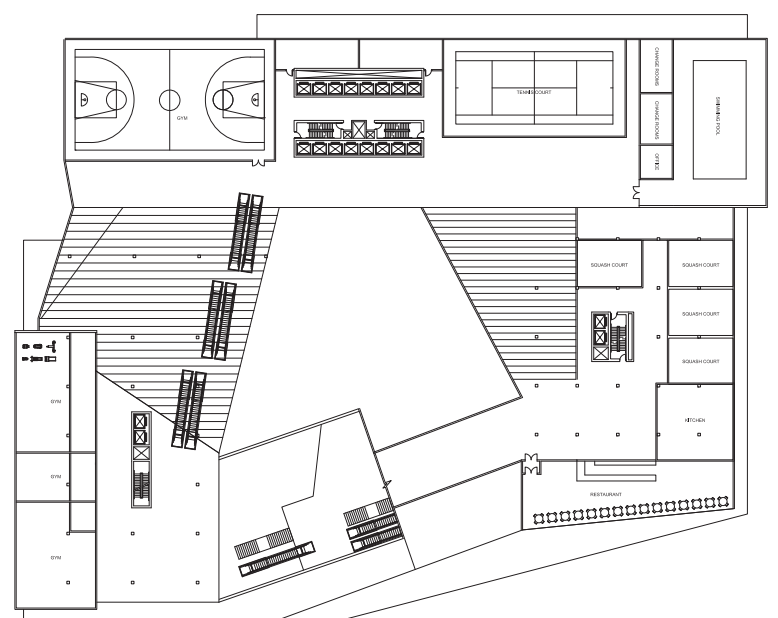

Fig 77: Community Floor Plan

for potential market vendors. The plaza can also be transformed into an event space that can be used for concerts and exhibitions (fig 71).

\section{Community Centre:}

The community centre houses various fitness rooms that include a basketball court, weight lifting equipment, spinning classes, a swimming pool, squash courts, and a tennis court. The program is organized along the

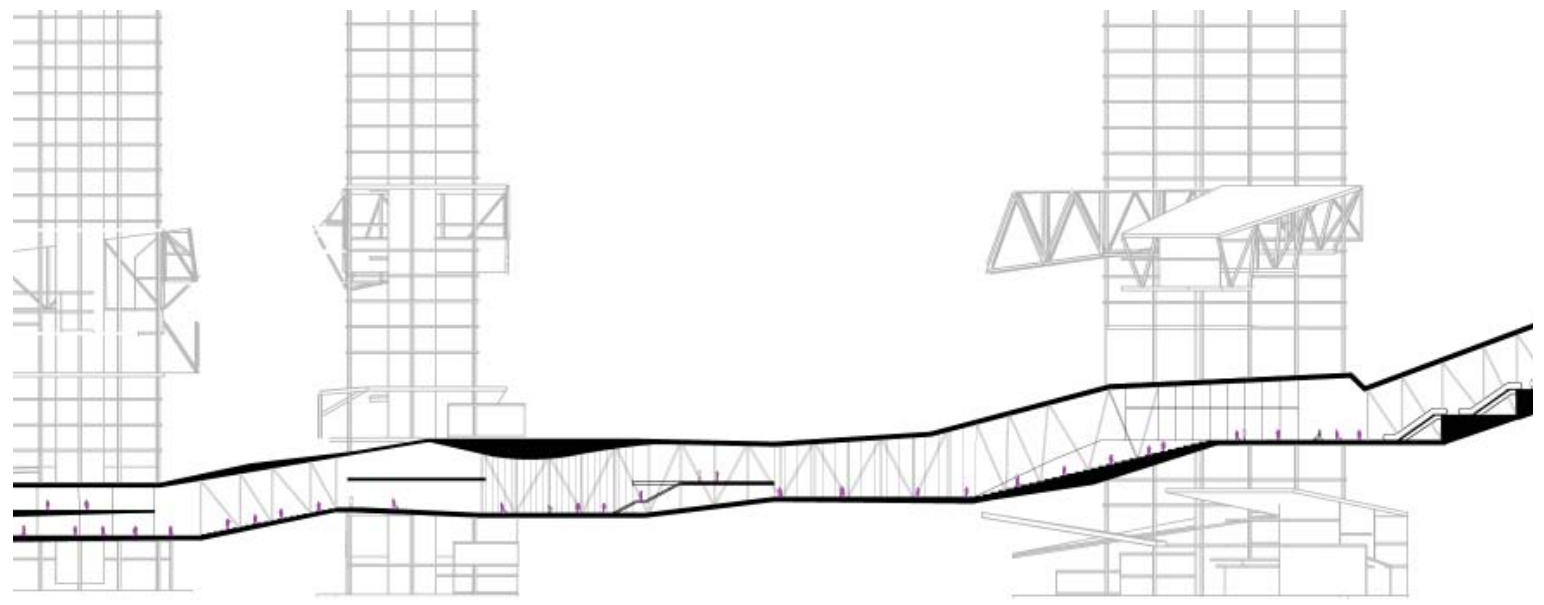

Fig 78: Community Centre Section 
circulation paths so that the public has views into these spaces when they are in use. Various seating conditions built into the circulation space allow for observers to see more than one event at a time (fig 72,77 ).

School:

The school serves primary students from kindergarten to grade 6 with a library, gym, and outdoor rooftop play space. An atrium enclosing the primary circulation for the school, which is directly adjacent to the primary circulation path of the building and has a view to the city (fig 82). The school also connects directly to the children's area of the library above. The primary school is designed to have a shared library space in the children's

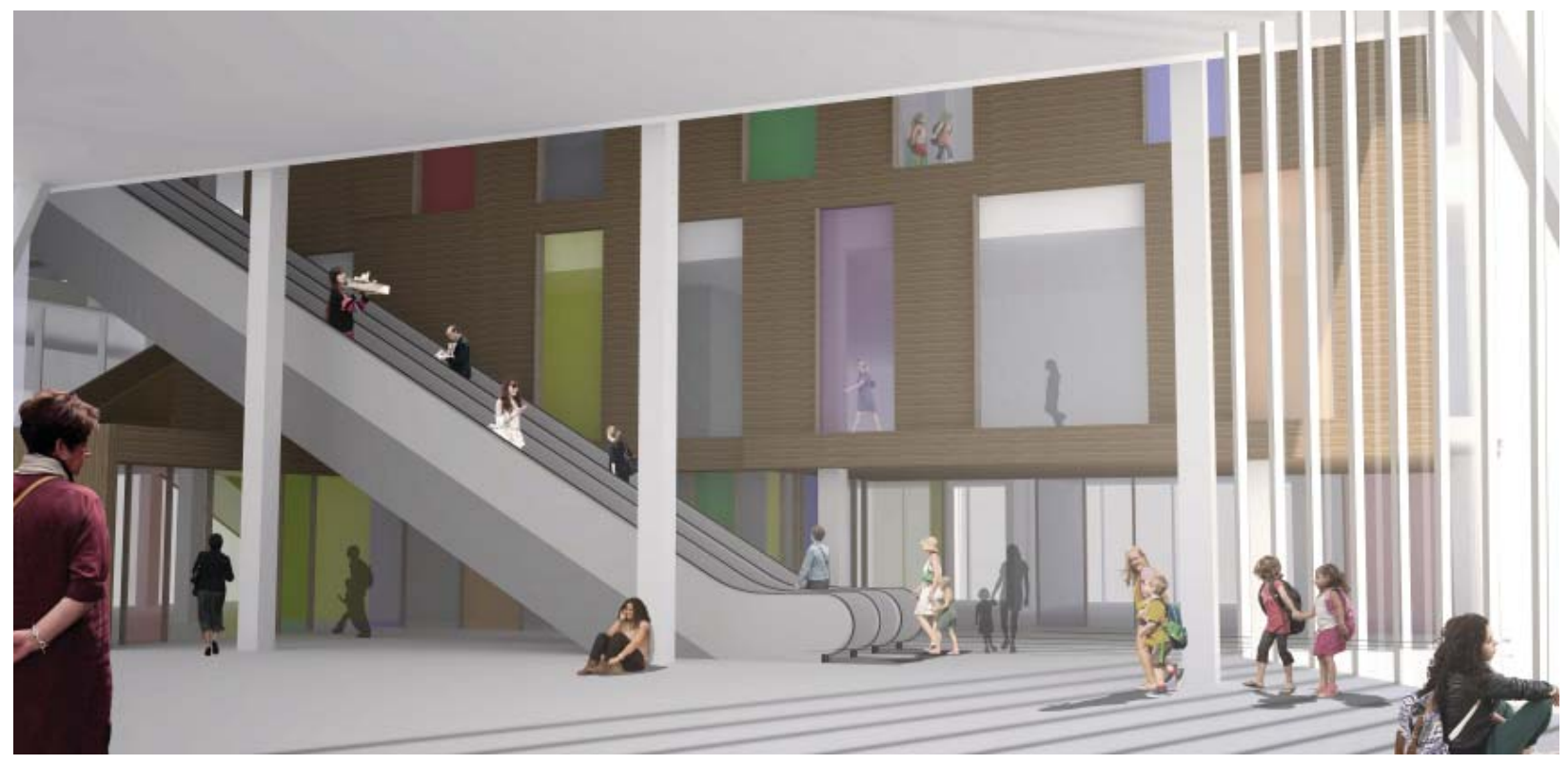

Fig 79: School Entrance 

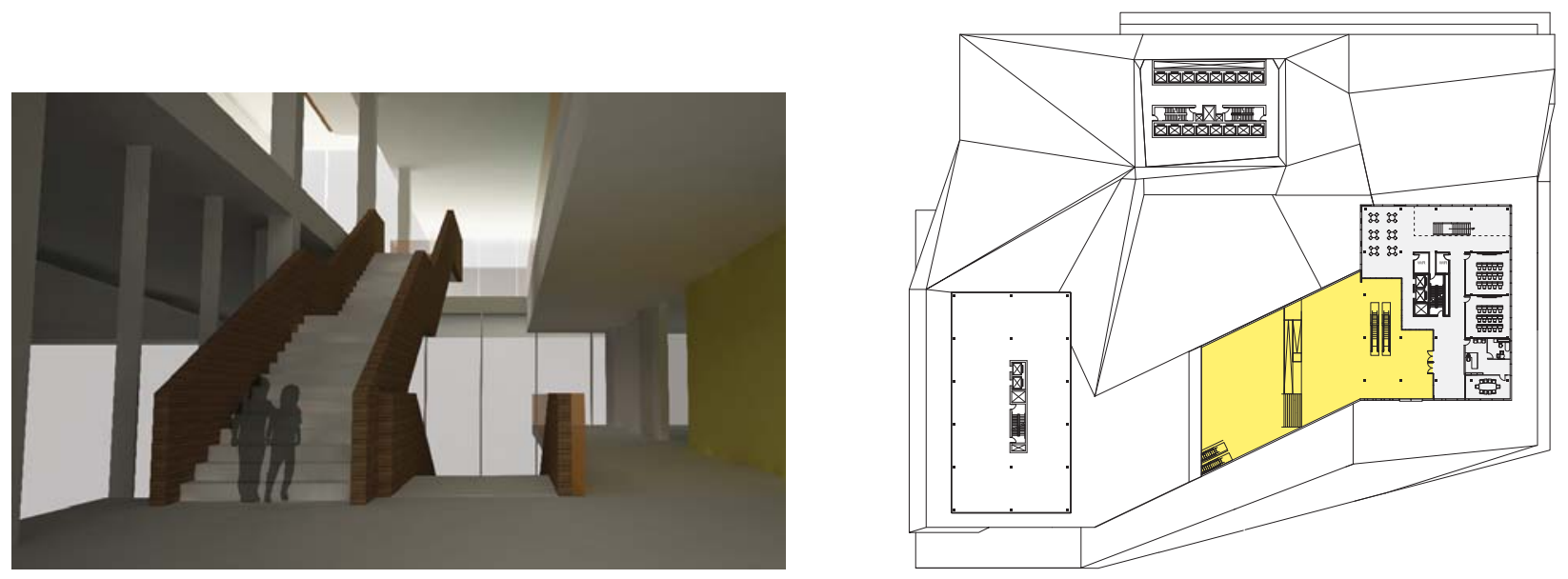

Fig 80: School Atrium
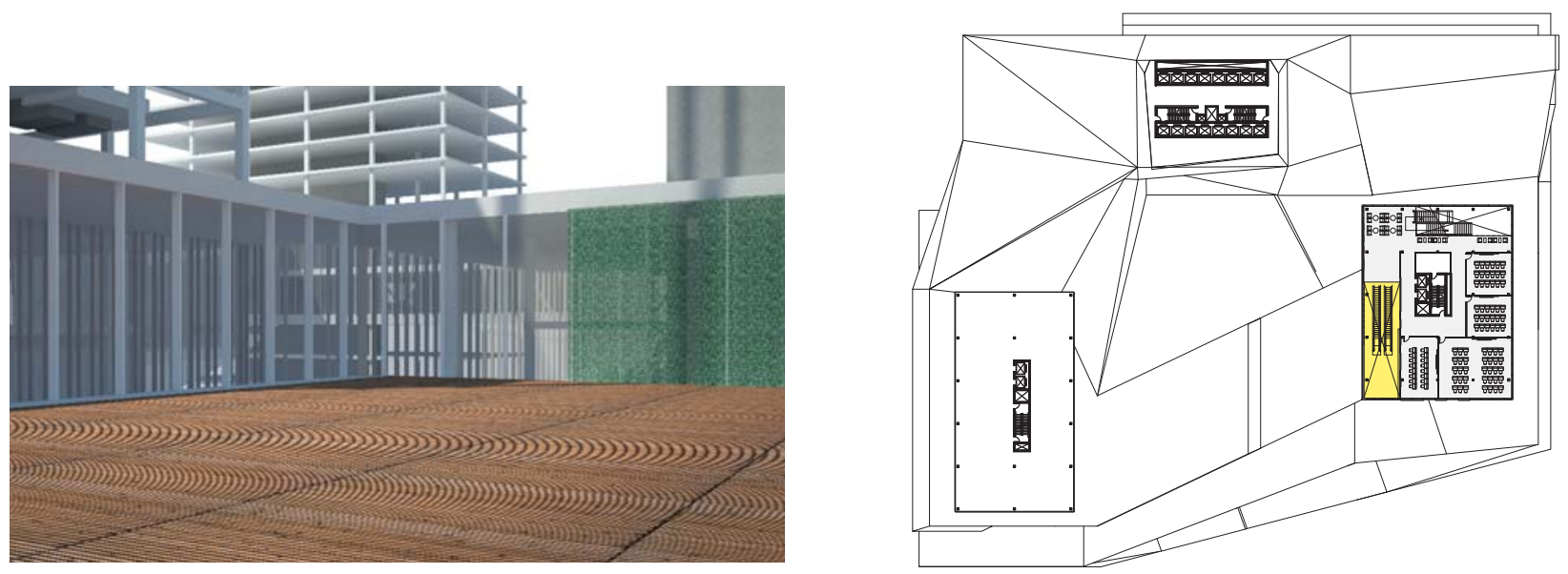

Fig 81: School Outdoor Space

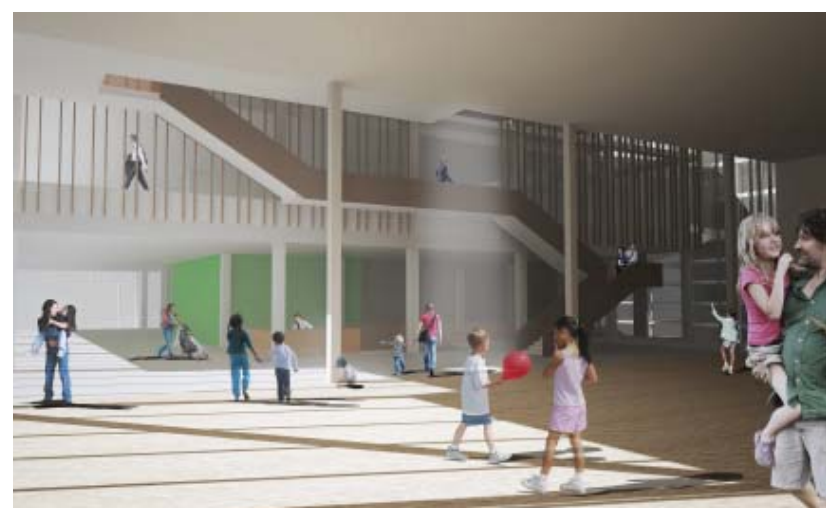

Fig 82: School Gym

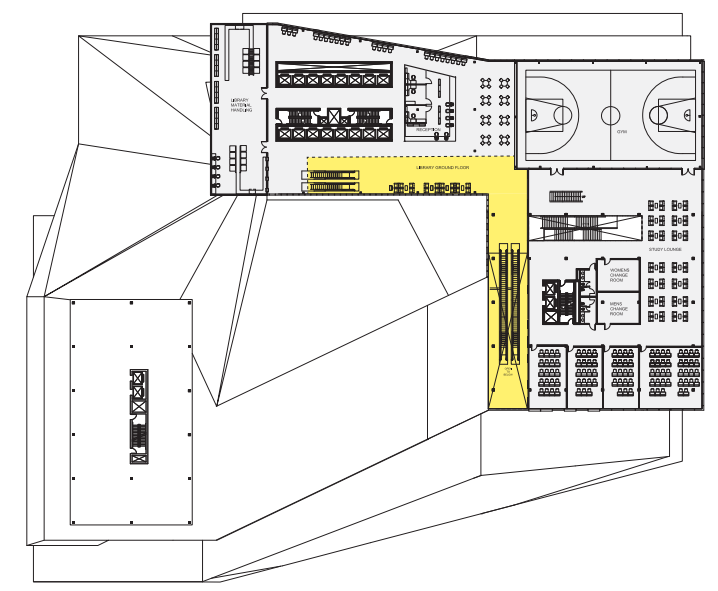

Fig 83: School Plans 
zone which would promote the interaction between kids from different schools. The school's interior facade has an institutional identity using colour and wood and offers students views inside the main circulation spine as well as to the city and waterfront (fig 79).

Library:

The library is a continuous public space loop that wraps around the building starting and ending at the school. The library functions as a series of interstitial spaces that can be used for reading, working, meeting, and studying. In each area where stacks are kept, there is an automated library check out machine which allows for the buildings circulation to be integrated into the public realm (fig 86). After hours, main working and sitting spaces are still accessible to the public loop but stacks are closed through a mechanical door that protecting its contents. The internal visual identity of the library consists of demarcated vertical wood fins which double as sun shading to protect the books from UV rays (fig 89). 

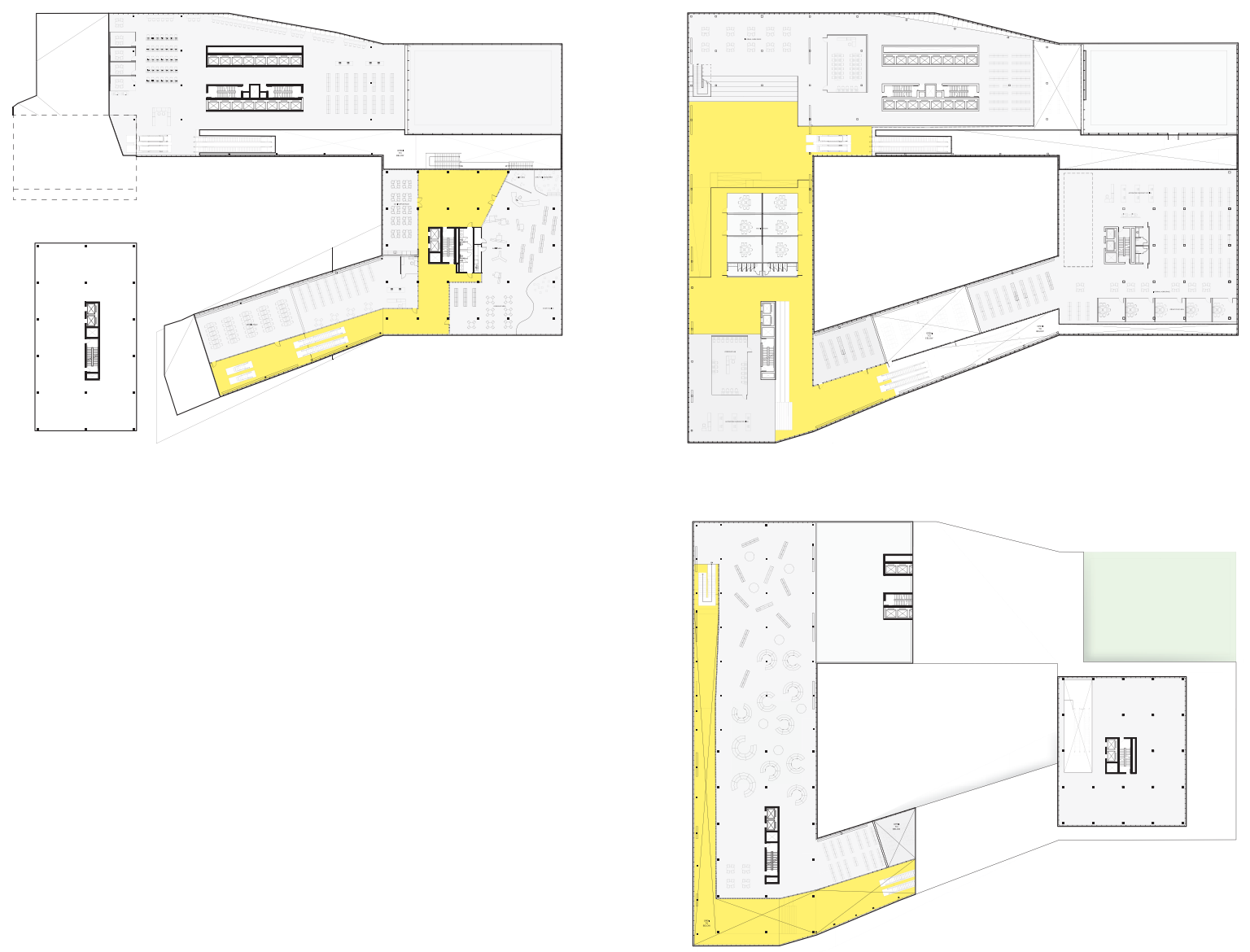

Fig 84: Library Plans

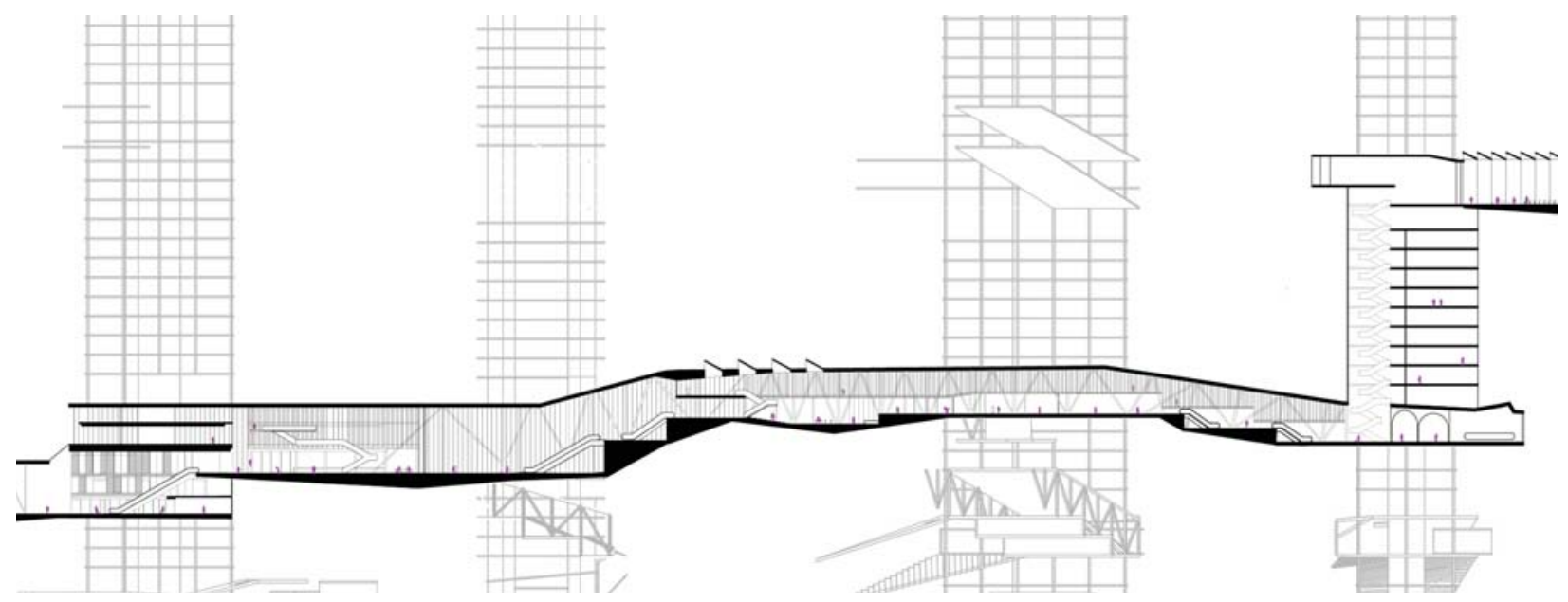

Fig 85h: School/Library Section 


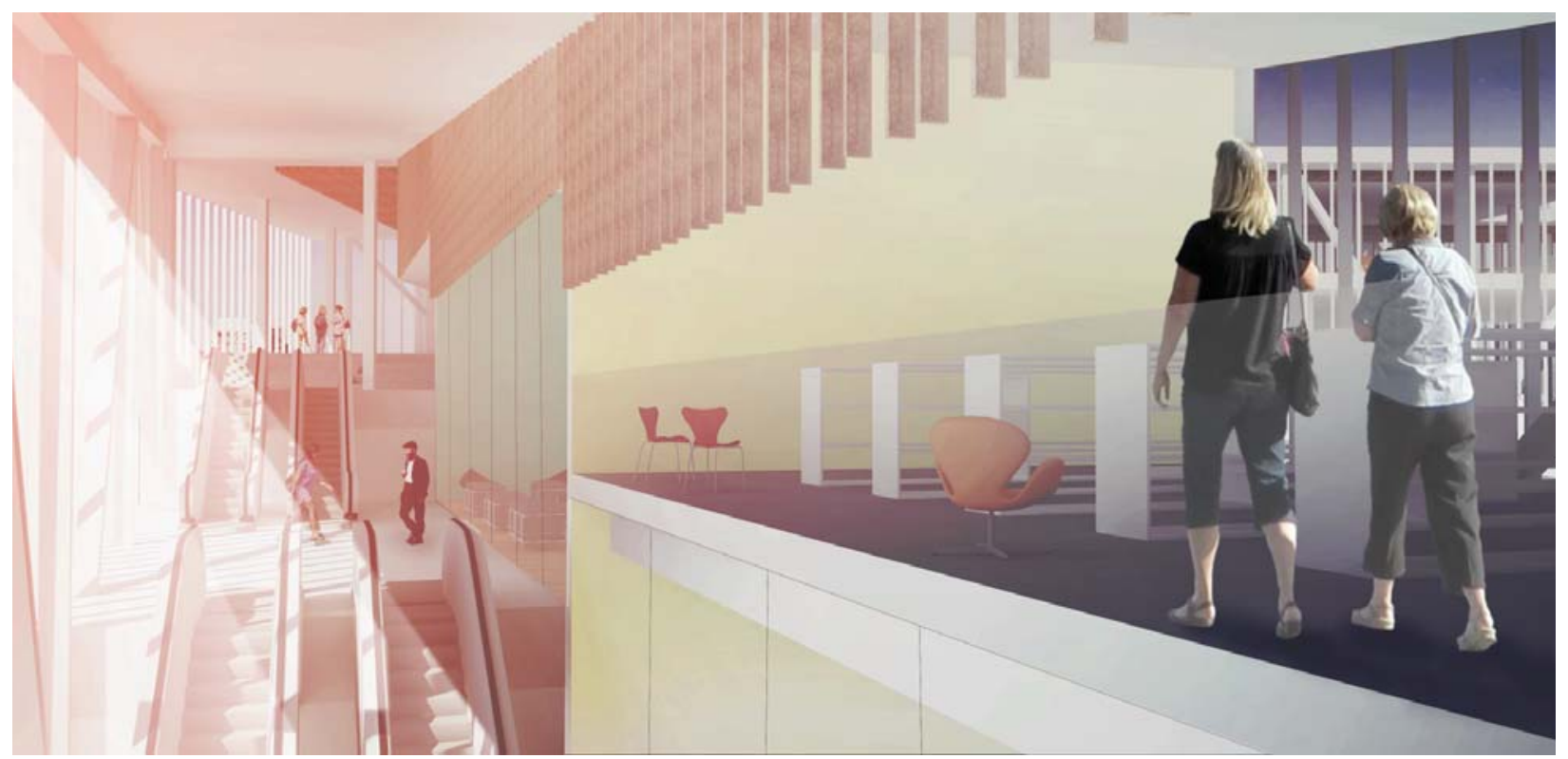

Fig 86: Library Reading and Stacks Space
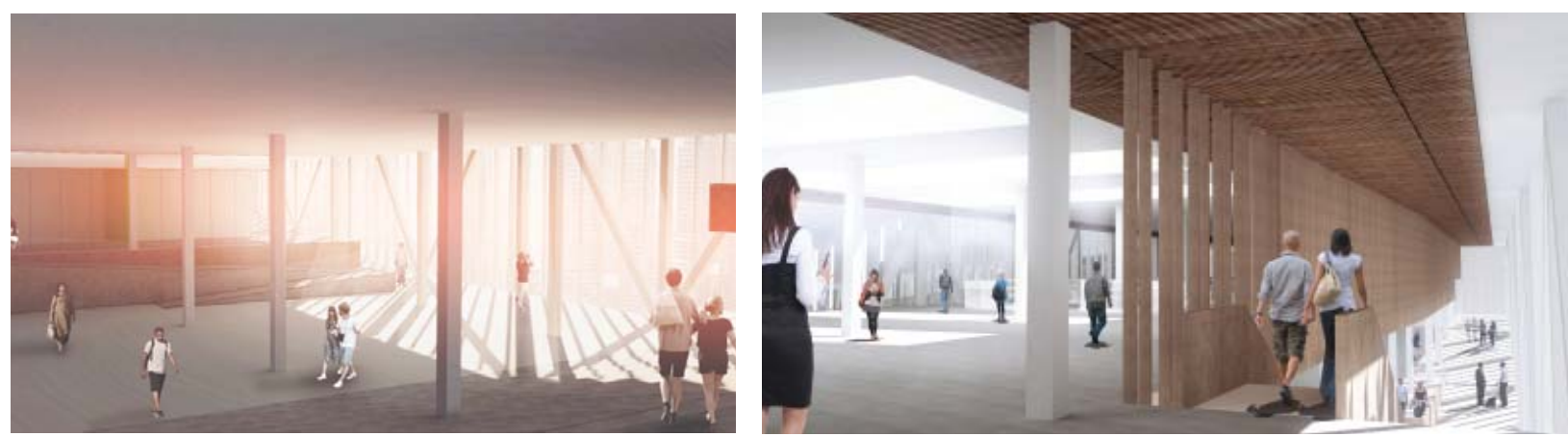

Fig 87: Library Lounge

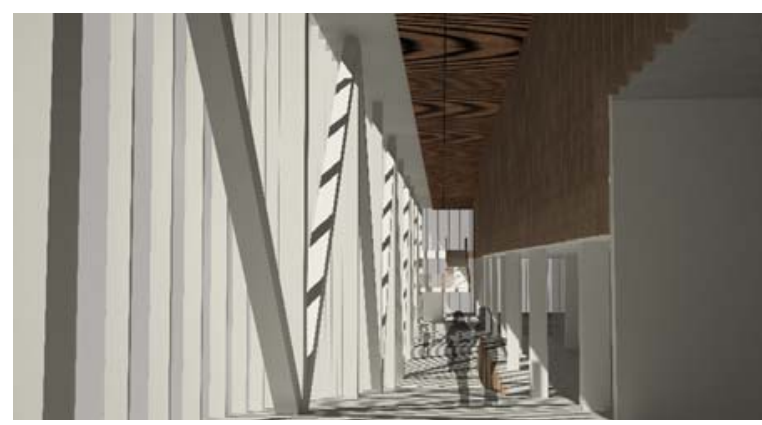

Fig 89: Library Stacks

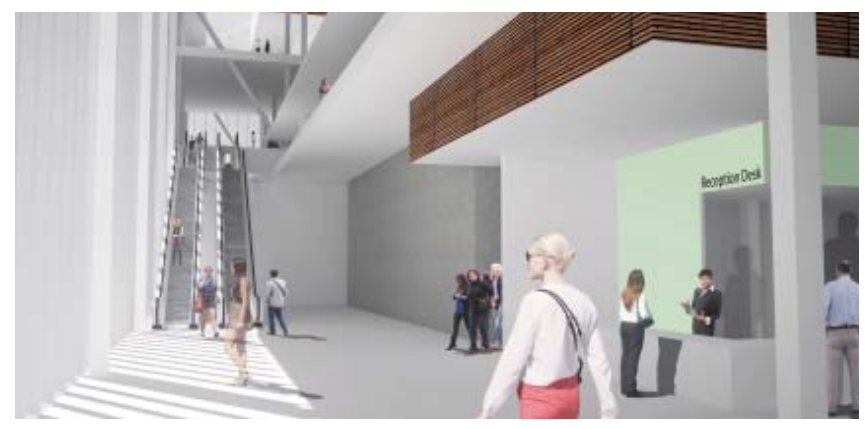

Fig 88: Library Circulation

Fig 90: Library Entrance 
Multi Faith Centre:

The multi faith center has three major prayer spaces. The synagogue, mosque, and church are designed to have their own distinct identity and internally contrast each other (fig 94-96). Each prayer space opens up to the sky capturing views and natural daylight. The spatial relationships of the three spaces are formally derived from the direction of prayer toward J erusalem for J ews, Makkah for Muslims, and East for Christians (fig 98). This directional relationship also plays out in the facade where the window bays are angled to align appropriately. In between, the facade transforms from one prayer direction to the other, acting as a gradient (fig 115). There is a multi-use space that can be used by everyone of any religion. A communal kitchen and event space, creates interaction between people of different faiths. Between the different faith zones there are areas for people to gather and engage in discussions. (fig 97).

Conference Centre:

The conference center has been positioned in the middle of the tower to create views for business events. The interior circulation network connects through this space to allow for visual engagement with the activities 
Fig 91: Library Diagram

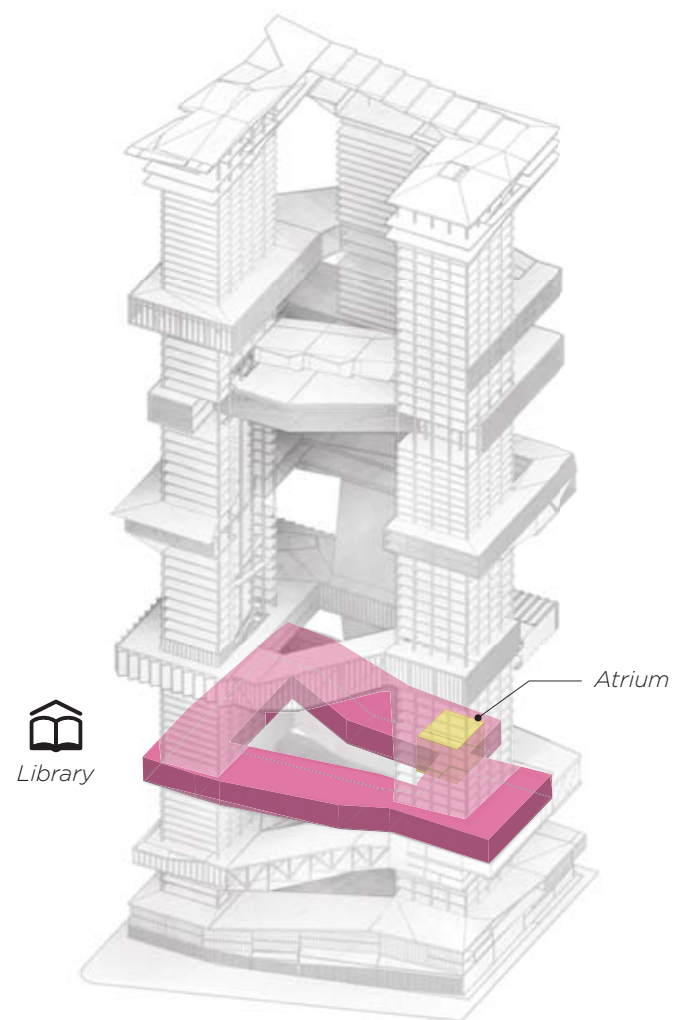

Fig 92: Multi-Faith Diagram

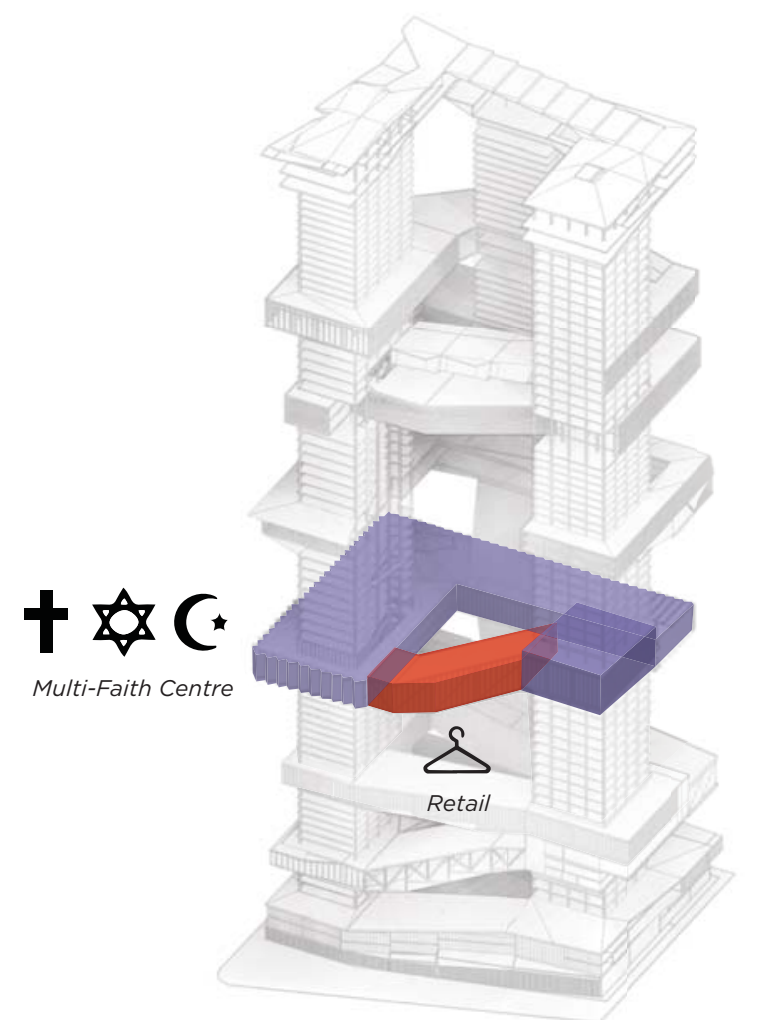




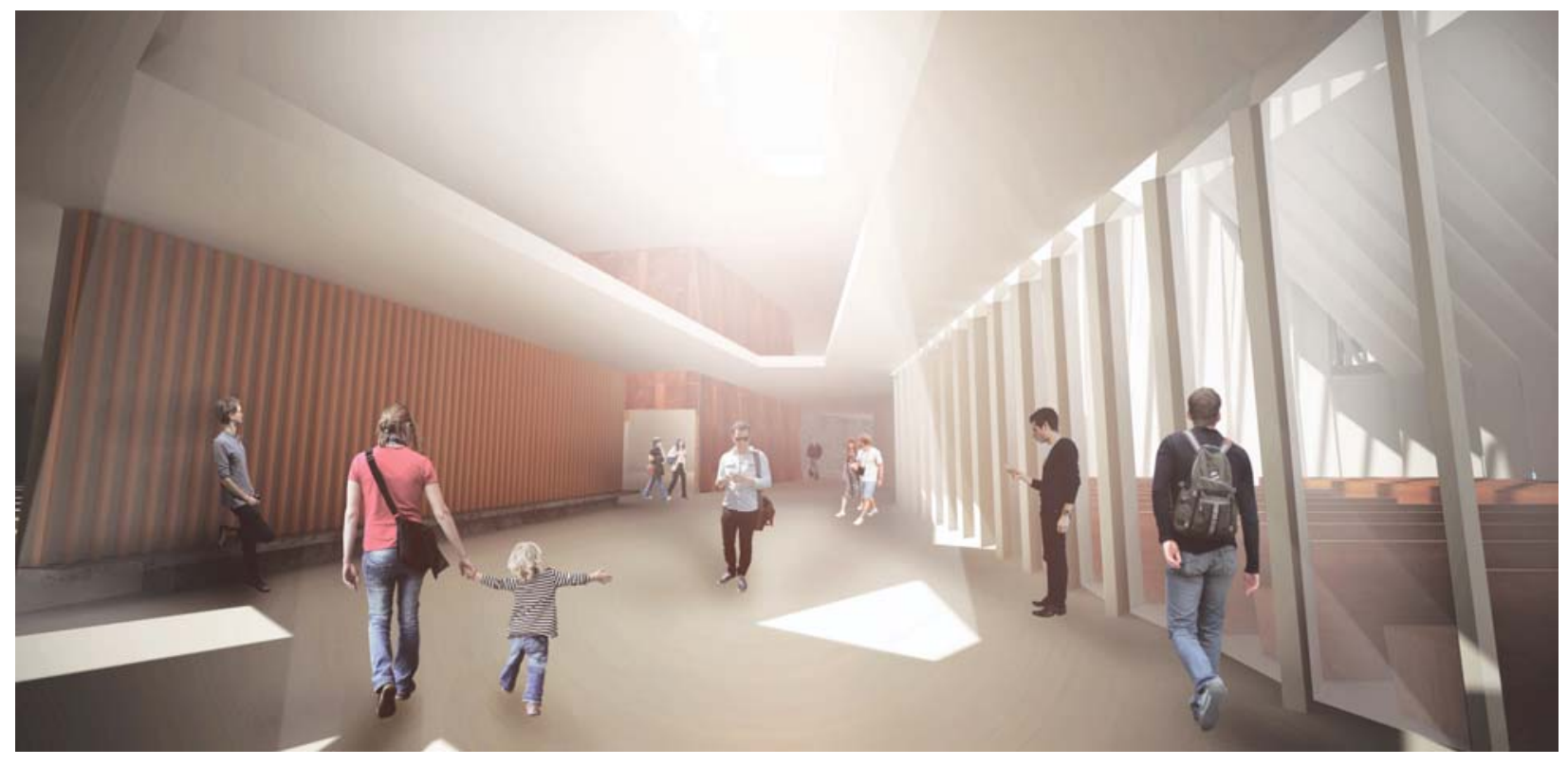

Fig 93: Multi-Faith Lounge Space

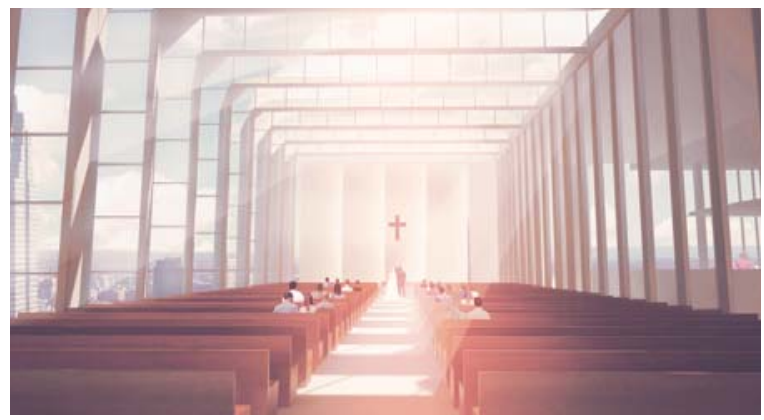

Fig 94: Church
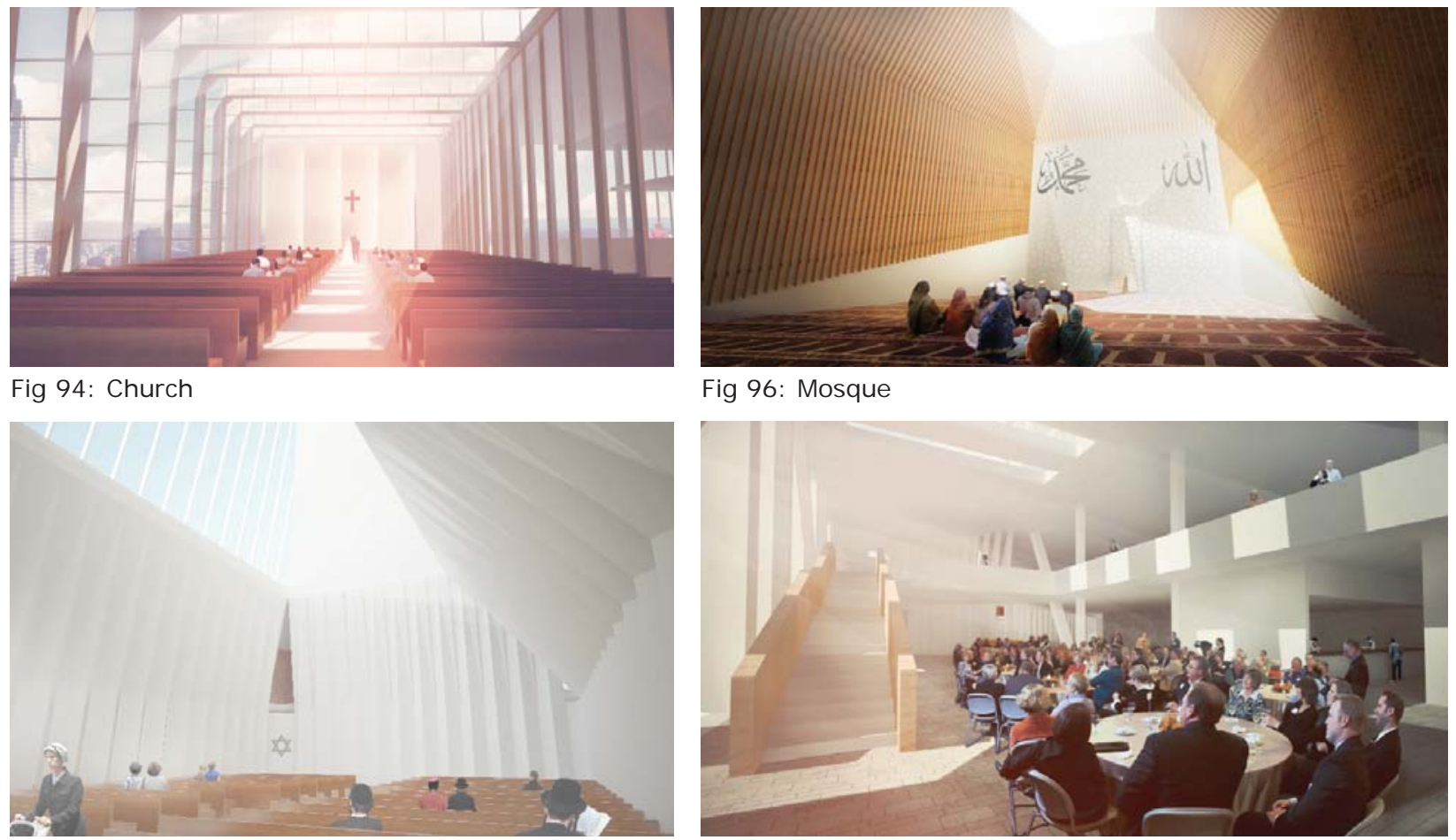

Fig 96: Mosque

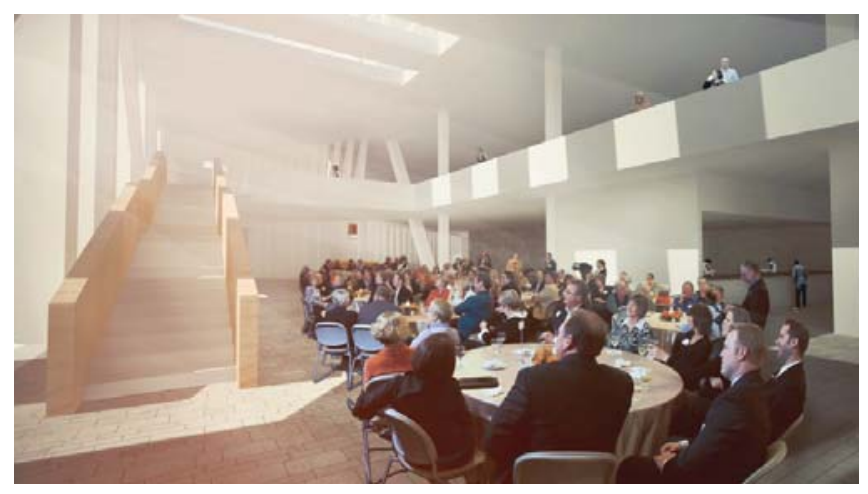

Fig 97: Multi-Faith Event Space 

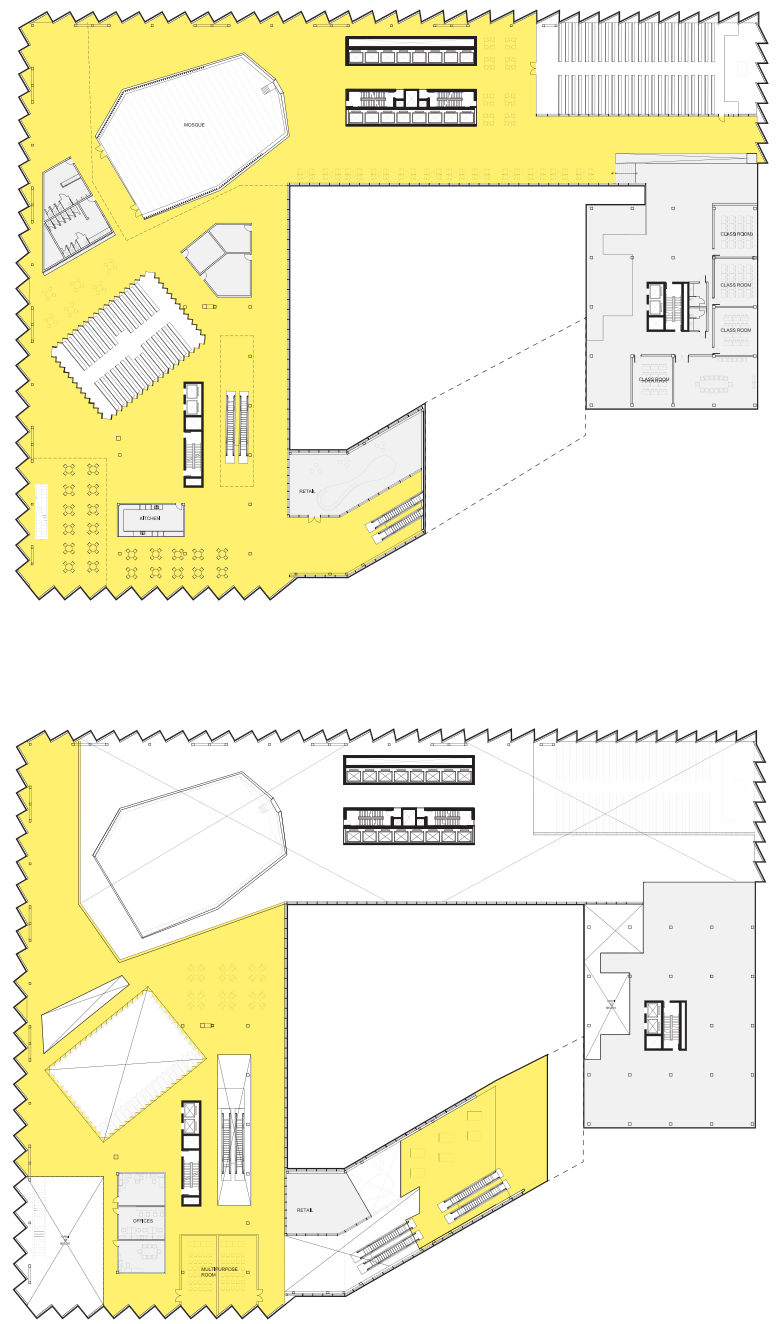

Fig 98: Multi-Faith Plans

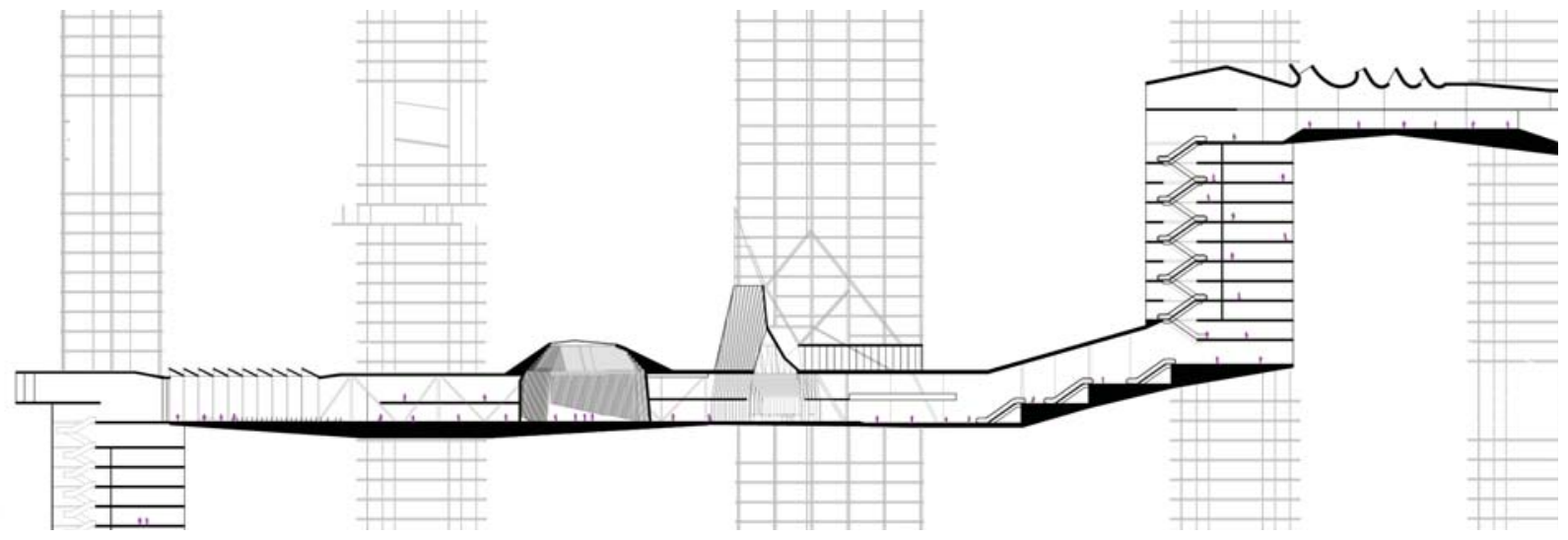

Fig 99: Multi-Faith Section 
inside the conference spaces (fig 101). A variety of different spaces are located here ranging from small rooms for 8 people up to large rooms for 200 people. This space is expected to act as a venue for both business located inside the building and companies located in the Central business district.

Art Gallery, Nightclub, Exhibition Space, and Theatre:

The art gallery and nightclub are designed to be adjacent to each other with the opportunity for their spaces to be combined for larger events. Views of Lake Ontario are framed within the gallery's circulation space. The circulation space is double height, connected by ramps and facing south to prevent glare from reaching the galleries (fig 105). The galleries vary in size. Some are double height with skylights and some are single height. The concept for this space was to display multiple types of work by varying artists at one time. The nightclub is a combination of single and double height spaces that connect to an outdoor roof patio with views looking over the city and the waterfront. The exhibition space is comprised of long open spans to maximise efficiency. This space can be closed off from the external light if needed. There are three cinemas linked with this 


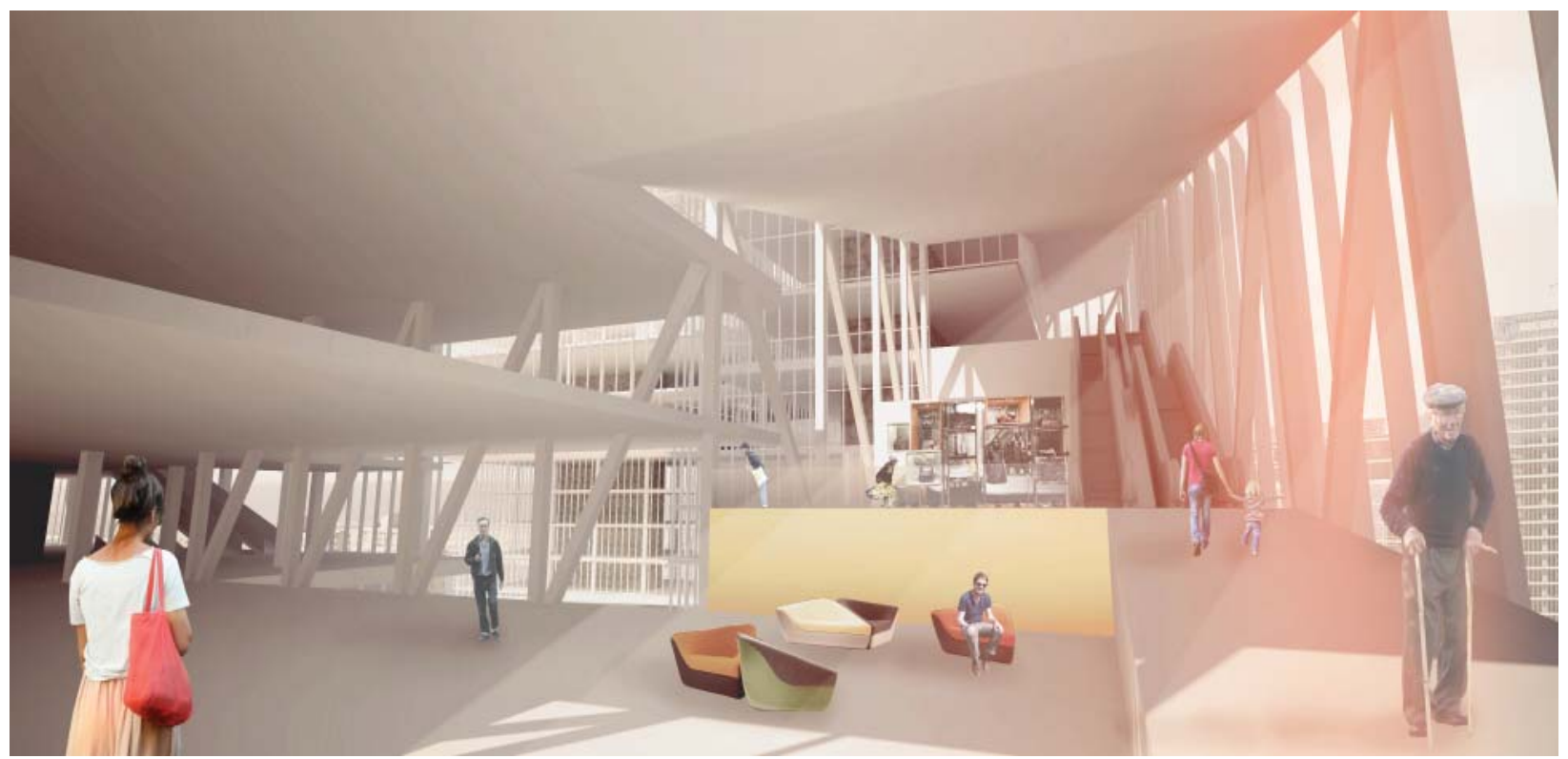

Fig 100: Hotel Lobby Retail
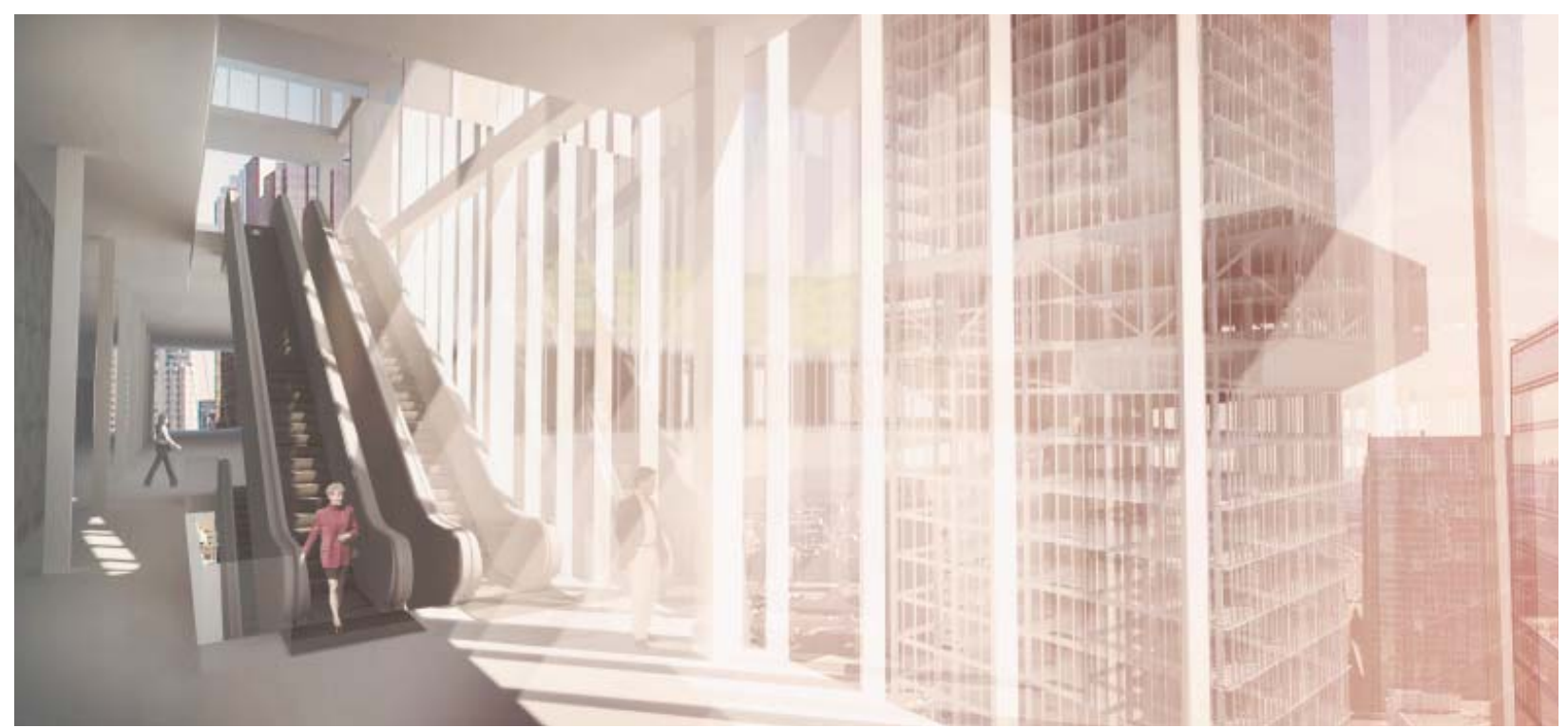

Fig 101: Circulation Atrium

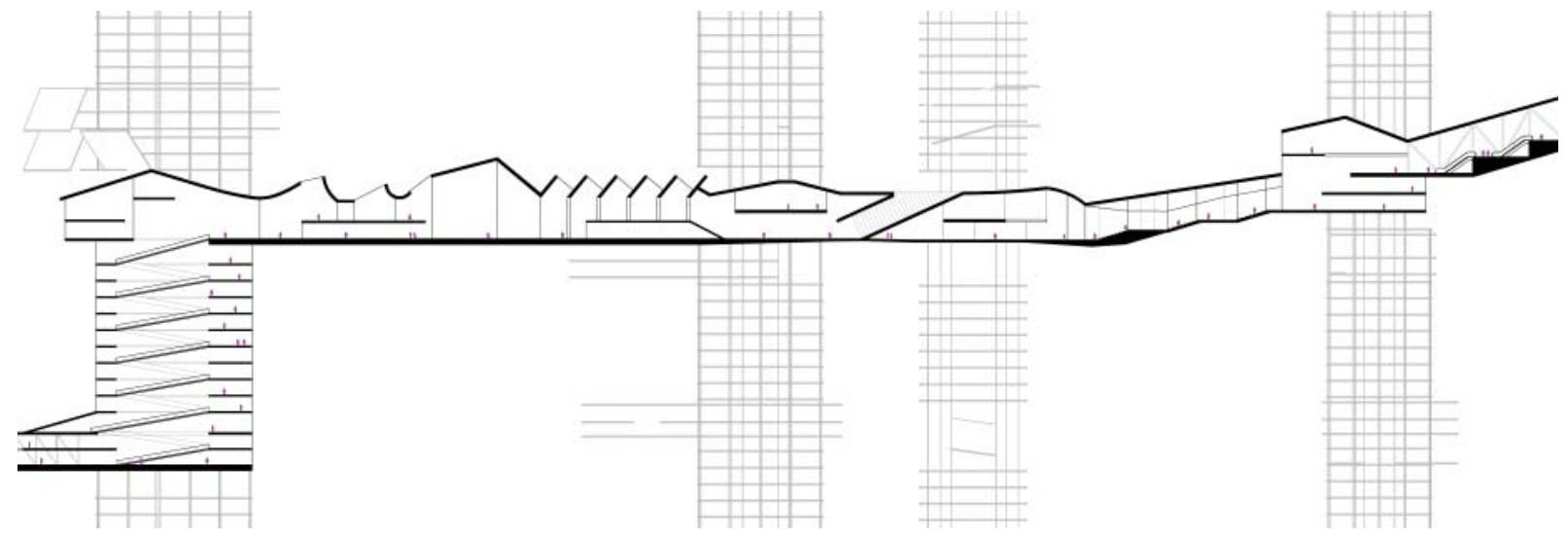

Fig 102: Art Gallery, Exhibition Space, Night Club Section 
Fig 103: Conference Centre Diagram
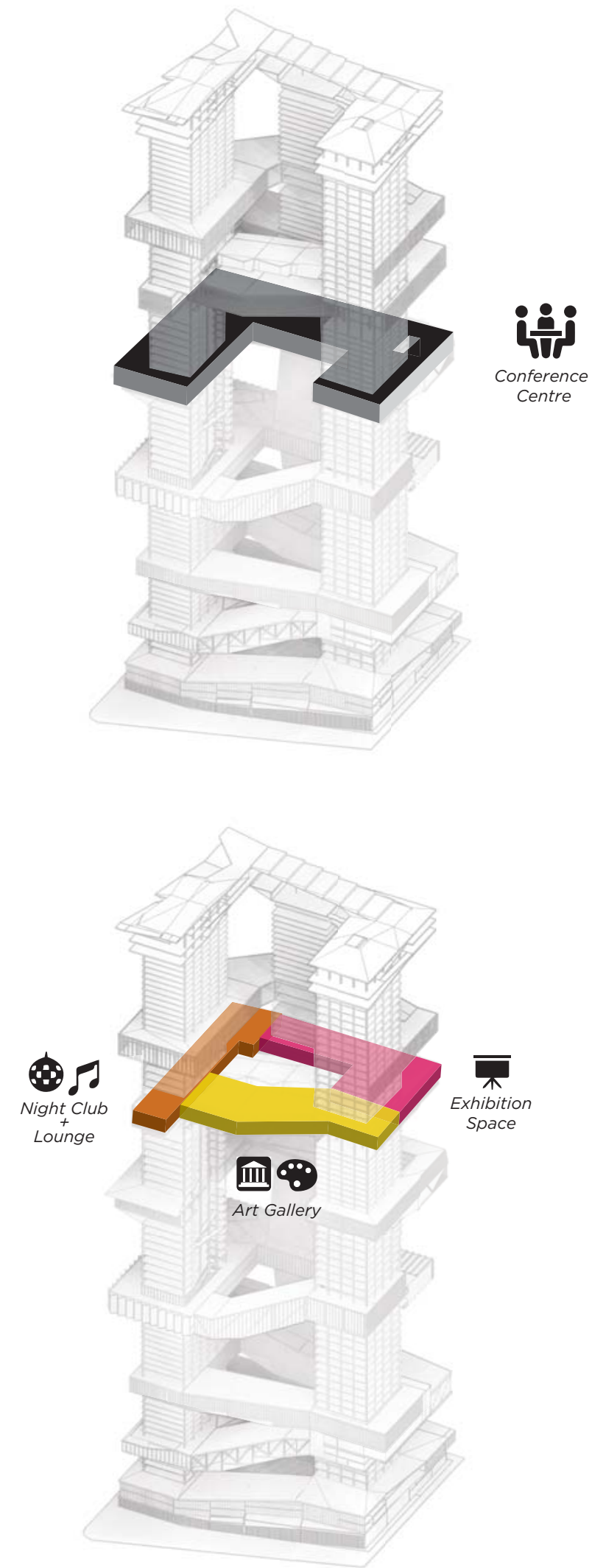

Fig 104: Night Club, Art Gallery, Exhibition Space 
cluster of program as well as the roof space. The theatres can be seen from the exterior because they are located on a horizontal bridge. The lobby space is aligned on the north to provide views to the city and other parts of the building.

Event Space, Hotel Lobby, Retail:

The event space, hotel lobby and retail are linked within each other but function as separate entities. The event space can be integrated with the hotel for weddings and ballroom events (fig 100)

Museum and Park:

The museum and park space is designed to be a

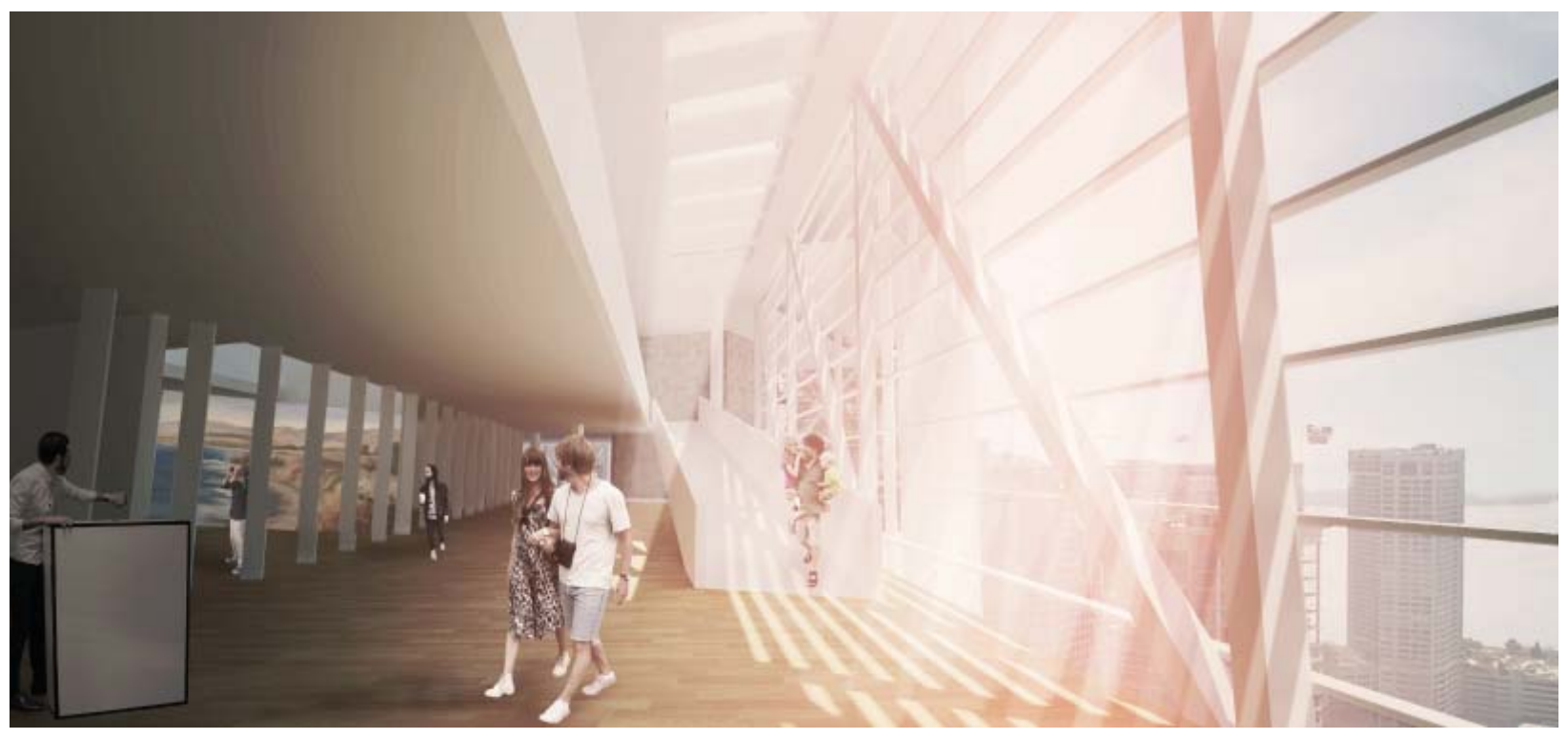

Fig 105: Art Gallery 
Fig 106: Movie Theatre Diagram

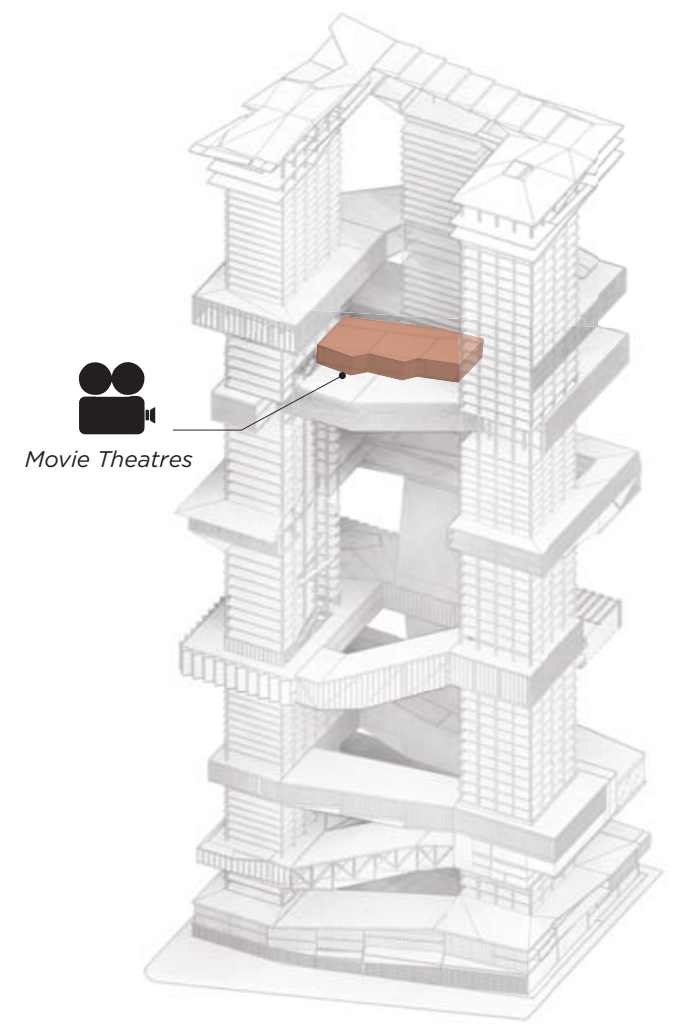

Fig 107: Event Space, Retail, Amenities, Hotel Lobby 
circulation driver which brings inhabitants and tourists through the building and gives them the opportunity to experience the city in the sky. The park space has sunken courtyards to form microclimates that would protect people from undesirable weather conditions (fig 109). The roof space is designed to cover the mechanical systems while providing places for people to sit and look out onto to the lake and city. The museum circulates from the east tower to the north tower to the west tower creating

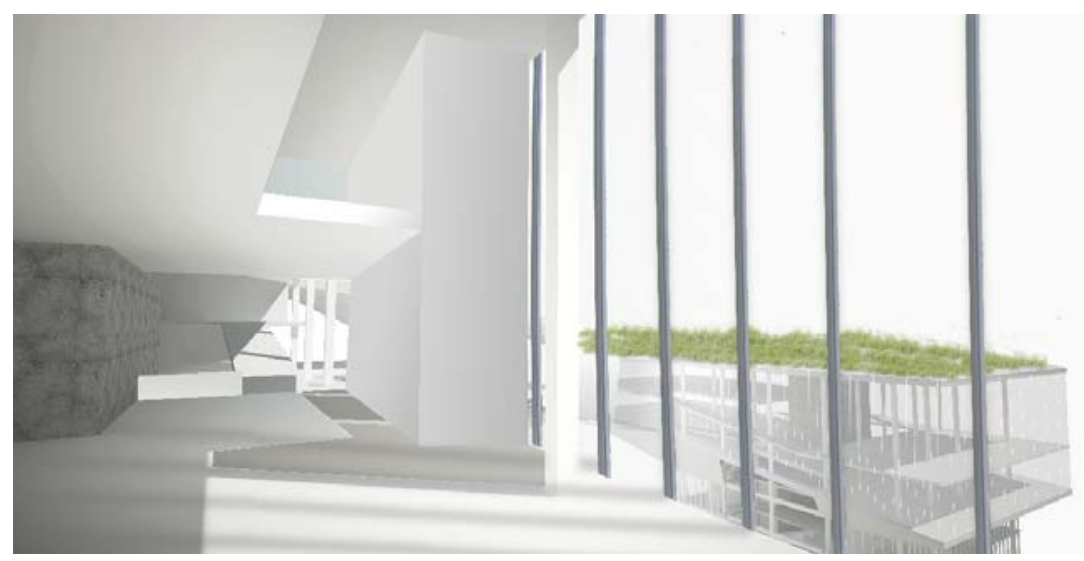

Fig 108: Museum Interior Rendering

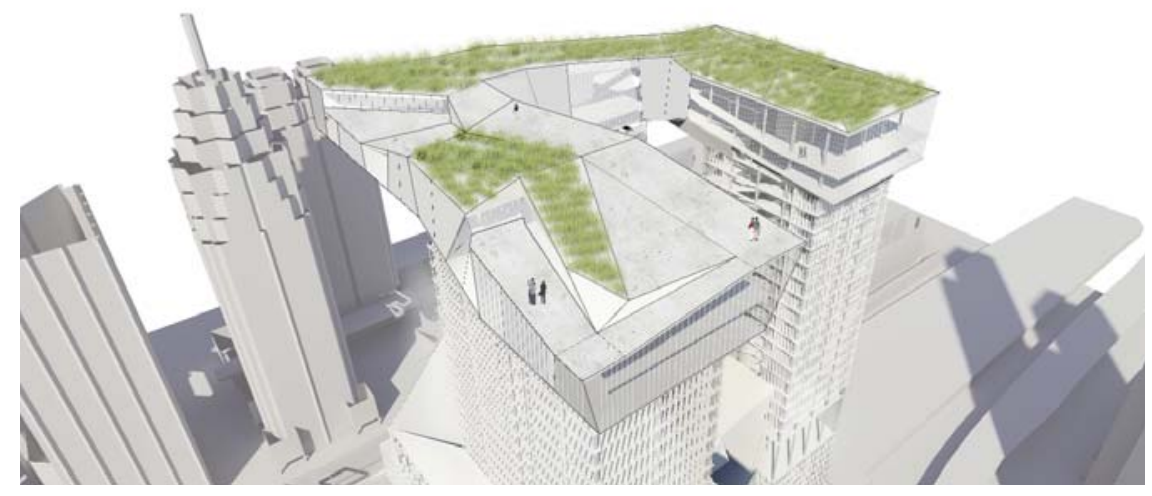

Fig 109: Museum Park Roof Rendering 


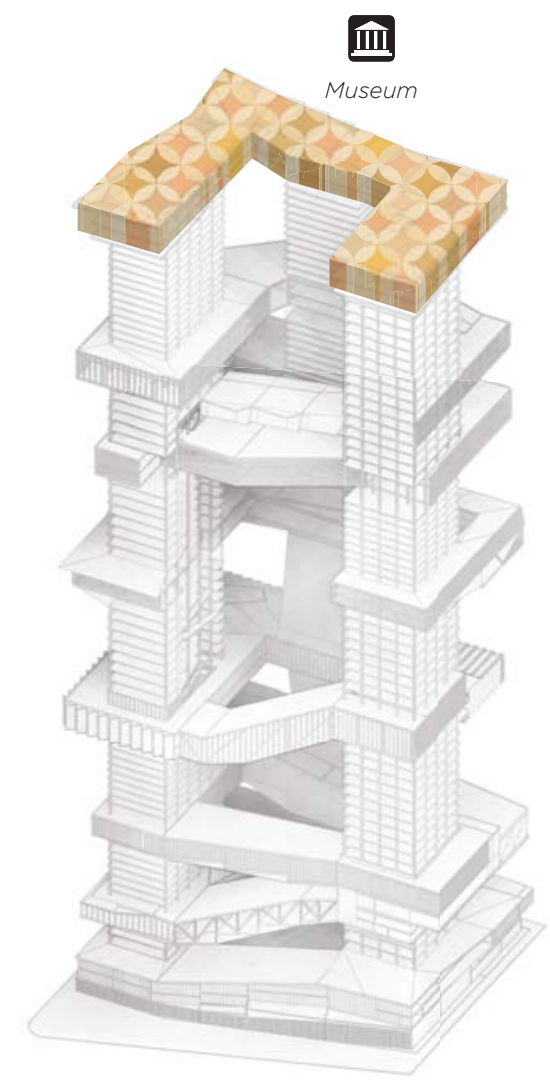

Fig 110: Museum Diagram

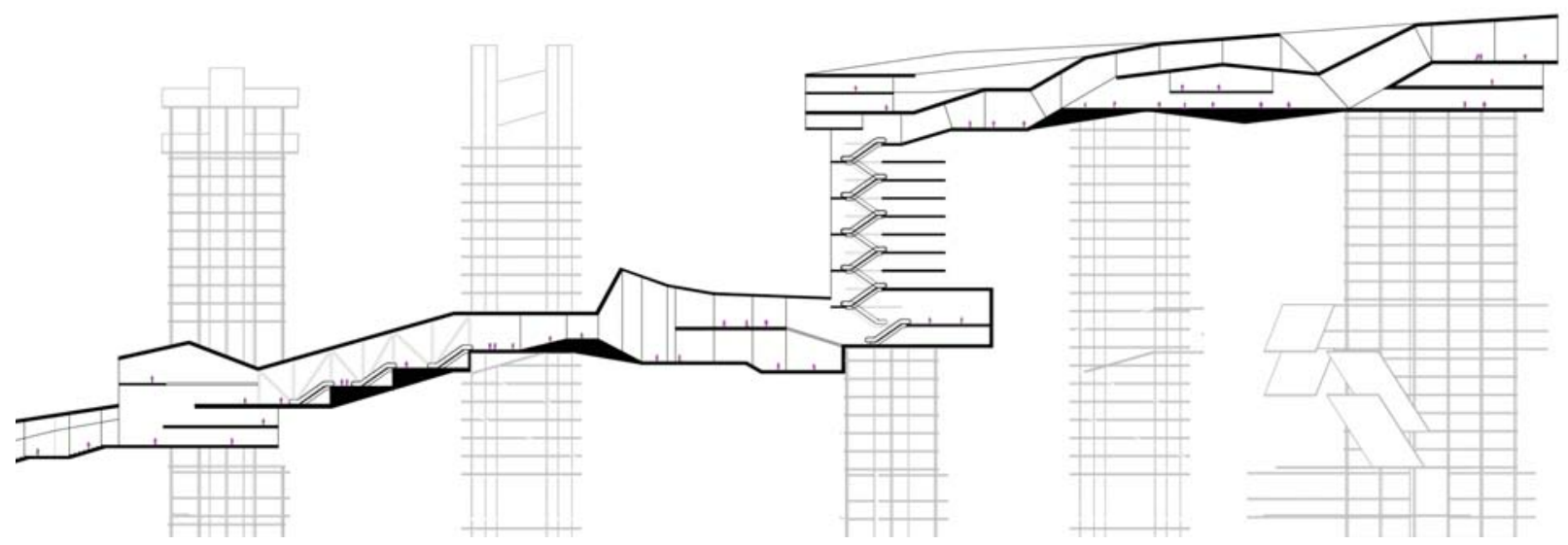

Fig 111: Event Space, Museum, Park Section 
a linear circulation that organizes the gallery spaces.

The gallery spaces are integrated within this circulation network and in some cases open up to the views of the city and lake.

\section{Visual Program I dentity}

This visual experience is articulated by the interior facades of the various programed spaces (fig 68). The exterior, to some extent maintains homogeneity (fig 122). The heterogeneity of the project is expressed and experienced inside the interior circulation spine. The exterior facades have been rendered generic except for the main interstitial spaces that are represented to contrast the rest of the tower.

\section{Creating opportunities where condensing can be integrated into the horizontal hybrid portions of the tower:}

The term condensing was identified as internalized areas where communities congregated socially. The nature of this project is that each one of the tower portions is a separate community/program or zone. All portions of the tower are accessible to the horizontal bars which connect to the north tower. These horizontal bars 


\section{Fig 112: Exterior and Interior Landscape Diagram}

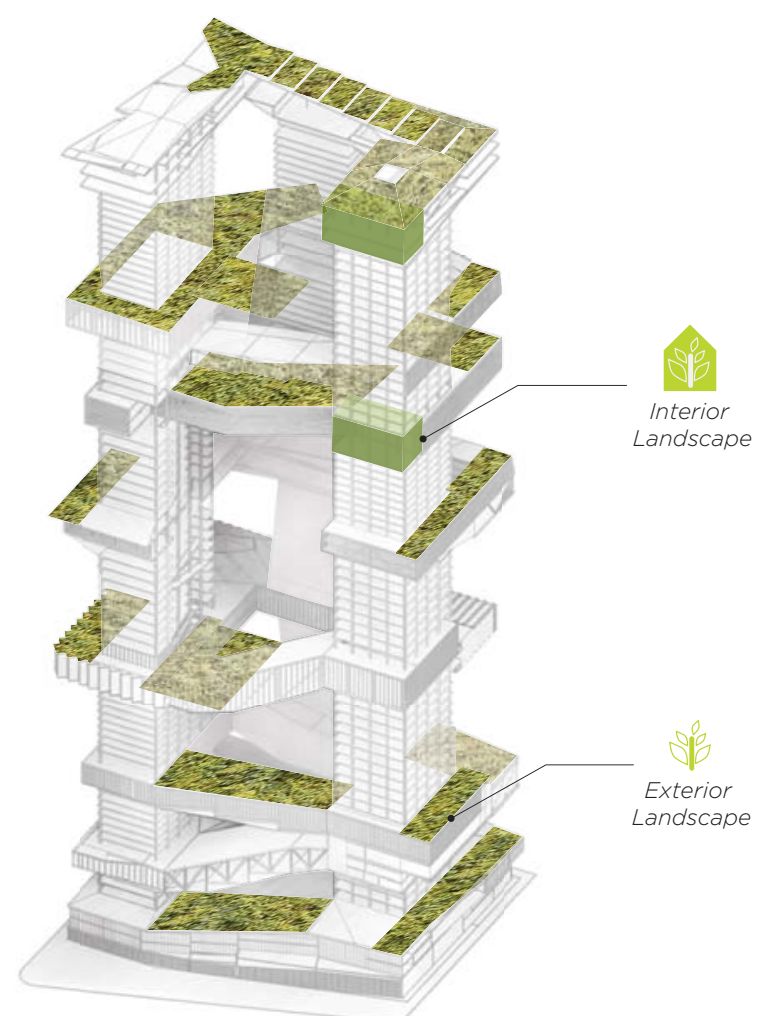

Fig 113: Commercial Office Space

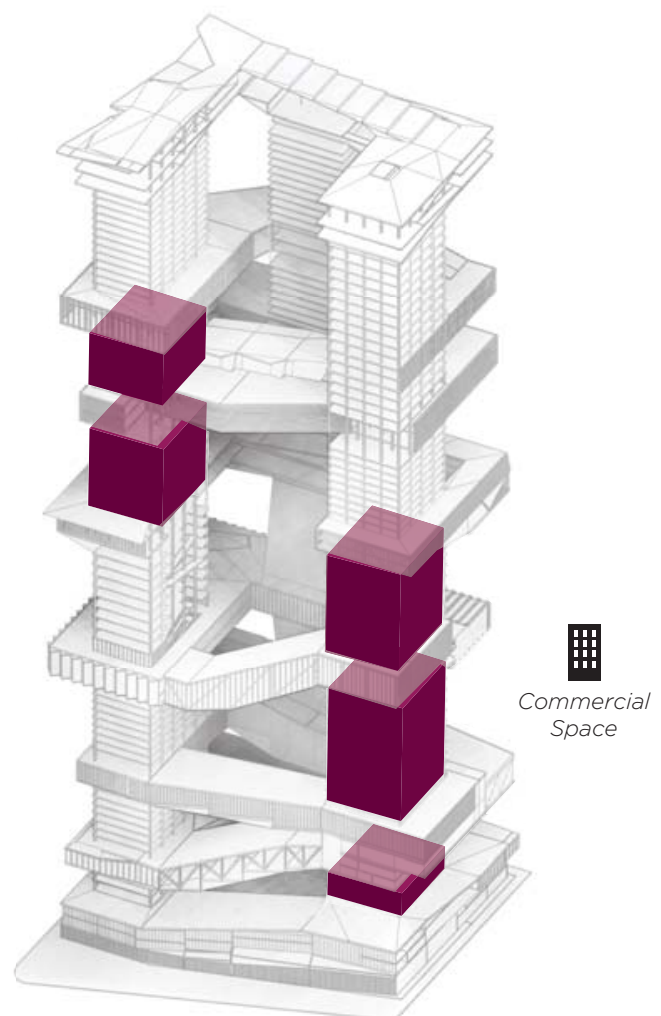


become interconnected with the vertical portions of the tower directly above.

Continuous outdoor green spaces located on top of the horizontal bars provide outdoor condensing space for both visitors and occupants of the condo units.

This green space acts as condensing space for both residents, workers, and visitors. The space can be used for urban farming, gardening, and other leisure activities.

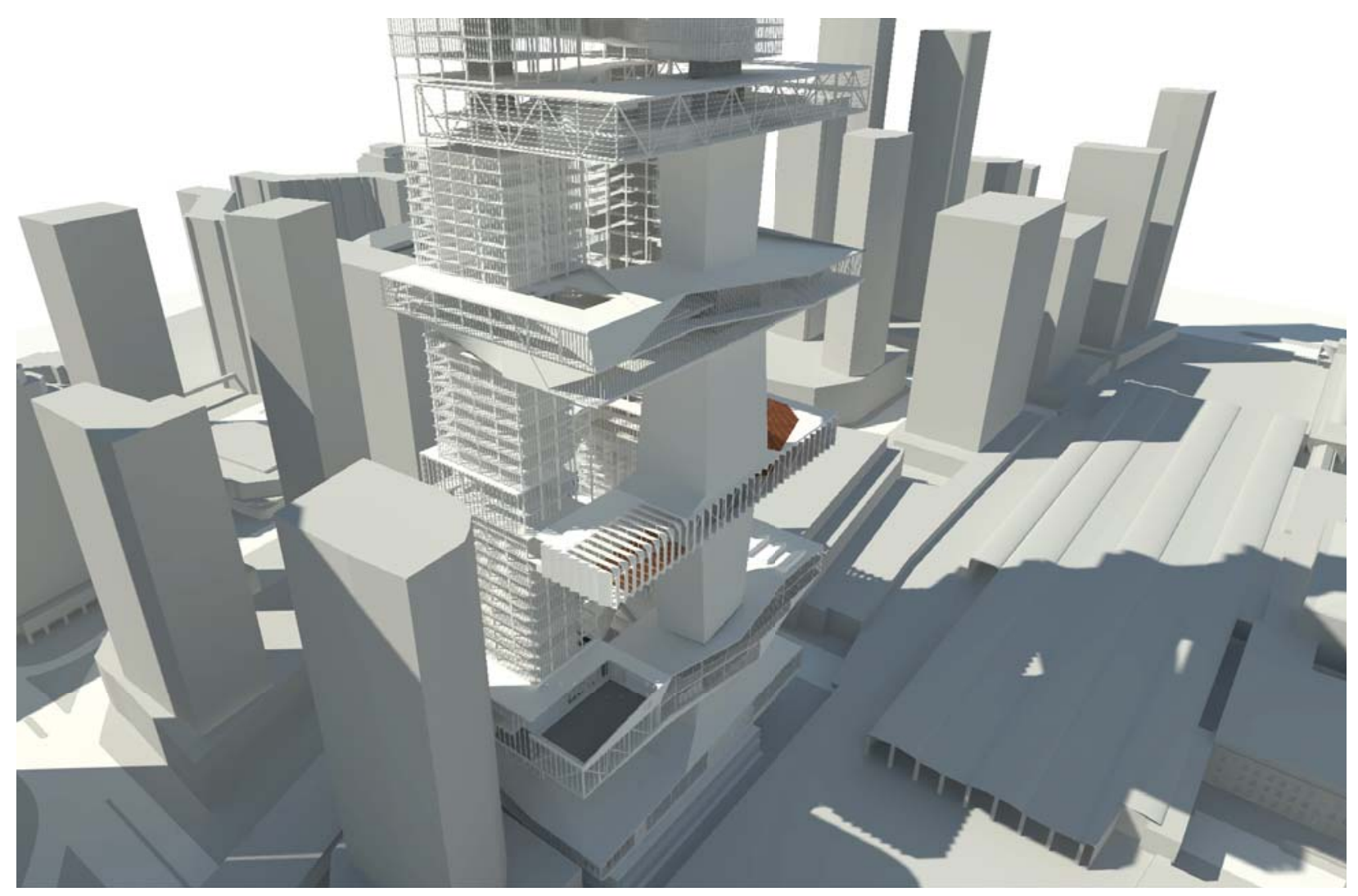

Fig 114: Roof Spaces Rendering 
The condominium units have limited balconies which encourages people to leave the private realm and enjoy the roof space collectively with their neighbours (fig 112).

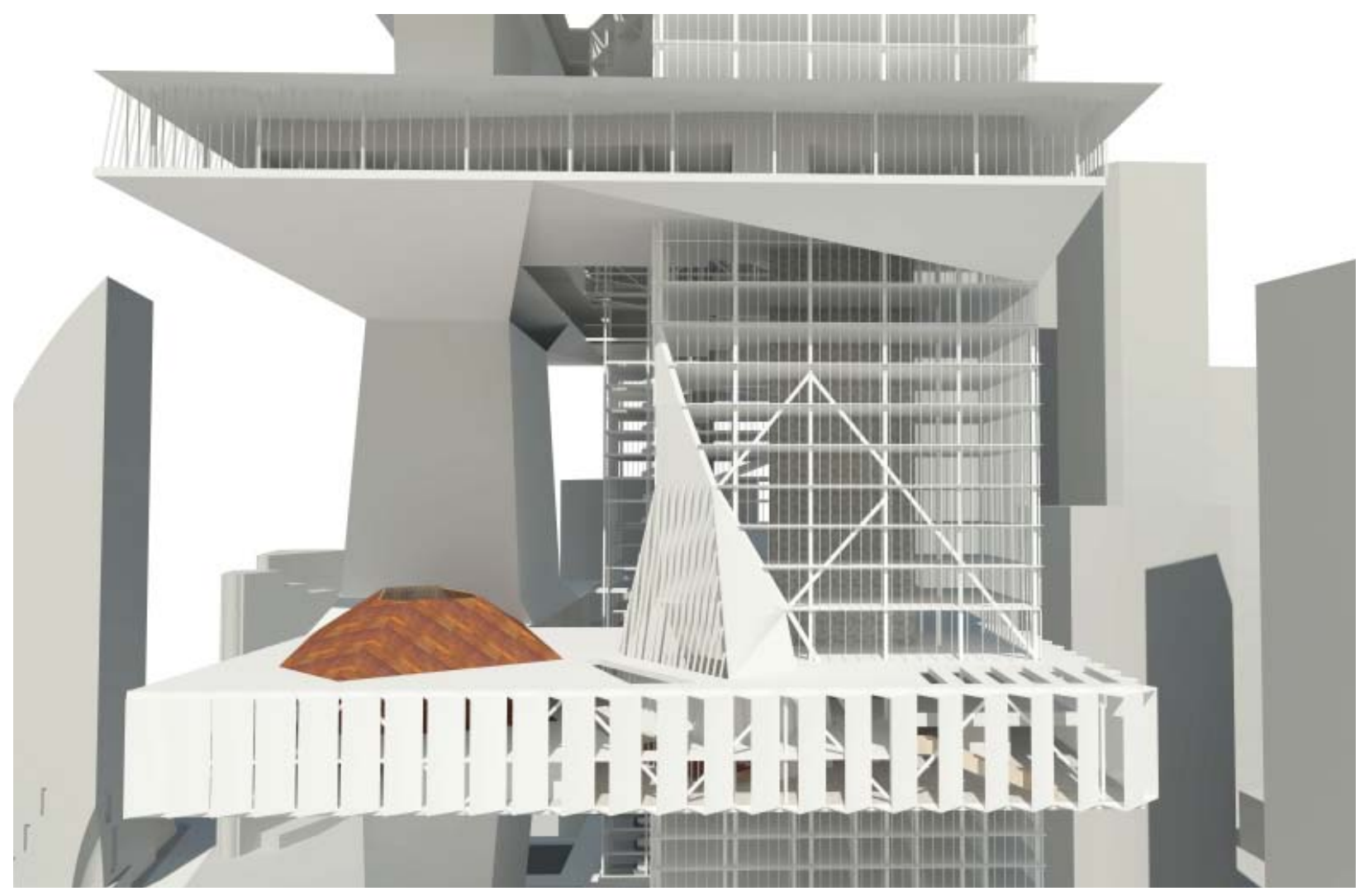

Fig 115: Multi-Faith Roof Rendering 


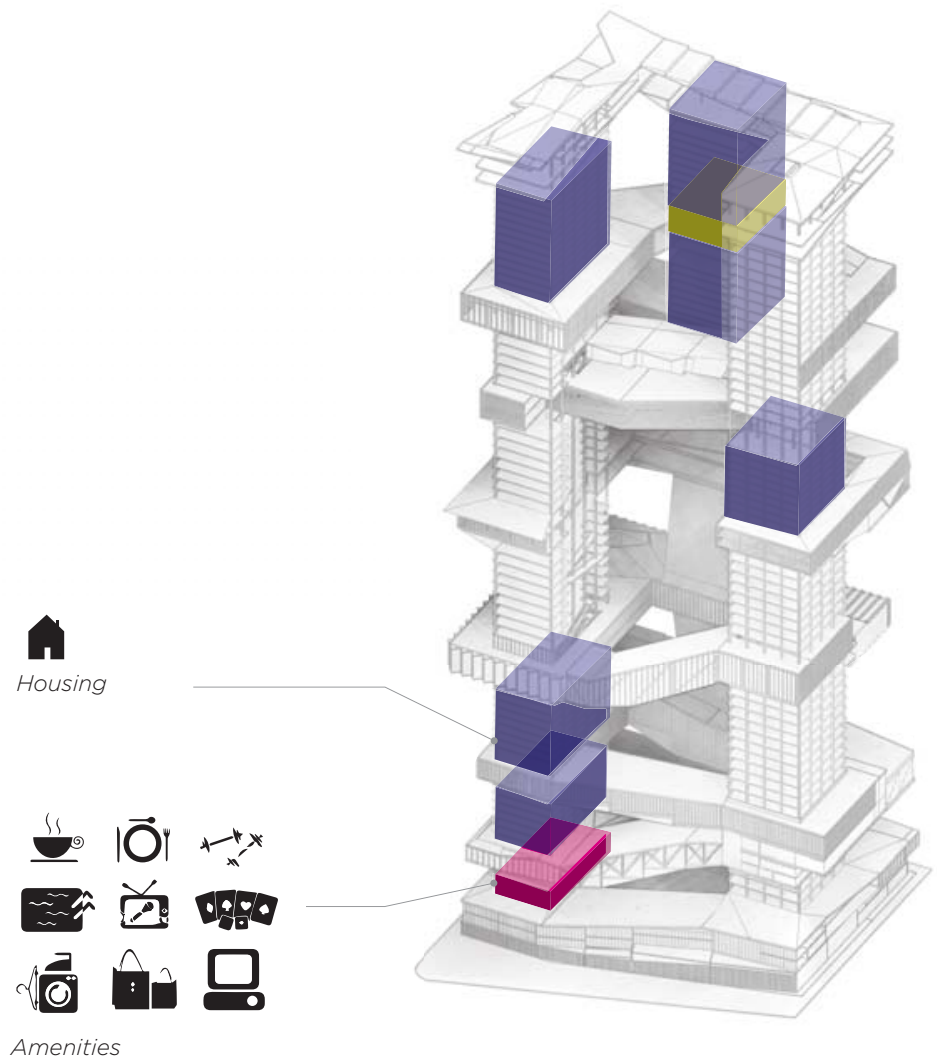

Fig 116: Housing and Amenities Diagram

Fig 117: Hotel Lobby Diagram

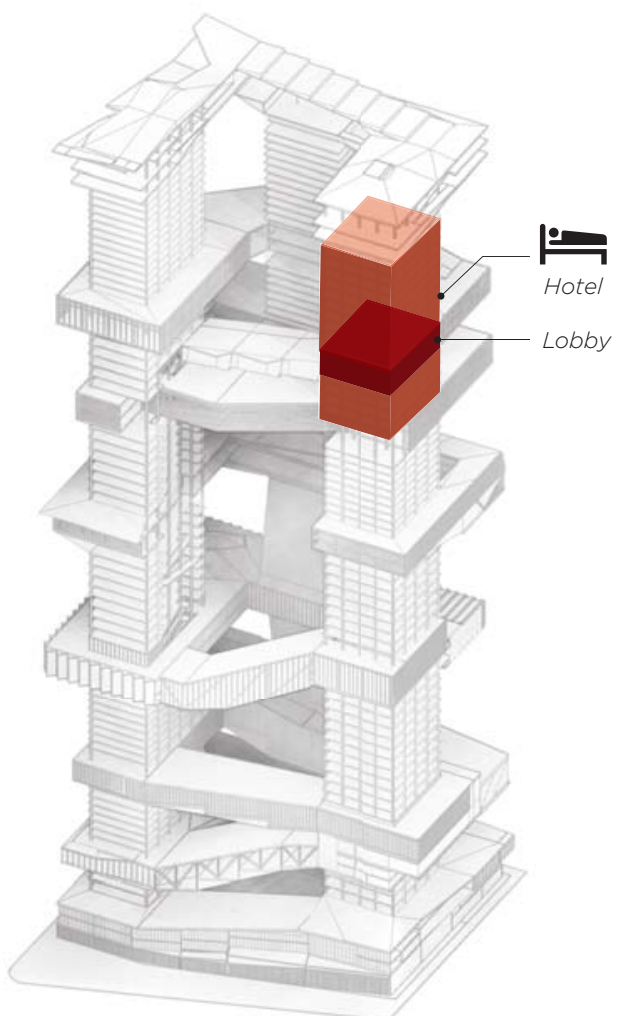



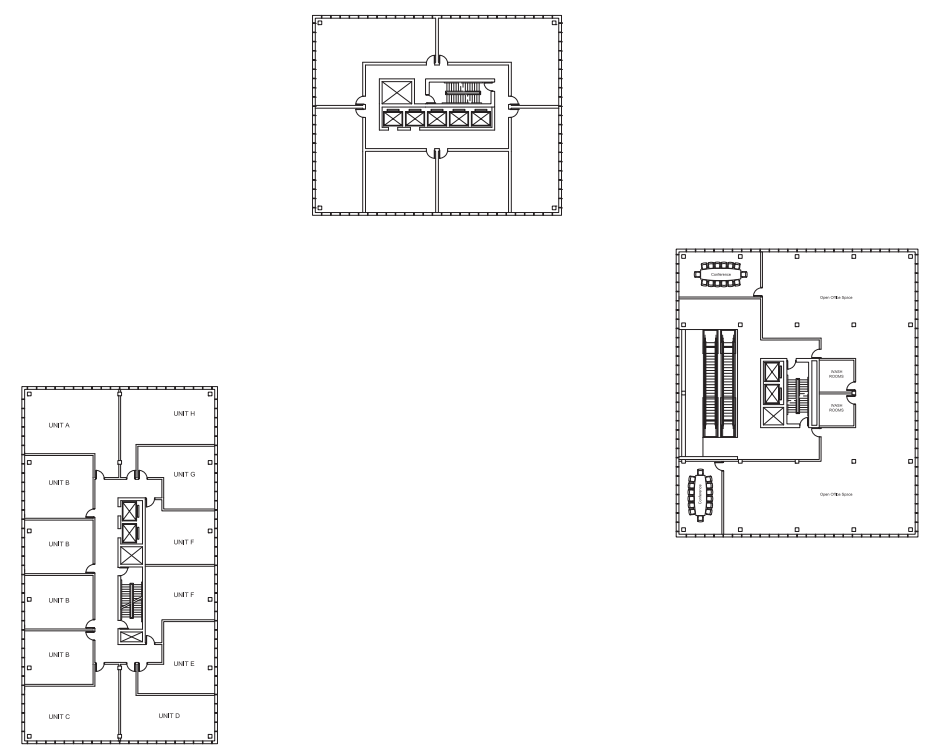

Fig118: Typical Condo and Office Floor Plan
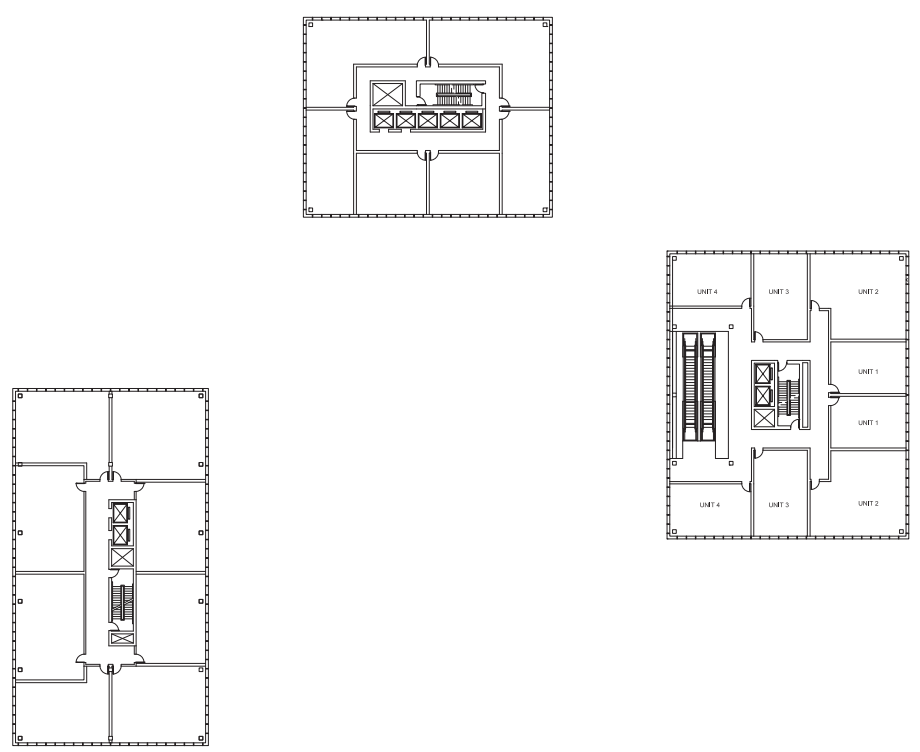

Fig 119: Typical Condo and Hotel Floor Plan 


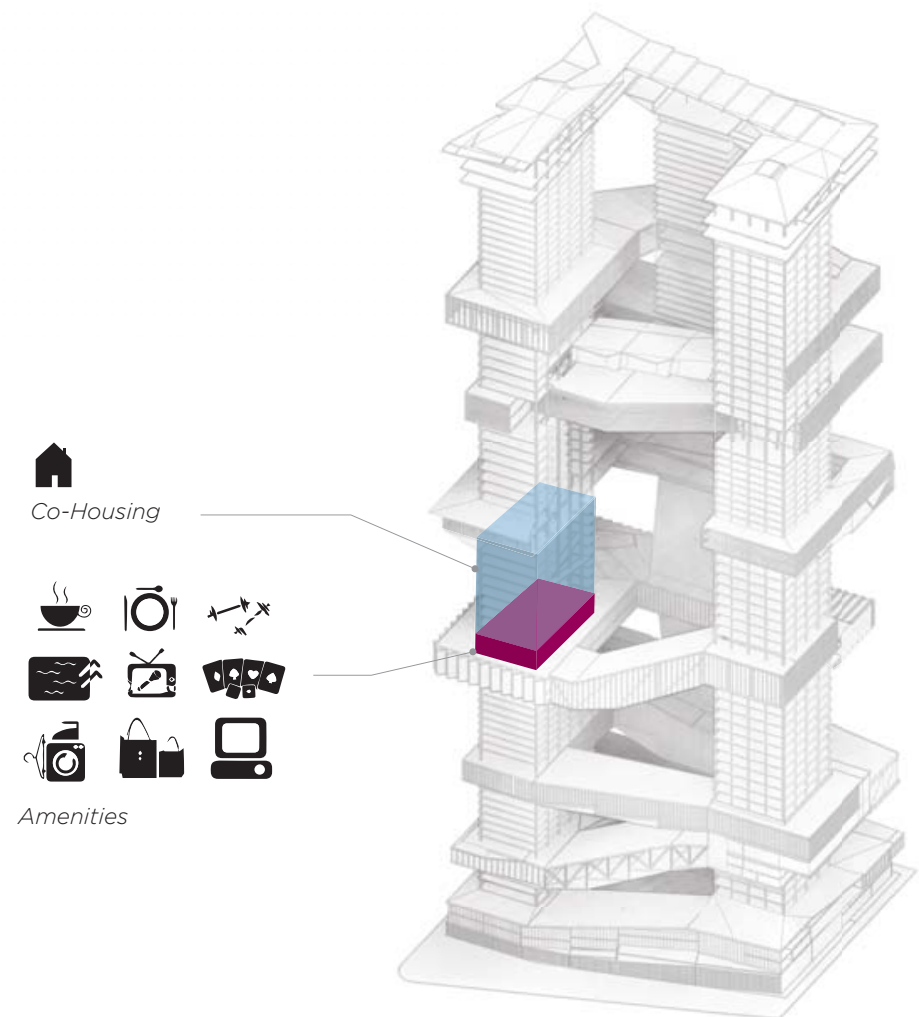

Fig 120: Co-Housing Diagram

Fig 121: Exterior Rendering

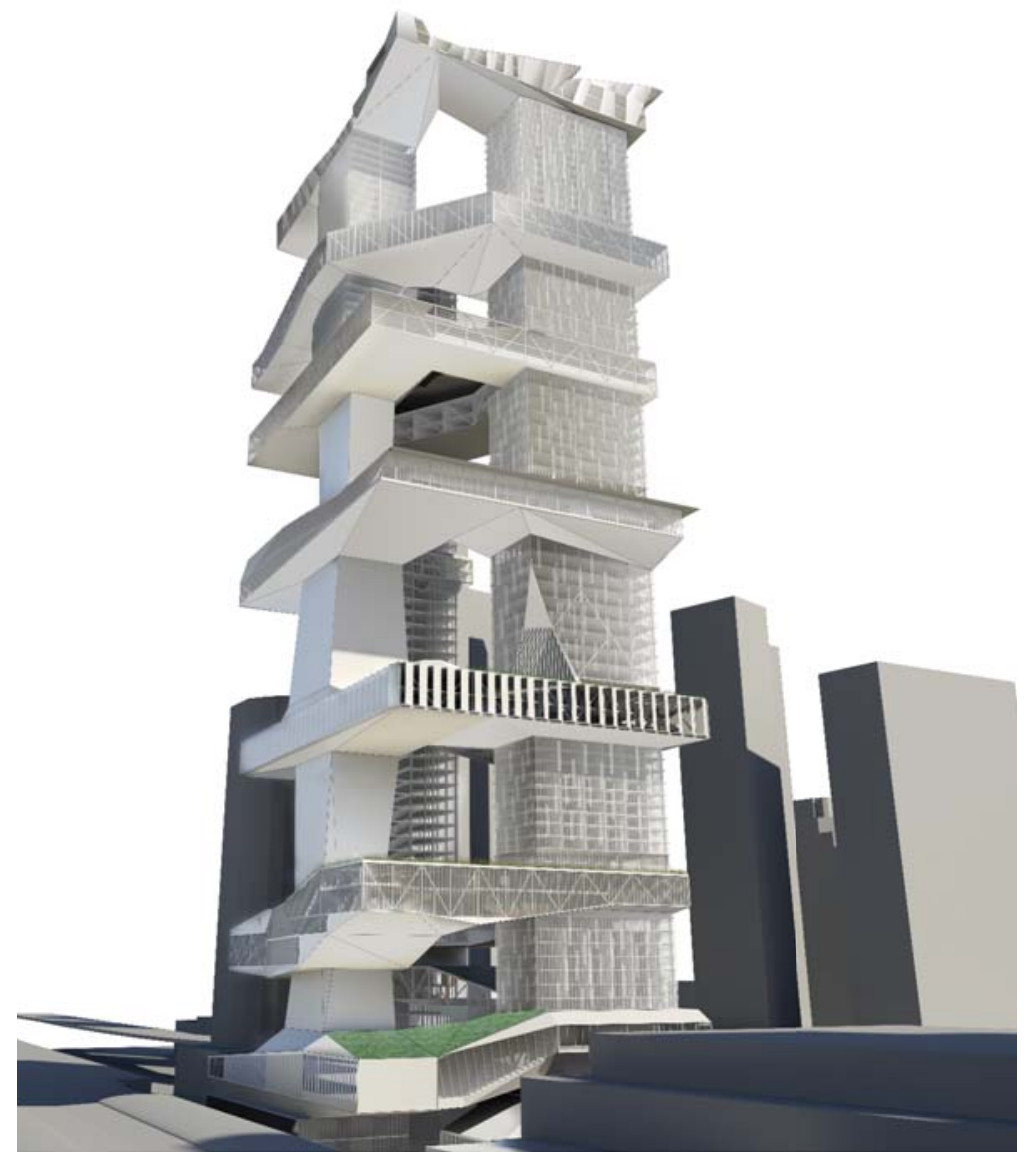




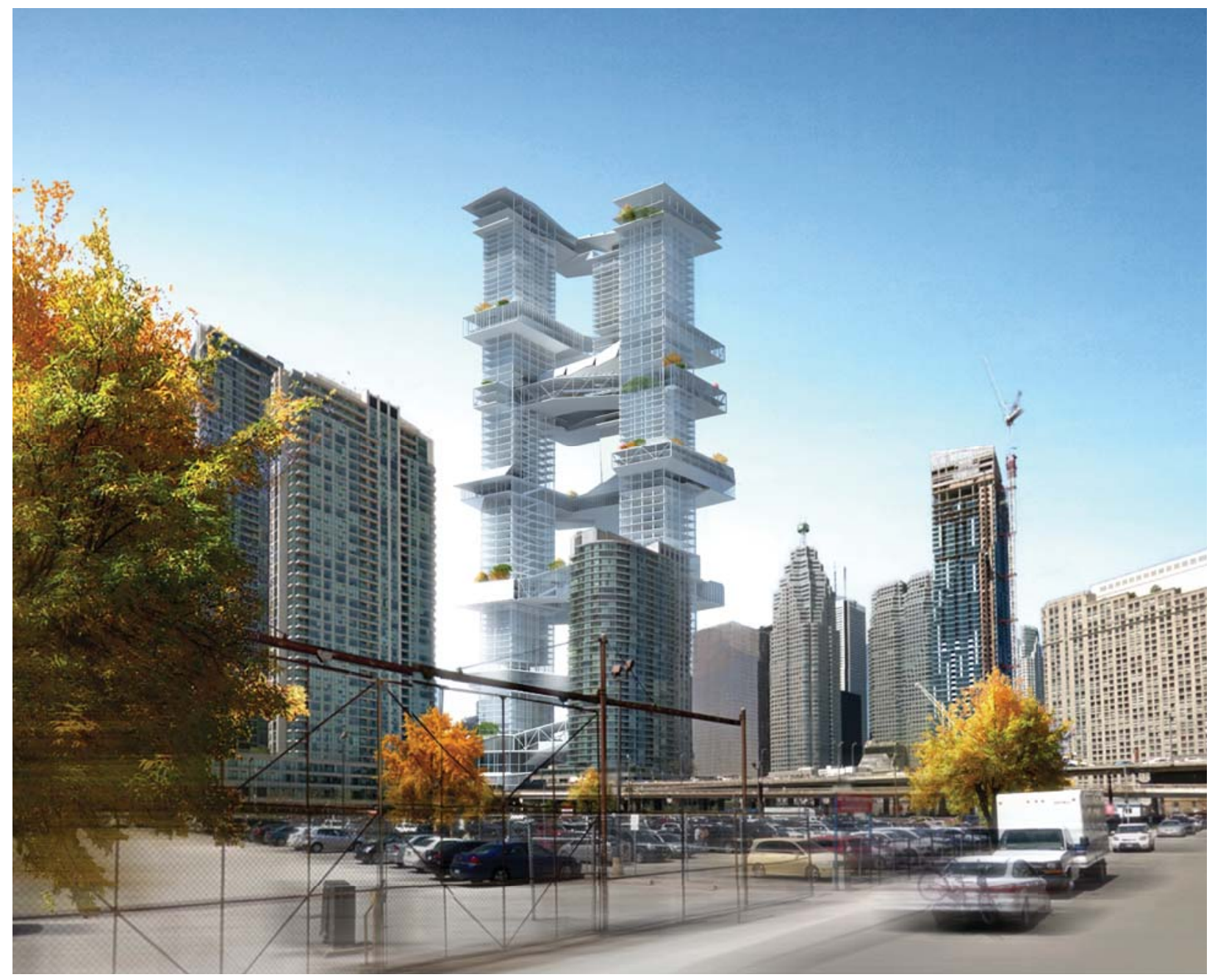

Fig 122: Exterior Rendering

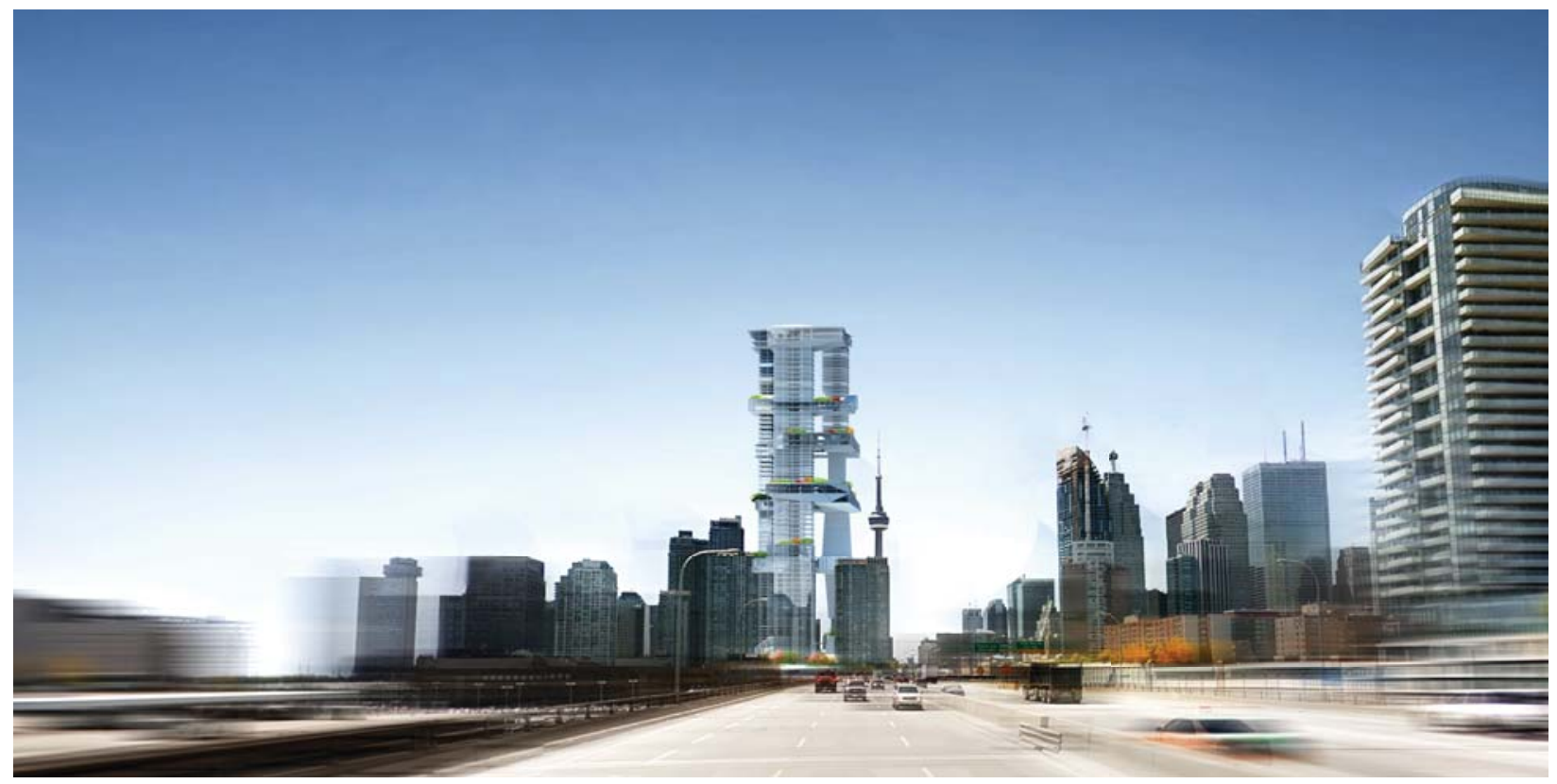

Fig 123: Exterior Rendering 


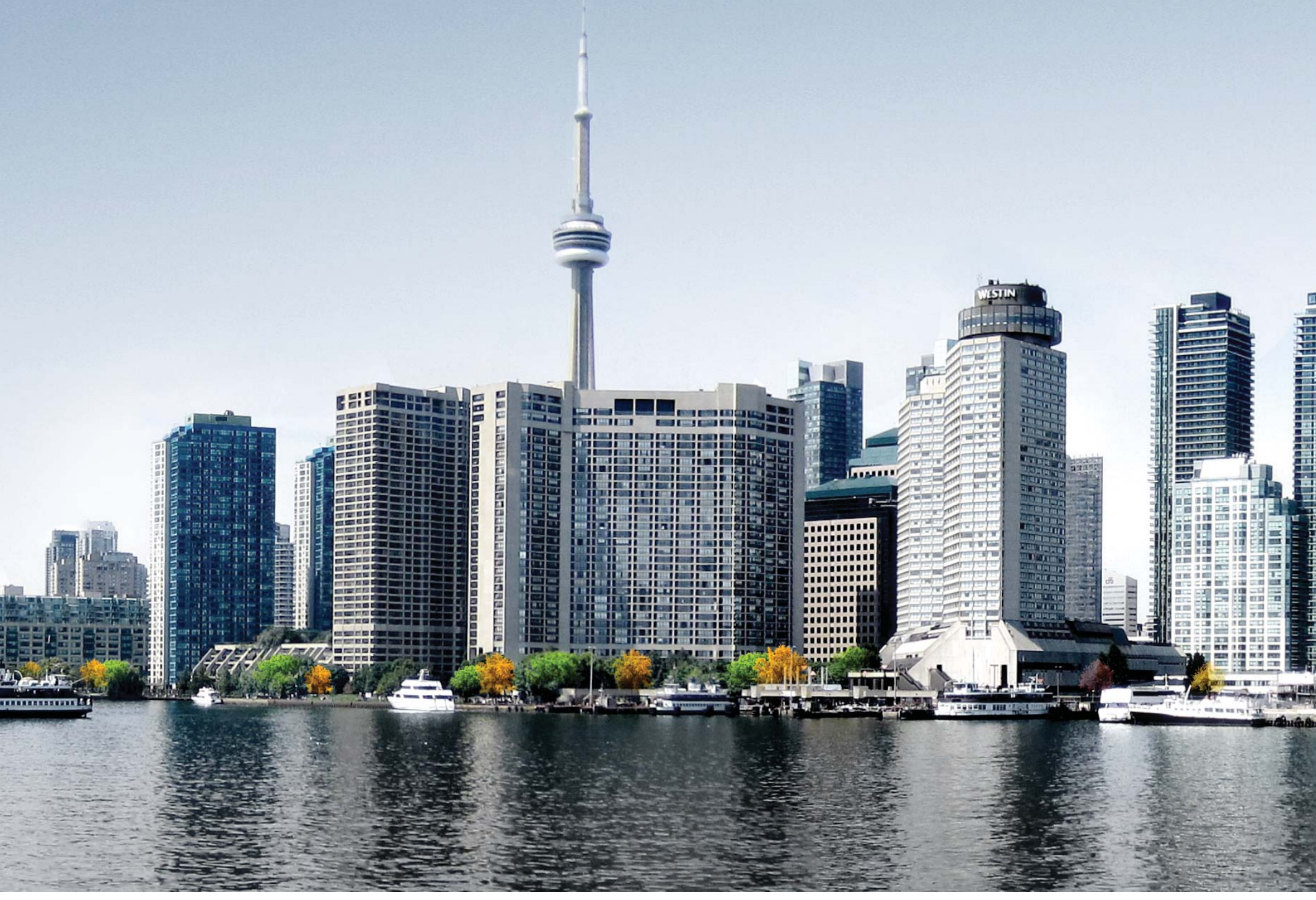

Fig 124: Exterior Rendering City View 

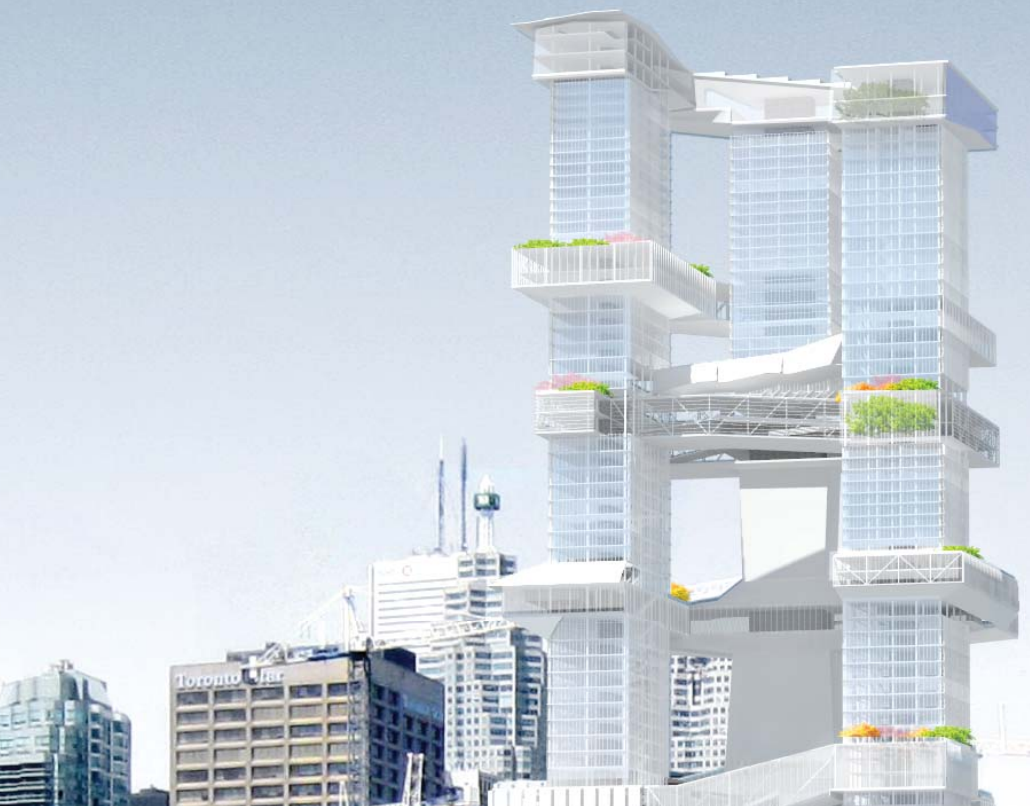

- =

resang

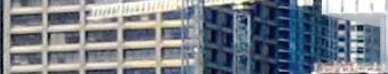

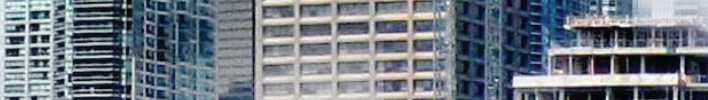

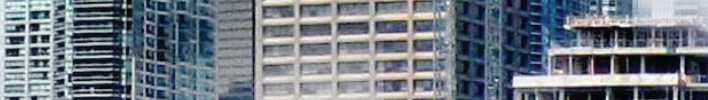

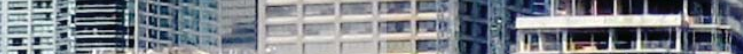

黄至

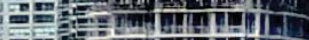

- min

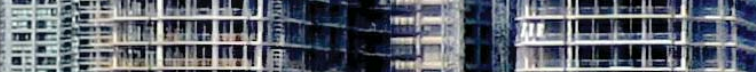

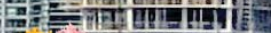

Af

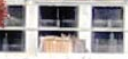
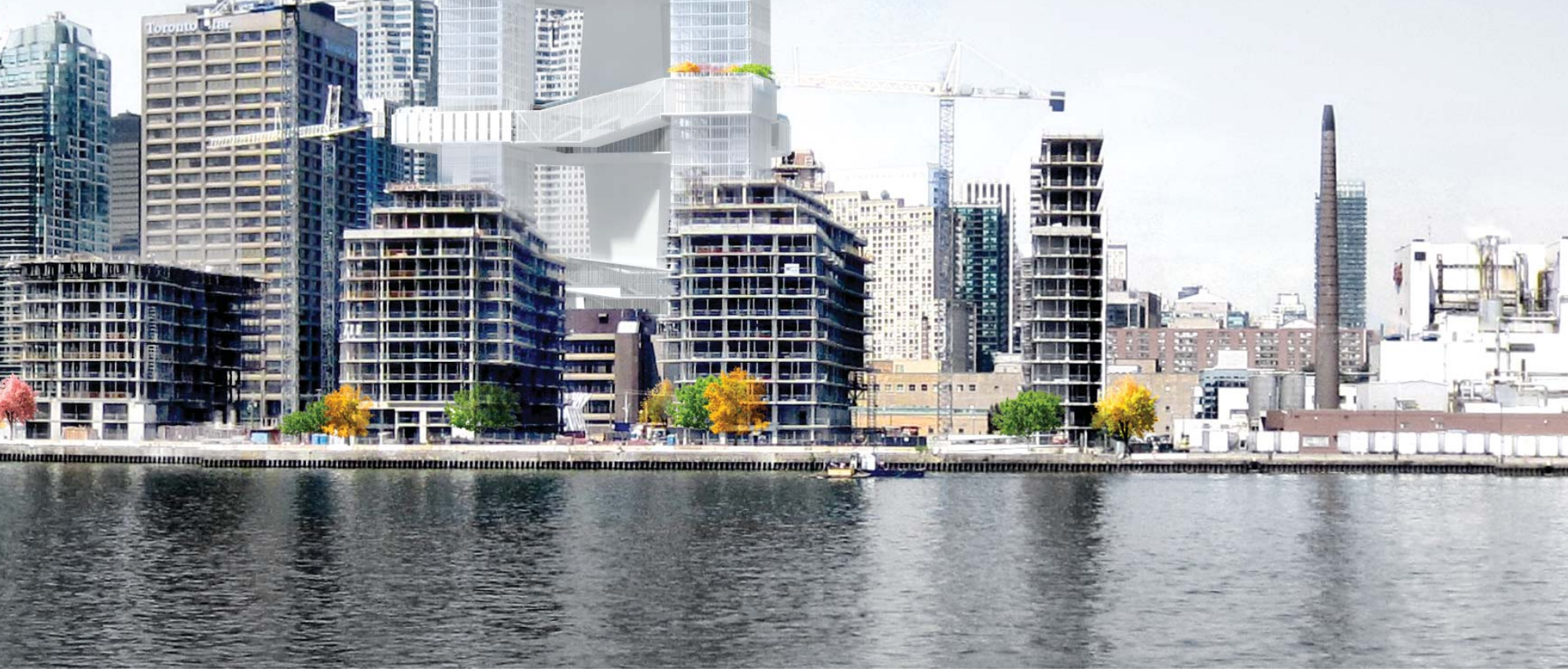


\section{Conclusion}

The aim of this thesis was to redefine high-rise residential living by proposing a new form of hybrid tower that integrates public realm into the built form of the condominium typology. Working within the existing hyper-dense, high-rise parameters of Toronto's emerging downtown core, it proposes a more holistic urban condition within the modern metropolis. The Hybrid Social Condenser integrates high-rise residential density with the public infrastructure needed to create a liveable city, in a condition of diminishing available terrain at grade. The extension of the public domain into the traditionally private domain of the residential tower creates a continuous vertical landscape throughout the building. This expanded ground plane exploits opportunities for social interaction between internal and external users of this new neighbourhood typology. This is exemplified in the unfolded section which expresses the continuity of the ground plane as it penetrates through the vertical towers, integrating disparate programs. Interstitial spaces are formed where institutions and amenities are given public presence and identity through unique façade compositions. The organization of these diverse programs activate a continuous circulation network in the building 
through the use of elevators, escalators, ramps, stairs, atria, and terraces. These collective transitional zones are designed to create contextual relationships where social interaction can occur. These are the ingredients of a lively, heterogeneous, civic life.

The creation of a social experience which blurs the line between the public and private was key in the creation of this new tower typology. The amount of vertical infrastructure needed to achieve such a proposal raised many questions. What would happen if the same concept was applied to only the midsection of the tower? In such a case, focus would be put on the development of circulation between the different vertical compartments. Another direction could be to interweave the circulation spine between different buildings on other sites. How could this be achieved while maintaining the integrity of public space in the project? How can the towers intersect the horizontal connections? What does the intersection of the horizontal spaces look like in order to service both the tower and the programmatic space? These questions continue the discussion and design exploration process on a subject that will benefit the discipline of architecture. 


\section{Bibliography:}

1. Alfredo Brillembourg \& Hubert Klumpner Urban Think Tank. Torre david informal vertical communities. ETH Zurich: Lars Muller Publishers; 2012.

2. Archdaily. Seattle central library / OMA + LMN. http://www. archdaily.com/?p=11651. Updated 10 Feb 2009. Accessed 09/11, 2014.

3. Boudreau J. Changing toronto: Governing urban neoliberalism. Toronto: University of Toronto Press; 2009.

4. Brody J. The neighbourhood unit concept and the shaping of land planning in the united states 1912-1968. J ournal of Urban Design. 2013; 18(3):340-362.

5. Cauter Ld. The capsular civilization: On the city in the age of fear. Rotterdam: NAi Pub. ;|aNew York, NY : |bAvailable in North America through D.A.P./Distributed Art Pub.; 2004.

6. City of Toronto. Tall building design guidelines. . May 2013.

7. Clarence Perry. "The neighbourhood unit" from regional plan of new york and its environs (1929). In: Michael Larice and Elizabeth Macdonald, ed. The urban design reader. ; 2007: 54-54-65.

8. Dautovich N. Can't afford a house in toronto? be patient. huffington post. 2014. Available from: (http://www. huffingtonpost.ca/nathan-dautovich/buying-a-house-intoronto_b_5397648.html).

9. Eisenman P. Ten canonical buildings: 1950-2000. New York: Rizzoli; 2008.

10. Emporis. Skyscraper stats http://www.emporis.com/statistics/most-skyscraper-citiesworldwide. Updated Spring 2010. Accessed July 14, 2014.

11. Fenton J. Pamphlet architecture: Hybrid buildings. Vol 11. 11th ed. Princeton Architectural Press; 1985.

12. Fernández Per A. This is hybrid : [an analysis of mixed-use buildings by $\mathrm{a}+\mathrm{t}$ ] / aurora fernández per, javier mozas, javier arpa ; [prologue by steven holl].. Vitoria-Gasteiz : a+t architecture publishers; 2011.

13. Frampton K. Le corbusier: Architect of the twentieth century. New York: H.N. Abrams; 
2002.

14. Fraser JC, Chaskin RJ, Bazuin JT. Making mixed-income neighborhoods work for lowincome households. Cityscape. 2013; 15(2):83-100.

15. French $\mathrm{H}$. Key urban housing of the twentieth century: Plans, sections, and elevations. 1st American ed. ed. New York: W.W. Norton; 2008.

16. Hart S. Ecoarchitecture: The work of ken yeang. Chichester, England: Wiley; 2011.

17. Holl S. Hybrid buildings. In: Fernández Per A, ed. This is hybrid: An analysis of mixeduse buildings by a+t. Vitoria-Gasteiz : a+t architecture publishers; 2011:6-7,8,9.

18. Holl S. Steven holl. New York: Princeton Architectural Press; 2004.

19. Hulchanski JD. The three cities within toronto: Income polarization among toronto's neighbourhoods, 1970 - 2000. . 2010.

20. Jacobs J. The death and life of great american cities. 50th anniversary ed., 2011 Modern Library ed. ed. New York: Modern Library; 2011.

21. Kaplan LK. Heterotic architecture. In: Widder L, ed. Pamphlet architecture: Hybrid buildings. 11th ed. princeton architectural press; 1985: 4.

22. Koolhaas R. Content. 1st ed. Taschen; 2004.

23. Koolhaas R. Delirious new york: A retroactive manifesto for manhattan. New ed. ed. New York: Monacelli Press; 1994.

24. Koolhaas RaM,Bruce. Small, medium, large, extra-large: Office for metropolitan architecture, rem koolhaas, and bruce mau. 2nd ed. ed. New York, N.Y.: Monacelli Press; 1998, 1995.

25. Kroll A. "AD classics: Unite d' habitation / le corbusier". http: //www.archdaily. com/? $p=85971$. Updated 05 Nov 2010. Accessed September 11, 2014.

26. Lancaster J. Throw-away buildings: Toronto's glass condos. http://www.cbc.ca/news/ canada/toronto/throw-away-buildings-toronto-s-glass-condos-1.1073319. Updated Nov 14, 2011. Accessed August 1, 2014.

27. Lau, S. Wang, J. Giridharan, R. Ganesan, S. High-density, high-rise and multiple and 
intensive land use in hong kong: A future city form for the new millennium. In: Mike Jenks and Nicola Dempsey, ed. Future forms and design for sustainable cities. Architectural Press is an imprint of Elsevier; 2005: 153.

28. Le Corbusier. Toward an architecture. Los Angeles, Calif.: Getty Research Institute; 2007.

29. Lionel Goddard and Helen Slinger. The condo game. Toronto: CBC Doc Zone; 2013.

30. McCabe M. How much does it cost to build a custom home in toronto . http://harlequinhomes.ca/how-much-to-build-custom-home.html. Updated 2014. Accessed September 1, 2014.

31. Moe K. Thermally active surfaces in architecture. 1st ed. ed. New York: Princeton Architectural Press; 2010.

32. PERKINS T. Toronto condo land prices take a breather. The Globe and Mail. Tuesday, May. 06 2014. Available from: http://www.theglobeandmail.com/report-on-business/economy/housing/toronto-condo-land-prices-take-a-breather/article18478387/.

33. Petit E. Steven holl. The Architectural Review. 2013;233(1393):20-21.

34. Pigg S. Average price of single home in toronto shoots up $13 \%$ to $\$ 965,000$. Toronto Star. 2014. Available from: http://www.thestar.com/business/real_estate/2014/05/06/single_home_prices_in_toronto_shoot_up_13_to_9 65000.html.

35. Prithi Yelaja. The 'manhattanization' of toronto will change family-housing dreams. ; 2013.

36. Richard B. Peiser and David Hamilton. Professional real estate development : The ULI guide to the business . 3rd ed. Washington, DC: Urban Land Institute; 2012.

37. Riley T, Nordenson G. Tall buildings. New York: Museum of Modern Art ;|aLondon :|bThames \& Hudson; 2003.

38. Shelton B. The making of hong kong: From vertical to volumetric. New York, NY: Routledge; 2011.

39. Spring M. Welcome to the machine: Le Corbusier's unité d'Habitation. http://www. building.co.uk/ welcome-to-the-machine-le-corbusier\%E2\% 80\% 99s-unit\% C3.. Updated September 26, 2008. Accessed September 11, 2014. 
40. toronto realestate board. Condo market report: Fourth quarter 2013. (http://www. torontorealestateboard.com/market_news/condo_report/2013/condo_report_Q4-2013.pdf). Updated 2013. Accessed September 1, 2014.

41. Toronto's Real Estate Team. How much does it cost to build A new house these days?. . 2014.

42. Wells M. Skyscrapers: Structure and design. New Haven: Yale UP; 2005.

43. Winy Maas. MVRDV the vertical village: Individual, informal, intense. NAi Publishers; 2013.

44. Yeang K. Eco skyscrapers.|nVolume 2. 1st ed. ed. Mulgrave, Vic.: I mages Publishing; 2011.

45. Yeang K. Reinventing the skyscraper: A vertical theory of urban design. Hoboken, N.J .: Wiley-Academy; 2002.

46. Zhou J. Urban housing forms. New York: Elsevier ;|bArchitectural Press; 2005. 
Appendices 


\section{A.1 Final Model}
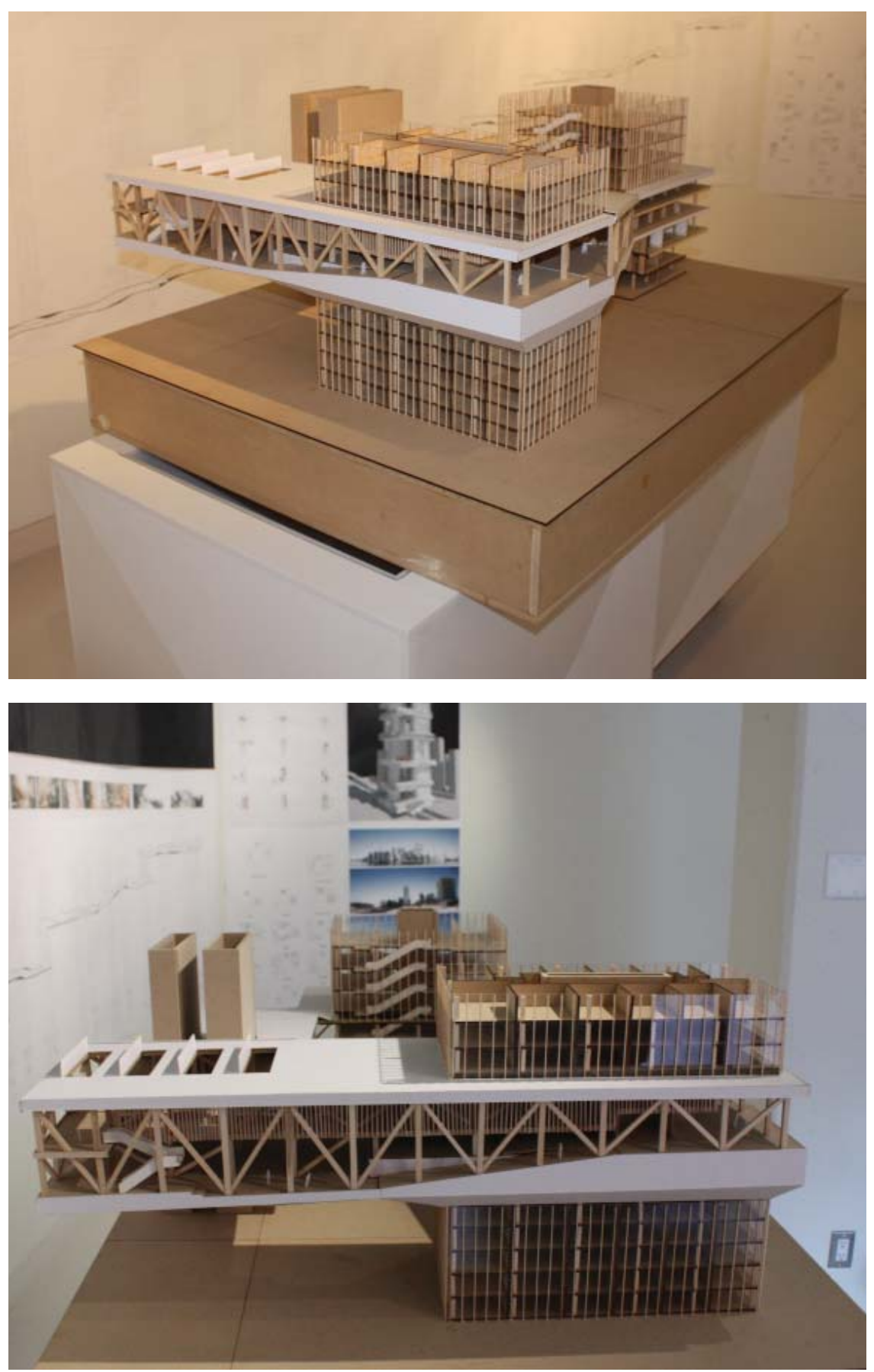

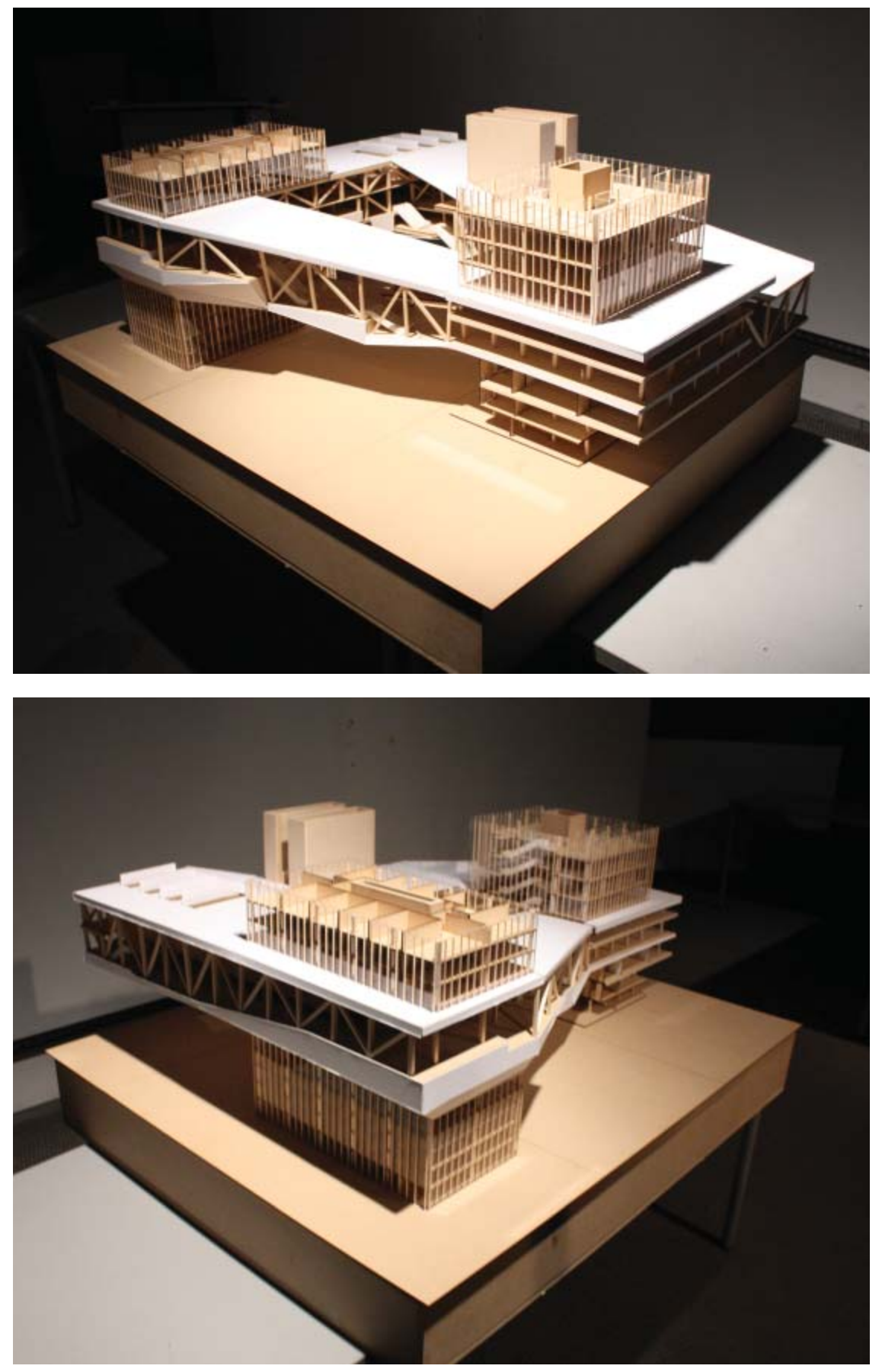

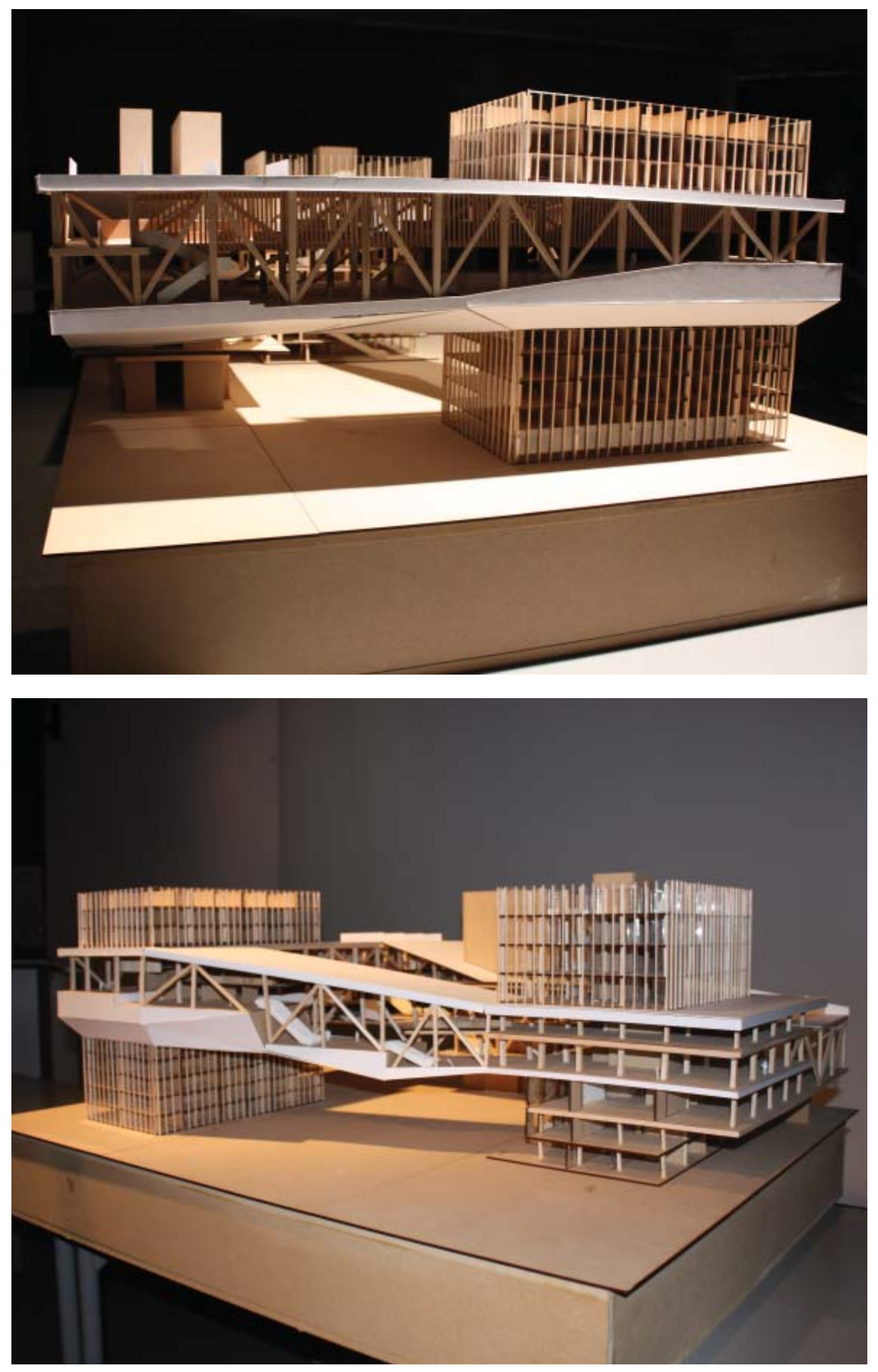

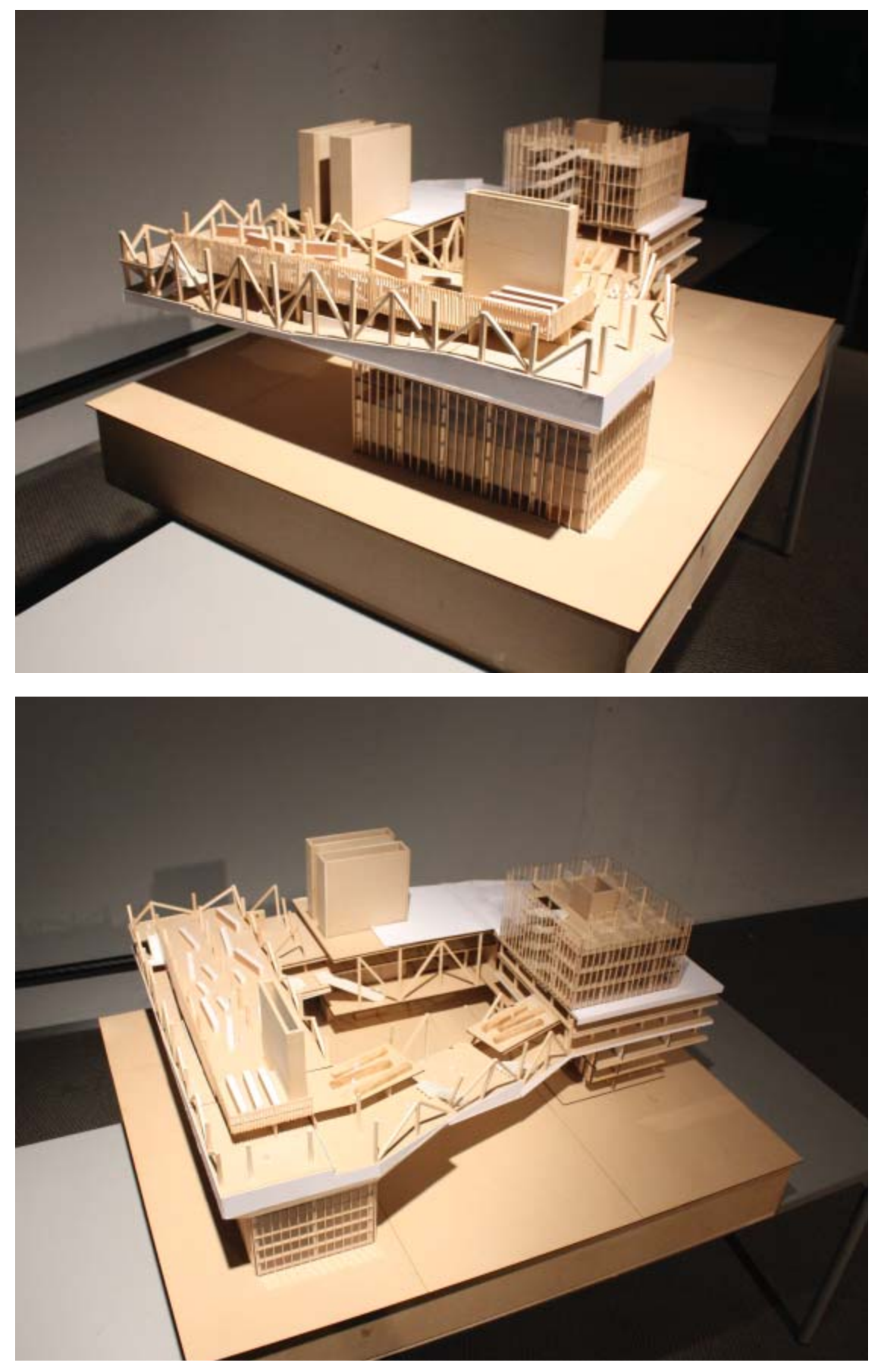

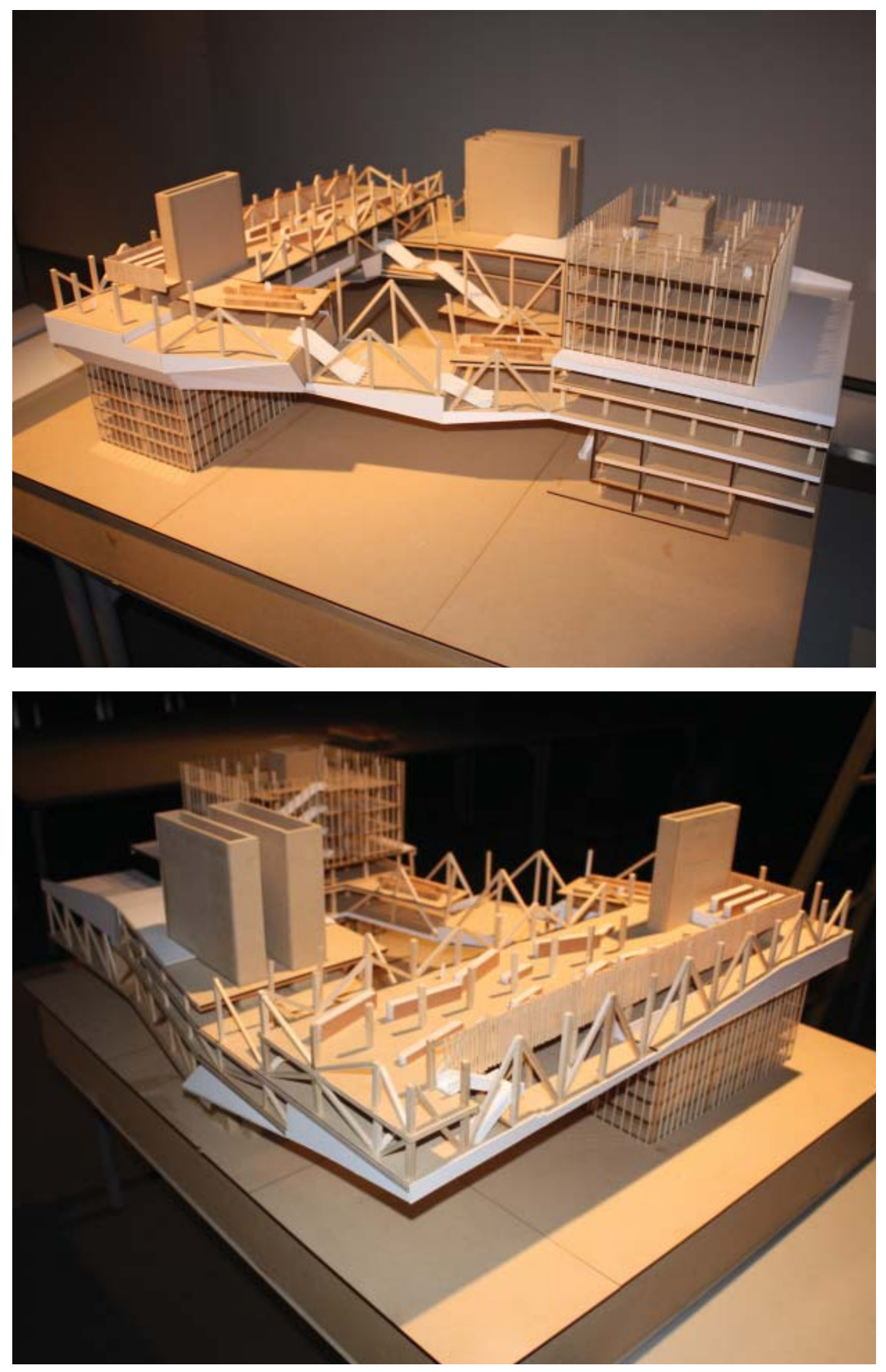

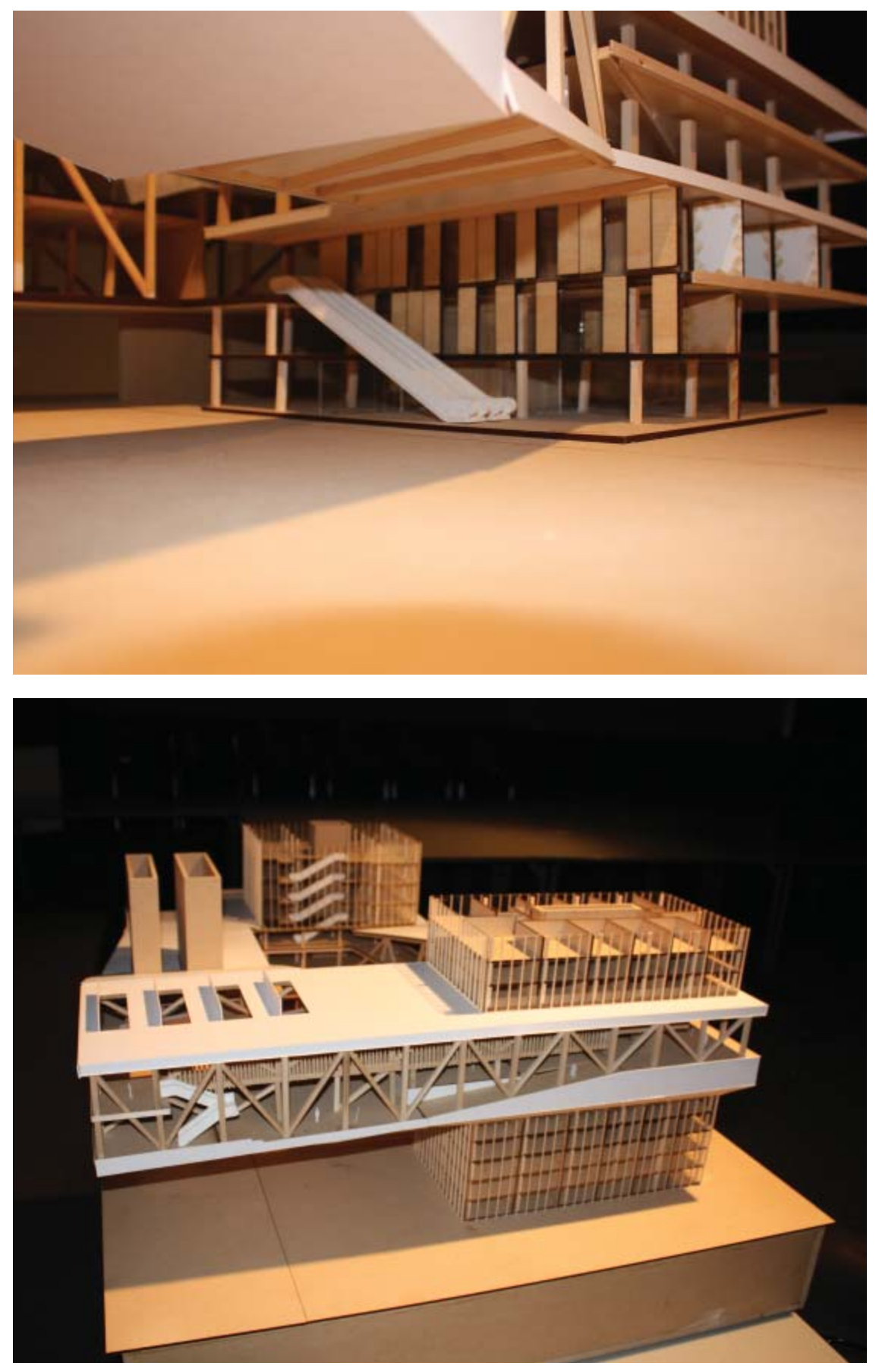


\section{A.2 Process Design}

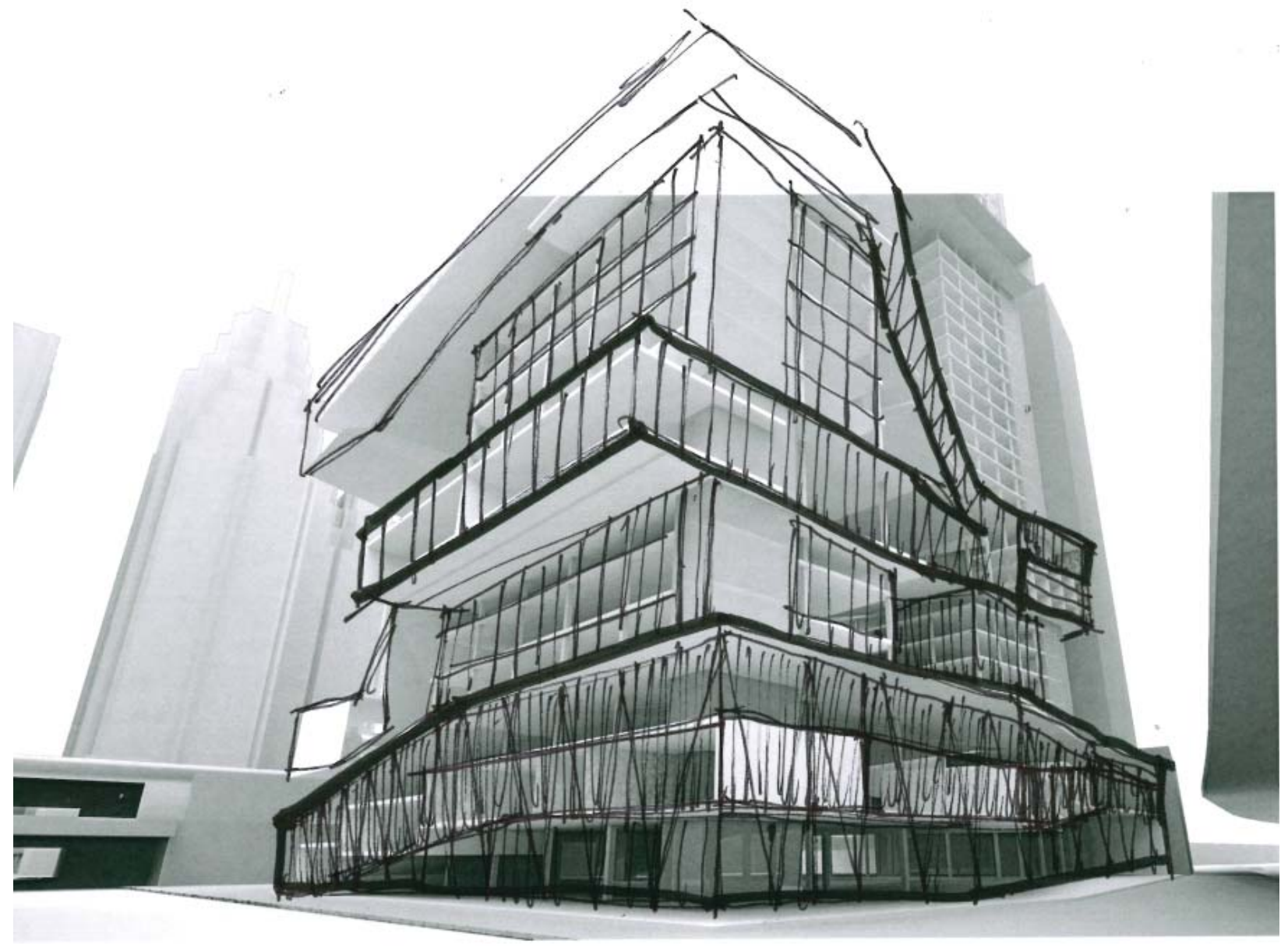



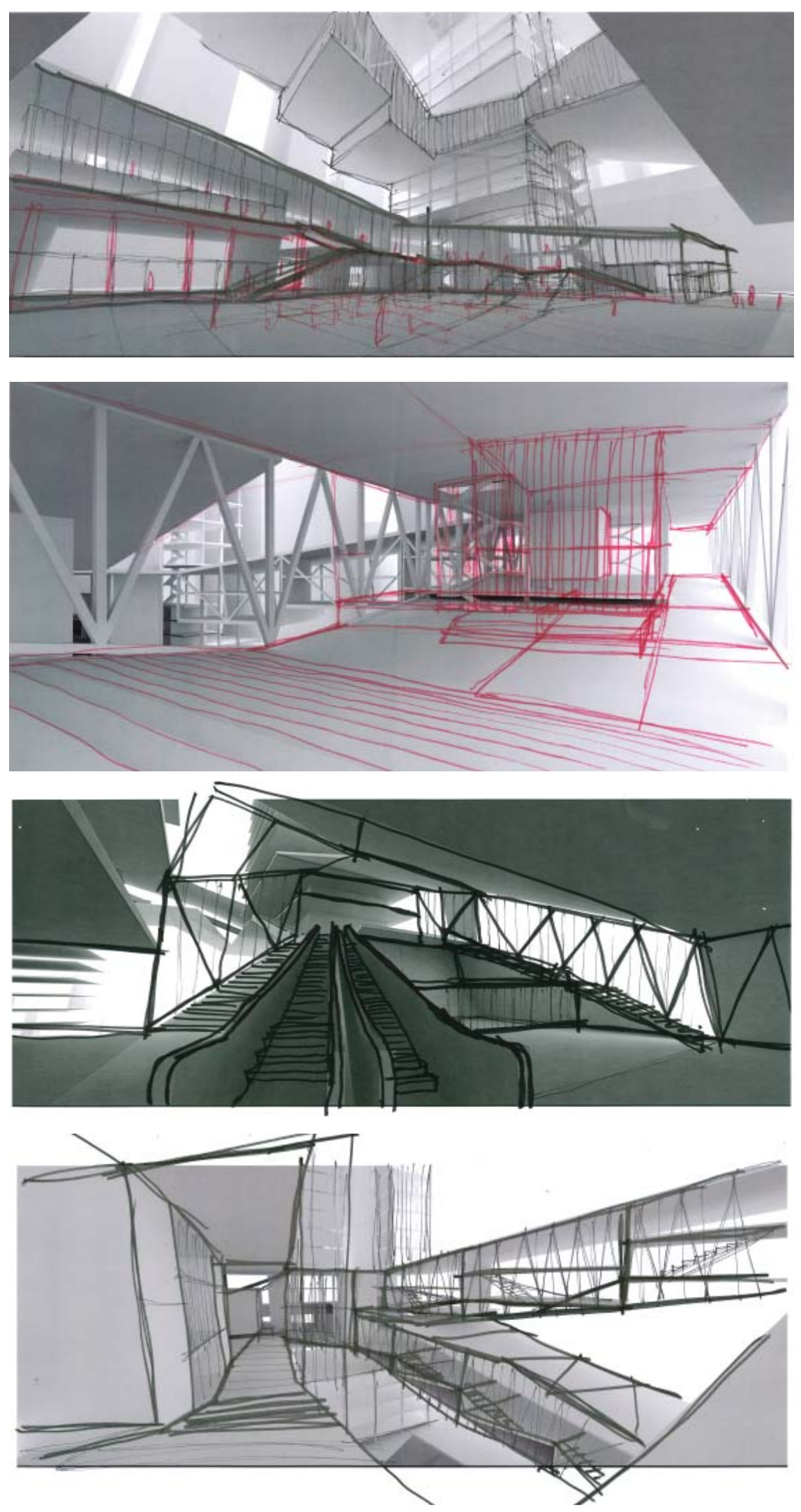

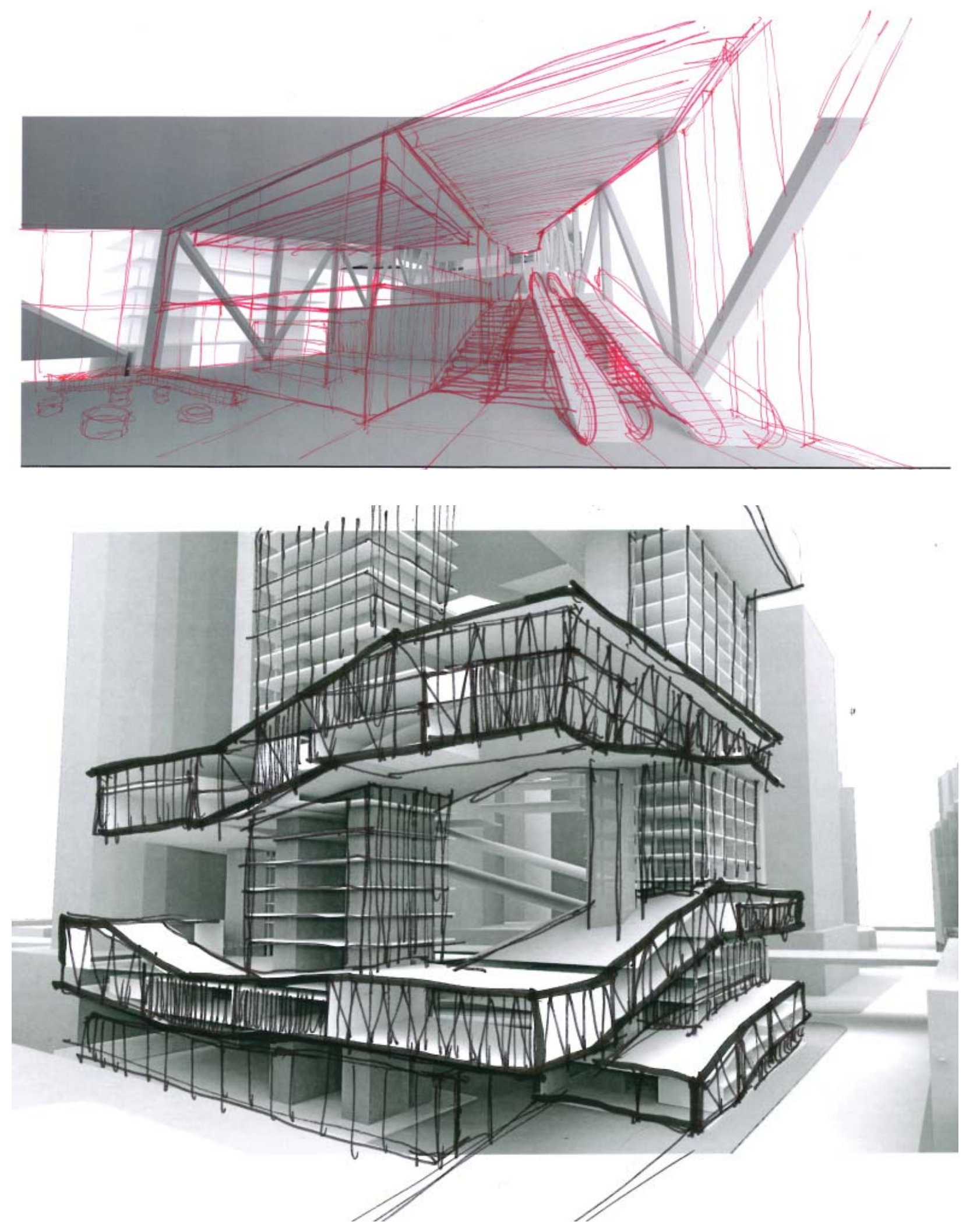

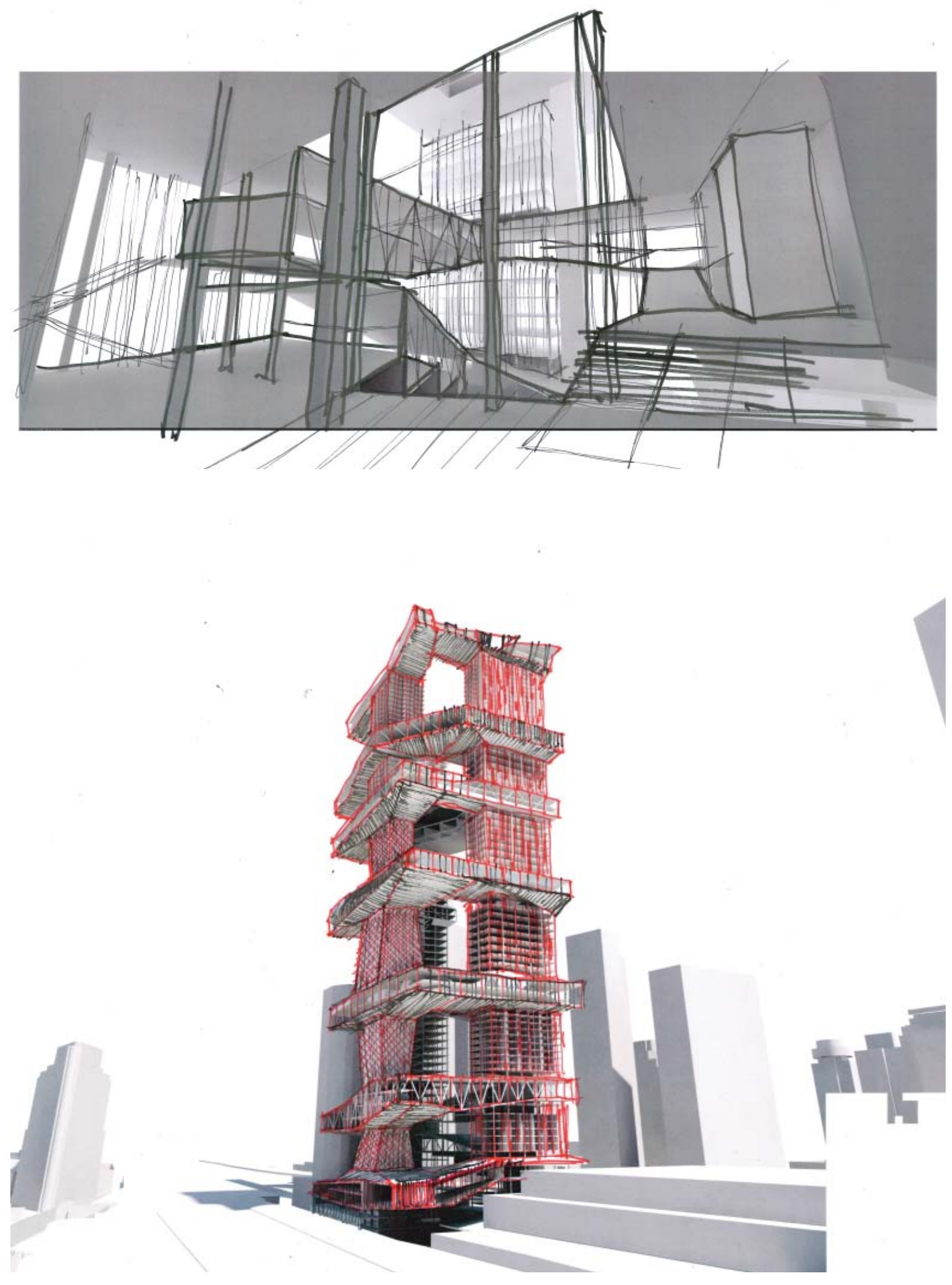

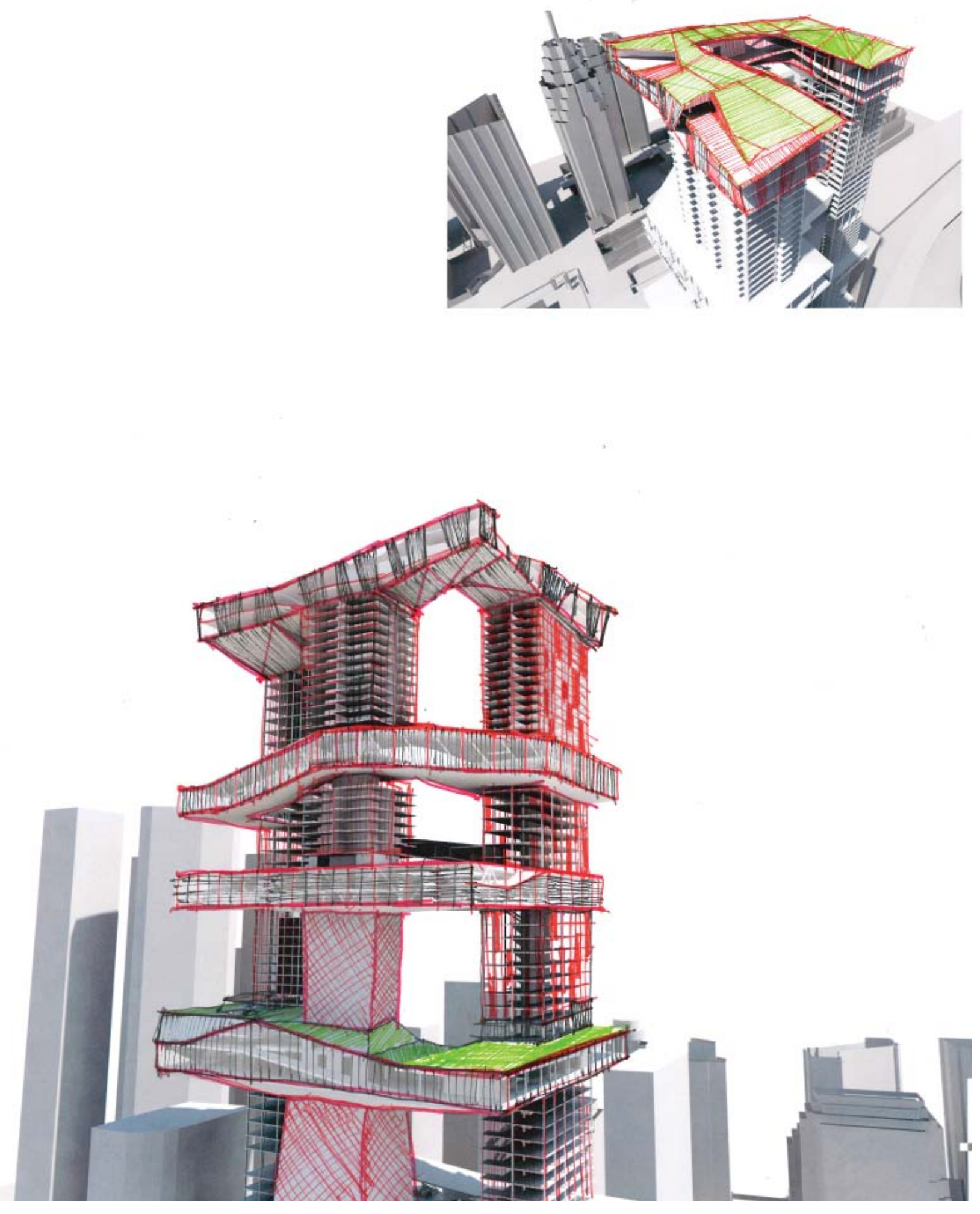